\title{
Balancing supply and demand in organ transplantation
}

Citation for published version (APA):

Cohen, B. (2001). Balancing supply and demand in organ transplantation. [Doctoral Thesis, Maastricht University]. Universiteit Maastricht. https://doi.org/10.26481/dis.20010420bc

Document status and date:

Published: 01/01/2001

DOI:

$10.26481 /$ dis.20010420bc

Document Version:

Publisher's PDF, also known as Version of record

\section{Please check the document version of this publication:}

- A submitted manuscript is the version of the article upon submission and before peer-review. There can be important differences between the submitted version and the official published version of record.

People interested in the research are advised to contact the author for the final version of the publication, or visit the DOI to the publisher's website.

- The final author version and the galley proof are versions of the publication after peer review.

- The final published version features the final layout of the paper including the volume, issue and page numbers.

Link to publication

\footnotetext{
General rights rights.

- You may freely distribute the URL identifying the publication in the public portal. please follow below link for the End User Agreement:

www.umlib.nl/taverne-license

Take down policy

If you believe that this document breaches copyright please contact us at:

repository@maastrichtuniversity.nl

providing details and we will investigate your claim.
}

Copyright and moral rights for the publications made accessible in the public portal are retained by the authors and/or other copyright owners and it is a condition of accessing publications that users recognise and abide by the legal requirements associated with these

- Users may download and print one copy of any publication from the public portal for the purpose of private study or research.

- You may not further distribute the material or use it for any profit-making activity or commercial gain

If the publication is distributed under the terms of Article $25 \mathrm{fa}$ of the Dutch Copyright Act, indicated by the "Taverne" license above, 


\section{Balancing supply and demand in organ transplantation}





\title{
Balancing supply and demand in organ transplantation
}

\author{
PROEFSCHRIFT
}

ter verkrijging van de graad van doctor

aan de Universiteit Maastricht,

op gezag van de Rector Magnificus, Prof. dr. A.C. Nieuwenhuijzen Kruseman volgens het besluit van het College van Dekanen,

in het openbaar te verdedigen

op vrijdag 20 april 2001 om 16.00 uur

door

\section{Bernard Cohen}

geboren te Bloemendaal in 1947 
Promotor:

Co-promotor:

Beoordelingscommissie:
Prof. dr. G. Kootstra

Dr. G.G. Persijn (Eurotransplant Leiden)

The Donor Action Foundation is acknowledged for its assistance in the preparation of this thesis by the award of an educational grant. The financial contributions made by the Dutch Transplant Foundation, BIS Foundation, Fujisawa Holland BV, Dr. F. K hler Chemie and Sangstat to the costs associated with the publication of this thesis are gratefully acknowledged. The author wishes to thank the Eurotransplant International Foundation in particular for its major support. 
"No man is an island, entire of itself; every man is a piece of the continent, a part of the main". (John Donne 1572-1631) 
CIP-gegevens Koninklijke Bibliotheek, Den Haag.

Cohen, Bernard.

Balancing supply and demand in organ transplantation/Bernard Cohen.-III.

Proefschrift Universiteit van Maastricht. -Met lit. opg.- Met samenvatting in het Nederlands. ISBN 90-71658-18-X.

Trefw.: donation, allocation, transplantation.

(C) B. Cohen, Leiden, the Netherlands.

All rights reserved. No part of this publication may be reproduced or transmitted in any form or by any means, electronic or mechanical, including photography, recording, or any information storage and retrieval system, without permission from the copyright owner.

Layout by Drukkerij Groen BV.

Cover design by Studio Multicolours.

Printed by Groen BV, Leiden, the Netherlands. 


\section{Contents}

Chapter 1. Introduction

Chapter 2. Some contemporary ethical considerations related to organ transplantation

Chapter 3. Commerce in transplantation, how does it effect European legislation?

Chapter 4. Changing patterns in organ donation in Eurotransplant, 1990-1994

Chapter 5. Trends in organ donation

Chapter 6. A European perspective on organ procurement breaking down the barriers to organ donation

Chapter 7. The European Donor Hospital Education Programme (EDHEP)

Chapter 8. Donor Action: a quality assurance program for intensive care units that increases organ donation

Chapter 9. Future trends in organ allocation

Chapter 10. Concluding discussion

Chapter 11. Summary

Samenvatting

Acknowledgments

Curriculum vitae 

Chapter 1

Introduction 


\section{Introduction}

Soon after the introduction of transplantation it was realized that not every donor organ was suitable for any recipient and an allocation process was devised, initially in individual transplant centers and then on a national and international basis.

Donor organs must be allocated to the best possible recipients, who may be stratified according to numerous demographic and immunological factors, such as age, gender, clinical diagnosis, urgency, time on the waiting list, transplantation center, number of previous transplantations, $A B O$ blood group, HLA types, and presence of anti-HLA antibodies.

HLA-matching is one of the constraints on the allocation process. The large number of antigens in the HLA-A, B, and DR loci makes it highly unlikely that, without prospective HLA-matching, a single donor organ will be completely compatible with a particular recipient. The use of immunosuppressive therapy has made it possible to reduce the adverse effects of HLA mismatches. Also, the chance of finding an acceptable match is increased considerably if the size of the pool of potential recipients is large. This consideration was the motivation for the creation in 1967 of Eurotransplant (Leiden, the Netherlands), the first multinational organ-exchange organization (OEO) [1]. The Eurotransplant concept has since been emulated in several other countries.

Table 1. Eurotransplant involvement

\begin{tabular}{|l|l|}
\hline In: & Since: \\
\hline Kidneys & 1967 \\
\hline Corneas & 1976 \\
\hline Livers & 1979 \\
\hline Pancreas & 1981 \\
\hline Hearts & 1982 \\
\hline Heart/lung & 1984 \\
\hline Tissues & 1986 \\
\hline Lungs & 1987 \\
\hline
\end{tabular}

Over the years, OEOs have become involved not only in renal transplantation but also in the transplantation of other solid organs, such as heart, lung, liver, and pancreas [table 1]. They were instrumental in the establishment of a more structured network in which donor hospitals, transplant programs, and tissuetyping laboratories could work together. They were able to apply the technical and administrative infrastructures developed for kidney transplantation to the transplant of other organs. However, HLA-matching does not provide the same beneficial effect on graft and patient survival that is seen with kidney transplants. Therefore, organ-specific allocation rules were devised at Eurotransplant, where they are regulated by organ-specific advisory committees [figure 1]. 


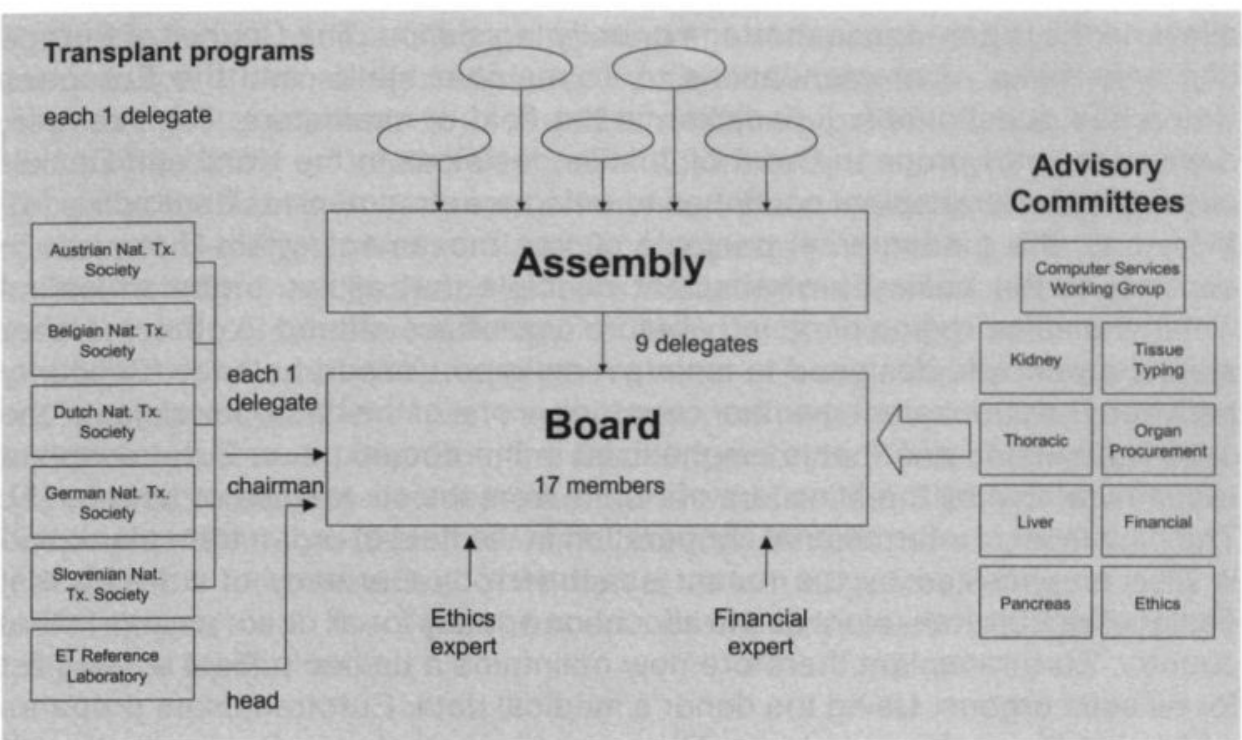

Figure 1

When transplantation was first introduced as a new therapy for end-stage organ failure, the number of patients on the waiting list and the number of available donors was understandably small. The acceptance of transplantation by both the medical profession and patients as the treatment of choice, in conjunction with the education of patients and the community as a whole, has led to an increase in the number of patients requiring transplant as well as the number of donors. Unfortunately, the number of patients continues to grow more rapidly than the number of donors. For example, in 1979 there were 1929 patients on the Eurotransplant kidney waiting list but only 1050 kidney transplantations were performed. These numbers increased to 7765 and 3048 , respectively, in 1989 and to 12305 and 3050 in 1999. Thus, the size of the waiting list increased six-fold in two decades while the number of transplantations increased only three-fold. Transplantation became a victim of its own success [2].

The almost exponential growth of waiting lists, which illustrates the magnitude of the donor-organ shortage, has resulted in an increased interest in the transplantation field among governments, the media, and the general public. Public debates have led to new legislation in several countries and some countries now use the rule of 'presumed consent' in which individuals are considered as potential donors unless they have stated otherwise, while others follow the rule of 'informed consent'. 
alleviate the organ-donor shortage or unify legislation. The Council of Europe can only make recommendations to its member states and the European Union has questionable jurisdiction in the field of healthcare. For example, despite recent European Court of Justice decisions in the Kohll and Decker cases [3], Eurotransplant continues to enforce a strict non-resident policy [4]. Moreover, the fundamental principle of free movement within Europe is in contrast to the basic Eurotransplant principle that allows organ allocation within the same region or country before organs are offered to other member states, a principle designed to maintain an import-export balance. Solidarity between Eurotransplant member countries is one of the basic principles of the organization and one that is emphasized in the document on Eurotransplant recently ratified by the Ministers of Health from the six member countries [5]. The high level of international cooperation in the field of organ transplantation is also emphasized by the recent enactment by Germany of a treaty that designates Eurotransplant as the allocation agency for all donor organs in that country. Eurotransplant therefore now maintains a unified patient waiting list for all solid organs. Using the donor's medical data, Eurotransplant prepares a shortlist of suitable recipients. All organs transplanted in Germany, regardless of their country of origin, must be provided through Eurotransplant according to the provisions of the treaty.

The reduction in the number of road traffic accidents and improvements in intensive-care facilities have contributed to a decrease in the number of deaths among young people and consequently to a decline in the number of high-quality organs available for transplant. Cadaveric donors still provide the majority of donated organs but, in Eurotransplant in 1999, living-related donors provided 579 kidneys and 64 liver segments for their relatives' transplants. The ethics of such donations are more complex than those for unrelated cadaveric donations because the question of consent is inevitably confounded by the emotional involvement of donors and their related patients. More recent additions to the class of living donors are cross-related donations and altruistic donations from individuals not genetically or emotionally related to the recipients.

Increasing the number of cadaveric donors through effective donation schemes is one way to increase the supply of donated organs. Better communication between the medical profession and the relatives of potential donors, as well as improved awareness of organ donation among medical professionals play an important part in these schemes. Another way to improve donation is to improve the efficiency of organ procurement procedures by using more than one organ from each donor. There are very few arguments against such measures. However, the use of organs from donors older than 65 years of age, very young donors or living donors presents more serious ethical dilemmas, as do other methods to increase donation rates, such as the use of non-heart beating donors [6], in situ kidney cooling prior to organ donation, and remuneration for funeral costs and/or organ donation. 
The potential use of organs from animals (xenotransplantation) not only raises the question of animal rights but also confronts society with the possibility of introducing foreign animal viruses and other pathogens into humans. Also, the formidable barrier of acute rejection of such transplants must be resolved. Recently, the British Government announced that it would take advice from a commission led by its chief medical officer to permit the cloning of human cells for 'therapeutic' purposes such as transplantation research and studies of the mechanisms of disease aetiology. In this procedure, the cell nucleus is removed and inserted into an egg whose own nucleus and genetic information has been removed. Stem cells, the precursors of organs and tissues, could be isolated and removed later from the resulting embryos. Those cells could then be cultured to provide the desired organs and tissues. Although the British Government emphasized that strict controls would be applied to such research, the announcement of its plan is certain to generate a considerable public debate over the ethical aspects of the proposal, even before it is considered by Parliament.

Allocation systems have evolved to make organ allocation procedures as transparent and flexible as possible. However, such systems are rarely clearcut and a completely fair system might not be attainable. Moreover, as Rudge emphasizes in his review of the ethics of organ donation, most clinicians would advocate an allocation system that takes clinical need into account as well as, for example, HLA status, time on the waiting list, and so on [7].

The admission of patients to waiting lists and the criteria used to allocate donor organs also raise other ethical questions. Most allocation algorithms favor the very young and clinically high-urgent patients. Such issues demonstrate the tension between the desire of the medical profession to provide the best possible care for each individual patient in a just manner, a duty-based approach, and the desire to provide the greatest good to the greatest number of people-utilitarianism.

In today's world of limited financial resources and increasing healthcare rationing, utilitarianism might have the upper hand, but no one approach is able to provide all the answers. They do, however, help the transplant community structure the debate on the problem and to draw up guidelines and legislation to govern the allocation of organs. Moreover, as transplantation technology evolves, the associated ethical dilemmas faced by medical professionals, the general public, and patients will also change. For example, now that xenotransplantation is recognized as a real possibility for relieving the shortage of donor organs, questions of animal exploitation and the acceptability of animal organs are raised. Similar questions will arise with each new development and the guidelines and legislation policies governing the field of transplantation must be regularly updated to take each new development into account. 


\section{Aim of the thesis}

The aim of this thesis is to survey current donation, procurement, and allocation trends in transplant programs across the world, but especially in Europe. The purpose of the survey is to provide a basis on which to judge some of the ethical dilemmas associated with transplantation and their influence on donation rates and European transplant legislation. These are discussed in chapter 2. Literature searches, including a brief review of some of the influential transplantation stories reported in the media, form the basis of chapter 3, which assesses current attitudes to organ donation, procurement, and transplantation. Data from OEOs, such as Eurotransplant, are analyzed in chapter 4, which provides a picture of the scale of the current shortage of donor organs. Chapter 5 focuses on recent trends in organ donation, including developments in living related and unrelated donation in different parts of the world. In chapter 6, potential solutions to the organ donor shortage crisis are assessed. The development of a special program called the European Donor Hospital Education Programme (EDHEP), which was created to meet the widely perceived need to help doctors and nurses feel effective in dealing with the bereaved and in requesting organ donation, is described in chapter 7 . In chapter 8, the Donor Action Programme, a quality assurance initiative specifically aimed to raising donation rates in intensive care units, is described. Finally, in chapter 9, new approaches to alleviate organ shortages are discussed, in particular the use of kidneys from elderly donors, an option that is currently being explored and one that could serve as an example of how to increase organ availability. 


\section{References:}

1. Van Rood JJ. A proposal for international cooperation in organ transplantation: Eurotransplant. In: Curtoni ES, Mattiuz PL, Tosi RM, eds. Histocompatibility Testing. Copenhagen: Munksgaard, 1967; 451-452.

2. Cohen B, Persijn GG, eds. Eurotransplant Annual Reports 1979, 1989, 1999, Leiden, the Netherlands.

3. Belcher PJ. European Union Legislation. In: Hospital Healthcare Europe 2000/ 2001: 49, Campden Publ.Comp.

4. Haase-Kromwijk B, Du Pré F, Cohen B. Organ transplantation and European community law: the case of non-residents. J Health Serv Res Policy 1997; 2: 3.

5. Vanrenterghem Y. Presidential address Eurotransplant annual meeting. Eurotransplant Newsletter 2000 (Oct); 165: 10-11.

6. Vanrenterghem Y. Cautious approach to use non-heart beating donors. Lancet 2000; 356: 528.

7. Rudge CJ. Organ donation: ethical aspects. In: Forsythe JLR, ed. Transplantation surgery. London: WB Saunders, 1997: 1-17. 


\section{Chapter 2}

\section{Some contemporary ethical considerations related to organ transplantation}

Bernard Cohen and Joe D'Amaro 


\section{Introduction}

In 1841, the American sailing ship William Brown, while en route from Liverpool to Philadelphia, drifted onto an iceberg just off the coast of Newfoundland. Its single lifeboat offered a very small chance of survival. It leaked and soon filled up with far more passengers than it could safely hold. Although the passengers worked throughout the night with buckets and pumps, the seawater continued to rise. By the light of dawn one thing was clear to everyone: unless the number of passengers was reduced by at least half, everyone would soon drown. Eventually, after some hesitation, the coxswain, in desperation, ordered the sailors to throw 14 passengers overboard to their certain deaths in the ice-cold sea, to the horror of the other passengers.

One hundred and fifty years later, we are faced with a similar ethical dilemma that is also related to a life-saving procedure, namely, organ transplantation. This ethical dilemma is unique in the annals of medical science since it is related not to the performance of a medical procedure per se but to the overwhelming success of the procedure.

Ethical constraints are inevitably linked to organ donation and transplantation. These activities are subject to regular and fairly penetrating attention from the media. The issues receiving attention are almost always closely linked to their ethical aspects, e.g., setting a maximum age for potential organ recipients or legislative constraints on a particular aspect of organ transplantation.

Continual developments in the field of organ transplantation, i.e., immunosuppressive therapy and organ preservation, leading to the ever-increasing success of, and possibilities for, transplantation, have led to an ever-increasing demand for donor organs. Unfortunately these increases have not been followed by similar increases in the number of organ donors. The consequence of this shortage is that many patients remain on waiting lists for transplantation for months or even years and, tragically, too many of them die while waiting. This situation leads to enormous ethical dilemmas: how to distribute the available organs, what methods to use to reduce the donor shortage and, finally, how to prevent the development of commercial trade in organs encouraged by this donor shortage. For whenever there is a distorted supply-demand ration, there are always people who cleverly manage to use the situation to their own commercial advantage.

In the United States, it has been suggested that the next of kin be paid a sum of money to cover funeral costs if they agree to organ donation [11], the underlying motive being, of course, to persuade people to allow their relatives' organs to be removed and used for transplantation purposes. This idea is, however, not really new. Funeral costs have long been covered in cases where a body has been made available for medical research purposes. However, the consequence of such measures will surely be that people in a financially weak position will agree to organ donation not for humanitarian but for financial 
reasons. It is, indeed, questionable as to whether this is the proper way to solve the great organ shortage. In any case, it is highly unlikely that a solution will be found in the near future. The discrepancy between supply and demand will continue to leave its mark on the distribution of organs among the increasing number of potential recipients.

In December 1990, a conference was held in Munich, Germany, on ethics, justice and commerce in organ replacement therapy. The problems that were addressed at that meeting still confront us. For that reason, we have decided to address some of them in the context of present-day conditions.

\section{Allocation}

The continuing shortage of donor organs confronts us with one of the greatest problems related to organ transplantation: allocation. Who decides which patient gets the available organ? Most people agree that doctors should decide, their argument being that, on the basis of medical criteria, doctors are in the best position to determine which organ should be allocated to which patient. This is, however, only partly true, for if, for example, one heart is available, there are almost always several patients on the current waiting list who can all be shown to qualify equally and simultaneously for that one heart. Which patient should then be chosen, and what criteria should be used to make this decision? Can such a decision be made purely on the basis of medical criteria? What other factors should be taken into account? The core principle of the Hippocratic tradition commits the physician to place the health of his patient as his first moral priority, but this principle is inadequate when it comes to transplantation.

The distribution of organs does not depend solely on medical factors. Many non-medical factors also play an important role, such as equal opportunities, compassion, justice, etc. Medical criteria must be considered in combination with non-medical ones. Obviously, a doctor will tend to seek what is best for his own patient, and this could lead to an unfair or incorrect organ distribution that would adversely affect other patients. Would it not be more fitting, from an ethical point of view, if all members of society were involved in this discussion instead of leaving the decisions solely in the hands of the medical profession? Even if this were the case, which criteria should be considered when allocating an organ? The choice is, indeed, a difficult one. The following four approaches have been suggested:

1. The "life-saving principle": the organ is given to the person who needs it the most urgently. This is a purely medical decision where patients in the poorest state of health have the highest priority.

2. "First come, first served": the organ is allocated to the recipient who has been waiting the longest. This would appear to be the fairest way.

3. Optimal usage of the donor organ: priority is given to the patient whose transplantation is expected to be the most successful. 
4. A random lottery: a lottery is held in which the medical and psycho-social status of the recipient is not considered at all. Such a practice is seldom applied and would certainly not be popular in the medical community.

Generally speaking, organ allocation takes place on three different levels. Firstly, there are the doctors and their patients. The doctors want their patients to get better as quickly as possible and, therefore, want to give them an organ that will save their lives or improve their quality of life. Secondly, there are the various transplantation centers which, although they are partners when it comes to the transfer of knowledge, become rivals when it comes to competing for available organs. And thirdly, there is the responsibility of politicians, e.g., with regard to determining a maximum age for potential transplant recipients or designating the maximum number of centers for transplantation. On a political level, decisions are often subject to budgetary constraints, which compounds the difficulty of allocation. Since this sometimes has direct consequences for a large group of people, it is likely to be influenced by public opinion.

The interest groups directly affected (i.e., potential transplant recipients and their families) naturally want to influence the distribution policies for donor organs. This clearly does not make it any easier for those directly involved in the organ allocation process. The system of organ allocation differs greatly from one type of donor organ to another. For donor kidneys, one is confronted with the "conflict of interests" faced by dialysis doctors [14]. On the one hand, they want to encourage transplants for their kidney patients undergoing dialysis but, on the other hand, this then leads to a loss of income for them. Looking in particular at private dialysis centers, there is clear evidence that proportionally fewer patients from these centers are referred for transplantation than from public hospital centers. After all, the fewer patients there are undergoing dialysis, the less income there is for the center's medical and other personnel $[12,19]$.

The allocation problem for patients waiting for a heart transplant is completely different. In practice, patients referred for a heart transplant often die while on the waiting list, due to the shortage of donors. This is closely linked with the ethical problem that a patient with a good chance of being cured may die while on the waiting list because, at present, organs are often assigned to the clinically more urgent patient whose condition is unstable and who is, therefore, clearly less likely to survive while on the waiting list [13]. The development of mechanical support devices now makes it possible for some of these patients to survive while waiting for a transplant. Although the transplantation results were initially disappointing for these patients, their results are now improving [1]. An organ is found in time for just over half of this category of patients; yet, of these patients, less than half leave the hospital alive following transplantation. The poor medical status of these patients is thought to be the main contributing cause of failure of these transplants. This situation has led some of the medical specialists involved to increasingly wonder whether it 
would not be more responsible to implant the available donor hearts in patients with the best chance of survival.

The allocation of donor livers raises ethical problems that are similar to those encountered in heart transplantation. Here, too, the question arises as to who should receive an available liver: the patient who has been waiting the longest, the patient who has the best chance of success, or the patient with the most urgent need? Difficult questions like this are the order of the day. Imagine, for example, that there is a good donor liver available. Who is the most eligible candidate for the liver: the younger patient who urgently needs a liver due to acute fulminant hepatitis and who has good prospects for a healthy life following liver transplantation or an older patient with carcinoma of the liver, knowing that the results of liver transplantation in the latter case are often disappointing? Should we conclude that it is wiser from an ethical point of view to make the liver available to the recipient with the greatest chance of success? Is it ethically correct to make such a decision and to argue that if a liver or a heart transplant has a high chance of failure the organ should not be made available to that recipient? Or should the most urgent patient be entitled to the organ because the less urgent patient has the change of another offer in the future? Who should have to make such decisions over the life and death of a fellow human being?

\section{Living related transplantation}

Transplanting a kidney from a patient's relative often provides an alternative to having to wait a long time for a suitable donor kidney. However, such donations are ethically acceptable only if both the recipient and the donor are well informed and have voluntarily made a conscious decision. In addition to reducing the waiting period, living related transplantation had advantages from an immunological point of view, since there is often a large degree of similarity between the tissue types of the donor and the recipient. The small risk of rejection leads to a larger chance of a successful transplant [9]. Ethical considerations regarding living related transplantation include, among other things, the question of whether it is right to deliberately harm one person in order to help another. In order to answer this question, it is necessary to balance the risk to the donor against the benefit for the recipient, whereby it should be emphasized once more that donation as an option is only considered on the basis of voluntarism and full information, "informed consent".

Many years of experience in kidney transplantation using related donor kidneys makes it evident that the quality of life of such kidney transplant recipients is greatly superior to that of dialysis patients and that the risk to the donors is almost non-existent. In other forms of organ transplantation, this risk-benefit consideration needs to be examined from a completely different angle. Due to the shortage of organs, over the last few years research has been carried out, mainly in the United States, into living related transplantation with a section of liver, pancreas, lung, or small bowel The distinctive feature 
here is that this method uses a portion of organs that still retain their function in the donor after partial resection. The risks to the donor from such donations are obviously far greater that the risks involved in a kidney donation. In Chicago, a study on partial liver transplantation has been conducted, inspired by a chronic shortage of livers, especially for small children [22]. More than 20 small children have been transplanted -almost all successfully-with the partial liver sample from a relative. The following prerequisites have been set for this type of liver donation:

1. The liver transplantation must have a good chance of success.

2. The risk to the donor must be minimal.

3. The donation should be voluntary.

In the case of liver donation by a relative, the concept of voluntarism in particular raises a number of questions. How voluntary is this donation when it concerns the life or death of your own child? In contrast to kidney donation, where the alternative is dialysis, in the case of a liver transplant the life of the young liver patient is at stake, and parents are under enormous emotional pressure when making a decision on liver donation. This pressure on the donor is made even greater by the fact that the partial removal of the liver carries far greater risks to the donor than the removal of a kidney. to what extent can we legitimately speak of a donation that is ethically sound on the strength of these risk-benefit considerations?

Currently, living related transplantation with a section of the liver is mainly being carried out in a few centers in Europe, Japan and the United States, but with the long waiting lists and the shortage of donor livers, it is probably only a matter of time before the discussion on living related liver transplantation by partial resection finds its way to other parts of the world. Would it not be better to increase the opportunities for postmortem organ donation so that donations by members of the family are no longer necessary?

Another form of living related donation involves a section of the pancreas (usually in combination with one kidney). Unlike kidney transplantation, pancreas transplantation per se does not save lives, but it does contribute to a better quality of life for the diabetic patient. Research has shown that the best results are obtained in cases of combined kidney/pancreas transplants $[8,10,17,18]$.The prerequisites are similar to those for living related kidney transplantation, namely, a close immunological match between donor and recipient. However, in closely related donor-recipient pairs like identical twins and HLA-identical siblings, graft failure caused by the recurrence of diabetes has been observed when no or low-dose immunosuppression protocols have been used [16]. The advantage of a shorter waiting period does not apply to living related pancreas transplantation as it does to kidney transplantation, as there is currently no real shortage of pancreases. The fact that not all of the pancreases available from organ donors are actually used for transplantation 
is more a problem of logistics than of immunology. The argument for pancreas transplantation is that the mortality rate of diabetics undergoing conventional insulin treatment is considerably higher than the mortality rate after a successful pancreas transplantation. The argument against living related pancreas transplantation is the fact that it remains a major surgical procedure and, as such, poses an increased risk of postoperative mortality to the donor. The long-term results of living related pancreas transplantation cannot yet be determined as our experience with it is still too limited.

Research is also being done on a much smaller scale into living related donation of a section of the lung [15]. A small number of partial lung transplants from parent to child have been performed. An even smaller number of transplants with a section of the small bowel have also taken place [2]. This form of transplantation is the only hope for patients with the small bowel syndrom, an illness that causes massive deterioration of the small bowel. Both the partial lung transplants and the partial small bowel transplants are still in too much of an experimental stage to enable one to draw any conclusions about their efficacy.

\section{Future prospects}

As if the ethical questions already posed were not enough, we would like to take a brief look into the future. What can we expect?

In worldwide attempts to find a solution for the shortage of donor organs, other donor sources and new transplantation methods are being explored. Although the possibility of using so-called non-heart beating donors was introduced as long ago as 1980 , that policy has not received the attention it deserves $[4,20]$. Non-heart beating donors are those whose cause of death is failure of their cardiopulmonary systems rather than brain death. The results of short and long-term studies on the survival of grafts obtained from these donors have shown a high degree of similarity with those obtained from heartbeating donors [21].

Research is currently being done into the possibility of cell transplantation with isolated cells from fetal tissue $[5,7]$. The results to date are disappointing. The use of fetal tissue for transplantation raises several ethical questions, such as:

1. What is the position of the pregnant woman?

2. Who gives permission for the use of fetal tissue? Is it the woman?

3. Does the woman have a say in the choice of the recipient?

It seems that, for the moment, the use of fetal tissue should be permissible where it has been shown to be effective, provided certain rules are applied to prevent improper use (such as commercial use or elective abortion).

Research has also been carried out for many years on the use of animal organs (e.g., from pigs and monkeys) for transplantation purposes, so-called xenotransplantation [3]. The idea here is to implant animal organs in order to keep patients alive until a suitable human organ has been found or, perhaps, 
in the future even to use these organs for long-term therapy. From an ethical point of view, however, the relationship between man and beast forms a central theme in the discussion over whether the transplantation of animal organs can be reconciled with our moral feelings. The central question here is, what position does man occupy in the hierarchy of living creatures? It seems realistic to assume that most humans would ascribe a lower position to animals than to humans. However, this value judgment does not imply that we should allow animals to suffer unnecessarily or that we should use them without restriction for the sake of our won health. In view of the growing awareness and reverence for nature and the environment, it would be wise from a moral point of view to only use animals as "organ suppliers" when there is absolutely no other alternative for saving human lives.

\section{Conclusion}

The argument that every patient should wait his or her turn according to a random lottery is not without a legal precedent. After the lifeboat from the William Brown had reached the coast safely, a man named Holmes, who was one of the crewmen, was arrested, tied and convicted of murder. The judge decreed that the passengers should have been spared at the expense of the non-essential crewmen. If that was not possible, the passengers should have been able to select their own victims by means of a lottery. The Court of Justice decided that, under the circumstances, a lottery would have been the only morally acceptable selection process.

A more contemporary view was reached at the conclusion of a joint meeting of the European Society for Organ Transplantation (ESOT) and the European Dialysis and Transplant Association/European Renal Association (EDTA/ ERA) in Munich in December of 1990. One of the resolutions accepted by the participants was that "cadaveric organs procured within a community should be considered as assets of the community, and the community rather than just the medical profession should determine their allocation through announced criteria" [6].

Finally, it is encouraging to note that, recently, the Euro-Parliament, the Council of Europe, and the French Parliament have all addressed the ethical aspects of organ procurement and transplantation. 


\section{References}

1. Boer J de, Cohen B, Zantvoort FA, D'Amaro J, Thorogood J, Persijn GG. Results of acute heart re-transplantation in Eurotransplant. Lancet 1991; 337: 1158.

2. Deltz E. Medical risk and benefit in living small-bowel segment donors. In: Land W, Dossetor JB, eds. Organ replacement therapy: ethics, justice, commerce, Part II Springer, Berlin Heidelberg New York; 1990: 110-116.

3. Hammer C. Xenografting: its future role in clinical organ transplantation. Organ replacement therapy: ethics, justice, commerce, Part VI Springer, Berlin Heidelberg New York; 1990: 512-518.

4. Kootstra G, Ruers TJM, Vroemen JPAM. The non-heartbeating donor: contributing to the organ shortage. Transpl Proc 1986; 20: 841 .

5. Kupsch A, Sauer H, Oertel WH. Transplantation of fetal dopamine-synthesizing cells: experiment or therapy of Parkinson's disease? In: Land W, Dossetor JB, eds. Organ replacement therapy: ethics, justice, commerce, Part VI Springer, Berlin Heidelberg New York; 1990: 467-483.

6. Land W. Accepted resolutions. Resolution 8. In: Land W, Dossetor JB, eds. Organ replacement therapy: ethics, justice, commerce, Part VII Springer, Berlin Heidelberg New York; 1990: 555.

7. Landgraf R. Fetal islet cell transplantation: state of the art. In: In: Land W, Dossetor JB, eds. Organ replacement therapy: ethics, justice, commerce, Part VI Springer, Berlin Heidelberg New York; 1990: 484-490.

8. Landgraf R. Medical risk and benefit in living pancreas segment donors. In: Land W, Dossetor JB, eds. Organ replacement therapy: ethics, justice, commerce, Part II Springer, Berlin Heidelberg New York; 1990: 106-109.

9. Laskow DA, Diethelm AG, Hudson SL, Deierhoi MH, Barber WH, Barger BO, Gaston RS, Julian BA, Curtis JJ. Analysis of 22-years experience in living-related transplantation at the University of Alabama in Birmingham. In: Terasaki P, ed. Clinical transplants. UCLA Tissue Typing Laboratory, Los Angeles; 1991: 179-191.

10. Margreiter R. Medical risk and benefit in living pancreas segment donors. In: Land W, Dossetor JB, eds. Organ replacement therapy: ethics, justice, commerce, Part II Springer, Berlin Heidelberg New York; 1990: 102-105.

11. McGaw JL, Wesley AJ, Dilip KS, Michele HM, Vinod TK. Incentives for organ donation? Lancet 1991; 338: 1441-1443.

12. Michielsen P. Unlimited admission of patients to the waiting list for transplantation. In: Land W, Dossetor JB, eds. Organ replacement therapy: ethics, justice, commerce. Part V Springer, Berlin Heidelberg New York; 1990: 364-367.

13. Reidemeister JC, Zerkowski HR. Bridging in cardiac surgery: a reasonable surgical procedure or only a method for getting an emergency transplant? In: Land W, Dossetor JB, eds. Organ replacement therapy: ethics, justice, commerce. Part VI Springer, Berlin Heidelberg New York; 1990: 534-540.

14. Schoeppe W. Hypotheses, basal conditions, and facts in the provision and allocation of renal replacement therapy in Germany. In: Land W, Dossetor JB, eds. Organ replacement therapy: ethics, justice, commerce. Part V Springer, Berlin Heidelberg New York; 1990: 377-384.

15. Starnes VA, Lewiston NJ, Luikart H, Theodore J, Stinson EB, Shumway NE. Current trends in lung transplantation: lobar transplantation and expanded use of single lungs. J Thorac Cardiovasc Surg, 1990; 104: 1060-1065.

16. Sutherland DER, Goetz FC, Sibley RK. Recurrence of disease in pancreas transplants. Diabetes, 1989; 38 (suppl.): 85-87.

17. Sutherland DER, Goetz FC, Gillingham K, Moudry-Munns KC, Najarian JS. Medical risks and benefit of pancreas transplants from living related donors. In: Land W, Dossetor JB, eds. Organ replacement therapy: ethics, justice, commerce. Part II Springer, Berlin Heidelberg New York; 1990: 93-101.

18. Sutherland DER, Gruessner A, Moudry-Munns KC. Report on results of pancreas transplantation in the United States, October 1987 to October 1991, from the United 
Network for Organ Sharing Registry. In: Terasaki P, ed. Clinical Transplants, UCLA, Tissue Typing Laboratory, Los Angeles, 1991; 31-38.

19. Thiel G. Excuses of nephrologists not to transplant. In. Land W, Dossetor JB, eds. Organ replacement therapy: ethics, justice, commerce. Part V Springer, Bertin Heidelberg New York; 1990: 353-363.

20. Van der Vliet JA, Slooff MJH. Kootstra $G$, Krom RAF, Rijkmans BG. Non-heart beating donors: is it worthwhile? Proc Eur Dial Transplant Assoc 1980; 17: 445 .

21. Vroomen MAM, Leunissen KML, Persijn GG, Kootstra G. Short-and long-term results with adult non-heart beating donor kidneys. Transpl Proc 1998; 20: 743-745.

22. Whitington PF, Siegler M, Broelsch CE. Living donor nonrenal organ transplantation: a focus on living related orthotopic liver transplantation. In: Land W, Dossetor JB, eds. Organ replacement therapy: ethics, justice, commerce. Part II Springer, Berlin Heidelberg New York; 1990: 117-129. 


\section{Chapter 3}

\section{Commerce in transplantation: how does it effect European legislation?}

Bernard Cohen, Guido G. Persijn and Yves Vanrenterghem 


\section{Introduction}

Advertisements offering to buy or sell organs for transplantation appear in most countries, although they are most common in the developing world. Some of the desperate requests from patients themselves or the parents of children with end-stage renal disease evoke readers' sympathy, while the avarice exhibited in others is disturbing.

Most people consider such commerce in transplant organs abhorrent and demand its prohibition. However, the term commerce is not usually defined. According to The New Shorter Oxford English Dictionary, commerce is the exchange of merchandise and, in Webster's Dictionary, it is the interchange of goods, wares, productions, or property of any kind, between nations or individuals, either by barter, or by purchase and sale, trade, or traffic. Whether or not the opponents of commerce in transplant organs are against all forms of commerce is unclear.

However, what is implicit is the concept of a tough private market in which a donor sells an organ to a recipient for a price, paid either directly to the donor or to an intermediary. If private-fee enterprise markets were feasible then their distribution practices would be clear, at least on the demand side, and organs would go only to those with the ability to pay.

The allocation of organs based on ability to pay obviously violates the egalitarian ethic of distributive justice embodied in the legislation of most western countries. Furthermore, if life-saving organs were to be distributed on an ability to pay basis, thereby favoring the wealthy, any prospect of increasing the volume of voluntary organ donations would be seriously jeopardized.

In this article, we look at examples of commerce in organ transplantation, in particular the so-called organ trafficking story that first appeared in 1987. Publication of this report has had a great impact on the development of legislation in Europe in the past 10 years. We also address some more recent reports of commerce in transplantation and illustrate how they effect policy making.

\section{The organ trafficking story: kidnapped babies provide donor organs}

Rumors about the existence of child trafficking to satisfy the demand for donor transplant organs first began to circulate in Latin America in 1987. However, little or no documentary evidence was found to support these claims. Locating eyewitnesses to the events proved difficult, if not impossible, information was inconsistent, and the names and identities of the presumed victims were difficult to trace. Consequently, most of the accounts could not be confirmed and were concluded to be simply rumor [1-4]. Indeed, at a press conference on January 8, 1987, a senior official of the Honduran Committee of Social Welfare categorically denied reports of trafficking in babies to supply organs for transplantation. Nevertheless, the rumors continued and eventually the story appeared in Europe $[3,5]$. 


\section{European political consequences}

On May 5, 1987, an Italian member of the European Parliament tabled a motion on the issue that asked if the European Commission had any knowledge of children from Honduras and other Latin American countries serving as sources of replacement organs in Europe. The reply was: 'The commission does not know of any transplant operations performed in Europe for which the organs of Latin American children have been used. The adoption described by the honorable members would be strictly forbidden in the Community under the laws on adoption in the member states.'

On November 16-17, 1987, a Conference of European Health Ministers was convened in Paris under the auspices of the Council of Europe. The final text agreed by the Ministers includes the following paragraphs on the noncommercialization of human organs: 'A human organ must not be offered for profit by any organ-exchange organization, organ-banking center or by any other organization or individual whatsoever... Neither organizations nor individuals should advertise outside their national territory either for donation or transplantation' [6].

Despite the denials of the 'baby parts' story and the recommendations of the health ministers, the story continued to circulate and comments continued to be made [3]. For example, in the spring of 1993, a French European Parliament member published a report on the Prohibition of the trade of organs for transplant based on circumstantial evidence and rumored stories [7]. The report called for the European Council of Ministers to take the necessary measures to ban the trade in organs for profit throughout the European Union $(E U)$, including a ban on all organ import transactions in which the origin of the organ, the voluntary nature of the donation, or the anonymity of the donor with respect to the recipient were uncertain. In addition, the report recommended that members of surgical teams carrying out transplants should be approved and monitored by a supervised body, and that organs should not be removed from minors except in exceptional cases. A legislative code of conduct was also recommended. While such measures seem logical, the publication of this report, once again, damaged transplantation while the story continued to make good copy.

\section{Media consequences}

Later in 1993, television documentaries - a joint British-Canadian production called The body parts business, an independent French film entitled The organ thieves and a BBC Everyman documentary - broadcast the 'baby-parts' stories, thus adding credibility to the myth. These programs contained dramatic charges by Latin American 'victims' and their families, who claimed that their corneas had been stolen while they had been in hospital for other reasons. However, when officials investigated the charges, they discovered that the socalled victims had lost their sight following infections that had occurred years before. 
These documentaries also revealed serious irregularities in Russia in the way brain death was determined in organ donors. In a number of cases, organs were removed from patients who were technically and, perhaps, legally alive. Although the sale of human tissues is illegal in Russia, the TV investigators found a company which, in one year, claimed to have extracted many tissues, including 8000 thymuses, 2000 eyes, and more than 3000 pairs of testicles. These tissues were available for sale in any part of the world for use in pharmaceutical, cosmetic or surgical procedures. Trafficking of this kind has never been officially denied by the Russian Government.

Clearly, program makers, the transplant community, and governments need to ensure that a clear distinction is made between the facts behind such stories, which must be backed up by solid evidence, and the rumors and stories contrived by journalists on slow news days. In addition, clear communication of the facts is also important as many issues in transplant medicine confuse both the media and the public, such as cadaveric versus living donation and organ versus tissue donation. Such confusion may lead to misunderstanding and a reluctance to donate organs and tissues by the general public.

\section{Transplant tourism: registration on multiple European waiting lists}

As the shortage of organs persists, a phenomenon known as 'transplant tourism' has emerged. Transplant tourists are patients who travel to countries where organs are available. They receive transplants either through registration on established transplant programs in Europe or the USA or through the purchase of an organ from a living unrelated donor. The latter will not be discussed further as there is no evidence that buying and selling of organs from living donors occurs in Europe.

The registration of so-called non-resident patients on multiple waiting lists in Europe is well-known, although the allocation of organs to this category of patients differs widely between countries and centers. However, enabling nonresident patients to register on waiting lists leads to unfair competition for local patients and may falsely raise patients' hopes of a speedy transplantation. In addition, it is likely that only affluent patients can afford to register on multiple foreign waiting lists. Returning to the definition of commerce, it would also be reasonable to question if the acceptance of non-resident patients on a routine basis and on a large scale is entirely free of commerce. Perhaps this practice does not benefit the individual physician, but the acceptance of non-resident patients is certainly an incentive to the hospital, which is able to use its existing infrastructure more effectively and reduce overhead costs.

Transplant tourism in Europe is difficult to control. Problems, such as the prevention of multiple registrations on waiting lists of various European transplant centers and European organ exchange organizations, have not been solved, especially with respect to citizens of the European Union (EU). Nevertheless, recent attempts have been undertaken to improve the control of 
the movement of patients from one country to another. For example, in 1996 the Board of Eurotransplant - the international organ-exchange organization for the Netherlands, Germany, Belgium, Austria, and Luxemburg - issued several guidelines that effectively reduced the number of non-resident patients on the Eurotransplant waiting list to a minimum [8]. Within Eurotransplant, non-residents are patients not living in one of the countries participating in the Eurotransplant organization. In the same year, similar guidelines for Scandiatransplant were also confirmed by its member states [9].

In 1998, a Royal Decree was also published in Belgium that explicitly approved the exclusion of non-residents from Belgian transplant waiting lists with the aim of improving the chances of transplantation for Belgian citizens. Consequently, the nationality and the residency of patients registered through a Belgian transplant center must be carefully checked before the patient can be put on the waiting list.

\section{Recent developments}

Since the Latin American story hit the headlines, transplant horror stories have continued to appear. For example, recently, two Chinese men were arrested for offering for sale organs and tissues from prisoners executed in China $[10,11]$. The Chinese Government admits that organs are removed from executed prisoners, but that it only happens rarely and with the prisoners consent. Human rights campaigners, however, remain unconvinced [12]. Moreover, the EU has failed to support or introduce United Nations resolutions on human rights in China that might stop this practice.

Meanwhile, in Israel, attempts to increase the supply of donor organs have led to schemes in which organs are 'swapped' between suitable families $[13,14]$. The scheme enables a member of the family of a transplant recipient to donate a kidney to a member of the donor's family. The Israel Health Ministry regulates such transactions and ensures that no money changes hands between families, although payments for expenses are allowed $[13,15]$.

The Israeli Medical Association (IMA) regulates the conduct of transplant surgeons and recently questioned a surgeon who allegedly transplanted organs bought from Romanians into Israeli citizens [15]. The procedures took place in Estonia and, therefore, were not regulated by Israeli law. Nevertheless, the IMA is clearly unsure about such behavior.

Strictly speaking, such transactions are covered by the definition of commerce; should they be banned along with those transactions in which money changes hands?

\section{Conclusion and suggestions}

In many parts of the world, commerce in organ transplantation is rampant and the various official pronouncements that international organizations have made are not sufficient to combat such activities. Many tentative declarations 
of ethical principles have been made, but very few strategies for enforcing them have received adequate attention. Perhaps it is time to make a shift from making ethics declarations to the formulation of tough policies to prevent unethical transactions in transplant organs. Recently, the Dutch Minister of Health has taken the initiative to bring together colleagues from the countries collaborating within Eurotransplant. The aim of this meeting is to investigate possibilities to harmonize legislation in the Eurotransplant countries.

The fact that poor individuals are more likely than affluent people to sell their organs is a highly visible sign of exploitation that has the potential to undermine the integrity of the entire transplant community. Whenever there is an imbalance between supply and demand, the value of a scarce commodity rises. Inevitably, affluent people will try to use their financial advantage to acquire the organs or tissues they need while less fortunate patients remain on waiting lists. Given western guidelines on organ distribution, ethical abuse will most likely take place at the fringes, primarily in developing countries [16]. Medical and pharmaceutical institutions are, in general, in the best position to detect and prevent unethical commercial practices and should remain alert. In addition, the media may play an important role in detecting and reporting such incidents in an objective manner.

In 1991, the World Health Organization (WHO) adopted the report 'Guiding principles on human organ transplantation' [17]. Although such initiatives show a growing understanding of the urgency to establish international cooperation and to introduce law enforcement, the fact of the matter remains that guidelines are no more than recommendations and are therefore not legally binding on the acceding states.

However, if set up, an International Donor Surveillance Committee could serve as a central clearing house for information on malpractice in organ donation and as an early warning system. Such a highly regarded authority could regularly publish information on world commerce in organ donation and organ trafficking - in a document similar to the Amnesty International annual report on torture in the world - that would keep both the public and governments informed of these abhorrent and unethical practices. In such a joint venture of medical associations and human rights organizations, alleged incidents of organ trafficking could be properly publicized and thoroughly investigated.

The importance of this proposal is illustrated in a very recent report of an arrest in Rome of a US citizen. The man was advertising, via the Internet, human organs for transplantation. He was enticed to Rome by transplant surgeons to pick up payment for a graft and was arrested. No organs were used in Italy and it is unclear who the donors were or where the organs came from. 'Whatever the judicial outcome of this affair, transplantation experts in Italy are forecasting a transient reduction in organ donations as often happens after shocking news of human organ trafficking hits the headlines,' said the report of the arrest [18]. 


\section{References}

1. Public Affairs Alert no. 88-25; 10th August,1988, USA.

2. Leventhal T. The child organ trafficking rumor: a modern 'urban legend'. United States Information Agency, December 1994.

3. Campion-Vincent V. The baby parts story: a new Latin American legend. Western Folklore 1990; 49: 9-25.

4. Statement on live organ trade. Document $17 \mathrm{~m}$ of the 37 th World Medical Assembly, Brussels, October 1985.

5. Rucha J, Vallianny E. Brazilian children sold for transplants. Guardian Weekly 1990, September 30;10.

6. International Digest of Health Legislation 1988; 39 (1): 277.

7. Schwartzenberg L. Report of the Committee on the Environment, Public Health and Consumer Protection on prohibiting trade in transplant organs (Document + A30074/93). European Parliament, 25th February 1993; 10-11.

8. Haase B. Summary of Board Meeting. Eurotransplant Newsletter 134, August 1996;

9. Madsen M (Medical Director, Scandiatransplant, University Hospital Skejby, Denmark). Guidelines for necro organ transplantation of non-Nordic nationals within Scandiatransplant and the use of non-Nordic organs for Scandiatransplant recipients, 1996.

10. Chelala C. China's human-organ trade highlighted by US arrests of "salesmen". Lancet 1998; 351: 735.

11. Morris K. Europe will take no action on China. Lancet 1998; 351: 735.

12. Organ procurement and judicial execution in China. Human Rights Watch Asia 1994 (August 29); 6(9).

13. Fishman RHB. Israel proposes kidney swap to increase live donors for transplantation. Lancet 1998; 351: 735.

14. Fishman RHB. Israeli kidney swap unites Jews and Muslims. Lancet 1998; 351 : 1641.

15. Fishman RHB. Israeli surgeon questioned over transplantation ethics. Lancet 1998; 351: 812 .

16. Kennedy I, Sells RA, Daar AS, Guttmann RD, Hoffenberg R, Lock M, et al. The case for "presumed consent" in organ donation. Lancet 1998; 351:1650-1652.

17. World Health Organization, Geneva. Guiding principles on human organ transplantation, 1991.

18. Simini B. US human organ dealer arrested in Italy. Lancet 1998; 352:1289. 



\section{Chapter 4}

\section{Changing patterns in Organ Donation in Eurotransplant, 1990-1994}

Bernard Cohen, Joe D'Amaro, Johan De Meester and Guido G. Persijn 


\section{Introduction}

The Eurotransplant Foundation, founded in 1967, coordinates the matching and exchange of donor organs across five European countries: Austria, Belgium, Germany, Luxemburg, and the Netherlands. The primary goals of Eurotransplant are: 1. to achieve an optimal use of available donor organs, 2. to secure a transparent and objective selection system based upon medical criteria, and 3 . to assess the importance of factors that have the greatest influence on transplantation results [1]. These goals have changed very little over the years; however, a fourth goal has recently been added: to support donor procurement activities in order to increase the supply of donor organs. This reflects Eurotransplant's concern with the chronic shortage of organ donors.

This report addresses the consequences of that problem as reflected in the changing trends in organ donation which have become evident in the five year period between 1990 and 1994. Special attention is paid to the retrieval of multiple organs from individual donors and the acceptance of organs from donors who would have been previously considered as too old.

\section{Waiting lists}

The composition of the Eurotransplant waiting lists in 1990 and 1994 is set out in table 1 . The increasing disparity between the number of patients waiting for a renal transplant and the number of renal transplantations performed is not restricted to the Eurotransplant community [table 2], but is also observed throughout Europe and in the United States.

An overview of the numbers of organ donations and transplantations in ET in the same period is set out in table 3 . Transplants of multiple organs from a single donor to a single recipient are counted as one, irrespective of the number of organs involved. Transplants of multiple organs from a single donor to multiple recipients are counted as multiple transplants.

Table 1. Patients on the Eurotransplant waiting lists**

\begin{tabular}{|c|c|c|c|c|}
\hline Organ & 01-01-1990 & & $31-12-1994$ & \\
\hline Kidney & 10124 & & 12849 & \\
\hline Heart & 402 & & 8681 & \\
\hline Heart + Lung(s) & 42 & & 75 & \\
\hline Lung(s) & 46 & $897^{*}$ & 243 & $1736^{*}$ \\
\hline Liver & 220 & & 33 & \\
\hline Pancreas (+ kidney) & 187 & & 216 & \\
\hline Totals & 11021 & & 14585 & \\
\hline
\end{tabular}

Difference between 1990 and 1994: $3564=32 \%$

* Total non-renal organs

**Since 1991, Eastern Germany fully participates in Eurotransplant. 
Table 2. Kidney waiting list and transplantation in Eurotransplant

\begin{tabular}{llcc}
\hline Year & $\begin{array}{l}\text { Size of } \\
\text { waiting list }\end{array}$ & $\begin{array}{l}\text { Annual growth } \\
\text { waiting list (\%) }\end{array}$ & Transplants \\
\hline $1990^{*}$ & 10124 & - & 3171 \\
1991 & 10463 & 3 & 3395 \\
1992 & 11217 & 7 & 3101 \\
1993 & 11956 & 7 & 3293 \\
1994 & 12849 & 7 & 2997 \\
\hline
\end{tabular}

* Eastern Germany excluded

The substantial increase in the numbers of patients waiting for a transplant $32 \%$ more in 1994 than in 1990 - did not result in a proportional increase in the total number of transplantations, which rose by only $6 \%$ in the same period. Almost 1800 of the patients on the waiting lists died in the period $1990-1994$. The number of patients waiting more than 5 years for a renal transplant is almost $10 \%$ of the total [2].

\section{Non-renal donors and transplantations}

The number of patients waiting for a non-renal organ increased from 897 in 1990 to 1736 in 1994, an almost two-fold increase [table 1]. In order to satisfy the increasing demand for these organs, requests for multiple organ donations were introduced into donor retrieval programs. The proportion of so-called multi-organ donors (MOD) used in Eurotransplant in the study period increased from $48 \%$ in 1990 to $64 \%$ in 1994 [table 3]. These values represent a relative increase of $33 \%$ in 5 years. The numbers of non-renal transplantations (with the exception of heart transplantations), increased dramatically during the study period. The number of transplantations per donor rose from 2.8 in 1990 to 3.1 in 1994, an increase of almost $13 \%$.

\section{Elderly donors}

The acceptance of organs from elderly donors is clearly attributable to the shortage of donor organs. In 1983, $10 \%$ of all kidney donors were aged

Table 3. Organ donation and transplantation in Eurotransplant between 1990 and 1994 (MOD =Multi Organ Donors; Transpl./Donors = Number of transplants from one donor)

\begin{tabular}{|c|c|c|c|c|c|c|c|c|c|c|}
\hline \multirow[b]{2}{*}{ Year } & \multicolumn{10}{|c|}{ Number of transplantations ${ }^{a}$} \\
\hline & Donors & $\begin{array}{l}\% \\
\text { MOD }\end{array}$ & Kidney & $\begin{array}{l}\text { Heart } \\
\text { \& Lung }\end{array}$ & Heart & Lung & Liver & $\begin{array}{l}\text { Pan- } \\
\text { creas }\end{array}$ & Total & $\begin{array}{l}\text { Transpl.I } \\
\text { Donors }\end{array}$ \\
\hline $1990^{b}$ & 1615 & 48 & 3171 & 682 & 19 & 50 & 576 & 72 & 4570 & 2.8 \\
\hline 1991 & 1781 & 54 & 3395 & 806 & 24 & 71 & 715 & 74 & 5085 & 2.9 \\
\hline 1992 & 1622 & 57 & 3101 & 753 & 32 & 109 & 765 & 67 & 4827 & 3.0 \\
\hline 1993 & 1720 & 61 & 3293 & 773 & 28 & 119 & 878 & 100 & 5191 & 3.0 \\
\hline 1994 & 1544 & 64 & 2997 & 696 & 43 & 138 & 892 & 95 & 4861 & 3.1 \\
\hline
\end{tabular}

a. each transplant operation is counted regardless the number of organs per transplant, except for heart/lung transplants which are regarded as single transplants.

b. excluding former East Germany 
between 46 and 55 years, and only $2 \%$ were over 55 . Gradually, donor acceptance criteria changed and led to increased efforts and successes in the retrieval of organs from donors previously considered too old.

In 1994, the retrieval rate in the two oldest donor groups was $23 \%$ [table 4].

Table 4. Proportion of elderly kidney donors in Eurotransplant

\begin{tabular}{cccccc}
\hline Year & $\begin{array}{c}\text { Number of } \\
\text { kidney transplantations }\end{array}$ & $\begin{array}{c}46<55 \\
\text { N }\end{array}$ & \multicolumn{2}{c}{ DONOR AGES } & $>55$ \\
& & & $\%$ & N & $\%$ \\
\hline 1990 & 3171 & 694 & 22 & 385 & 12 \\
1991 & 3395 & 758 & 22 & 444 & 13 \\
1992 & 3101 & 696 & 22 & 459 & 15 \\
1993 & 3293 & 740 & 22 & 618 & 19 \\
1994 & 2997 & 698 & 23 & 689 & 23 \\
\hline
\end{tabular}

\section{Causes of donor death}

An overview of the causes of donor death in Eurotransplant in the 5-year study period is presented in table 5 . The most notable changes were in the number of cerebral traumas, which decreased from $43 \%$ to $40 \%$, and in the number of cerebrovascular-accidents (CVA), which increased from $40 \%$ to $45 \%$. In the presence of the same number of organ donors, the former reflects considerable reduction in traffic accident fatalities, largely due to the use of seat belts and helmets, while the latter is obviously related to the increased number of elderly donors [table 6]. There were only slight changes in brain tumors, suicide, and other.

\section{Outcome of transplanted organs from elderly donors}

The average age of 996 donors older than 55 years who provided kidneys to Eurotransplant between 1990 and 1994 was 62 years. The survival rate of primary renal allografts from donors older than 55 years was compared to that of grafts from younger donors [table 7]. All cases of recipient death before graft failure were excluded in order to avoid an unfair bias against elderly recipients. The mean actuarial graft survival rate for transplants from donors aged 6-55 years was $89.7 \%$ (range $86-92 \%$ ), and $85.2 \%$ (range $81 \%-91 \%$ ) at three years post-transplantation. The rates for grafts from donors in the youngest group (0-5 years) were $78 \%$ at one year and $73 \%$ at three years, while those for grafts

Table 5. Causes of donor death in Eurotransplant 1990 to 1994

\begin{tabular}{lrrrrr}
\hline Cause of death & $\begin{array}{r}1990 \\
\%\end{array}$ & $\begin{array}{r}1991 \\
\%\end{array}$ & $\begin{array}{r}1992 \\
\%\end{array}$ & $\begin{array}{r}1993 \\
\%\end{array}$ & $\begin{array}{r}1994 \\
\%\end{array}$ \\
\hline Head injury & 43 & 41 & 40 & 39 & 40 \\
CVA & 40 & 42 & 43 & 45 & 45 \\
Brain tumor & 3 & 3 & 3 & 2 & 2 \\
Suicide & 4 & 5 & 4 & 4 & 4 \\
All others & 10 & 9 & 10 & 10 & 9 \\
\hline
\end{tabular}

"cerebrovascular accident 
Table 6. Donor age and cause of death

\begin{tabular}{ccc}
\hline Age (years) & Head injury $(\%)$ & CVA (\%) \\
\hline $0-5$ & 50 & 8 \\
$6-10$ & 70 & 12 \\
$11-15$ & 64 & 14 \\
$16-25$ & 74 & 13 \\
$26-35$ & 45 & 39 \\
$36-45$ & 30 & 57 \\
$46-55$ & 26 & 61 \\
$>55$ & 23 & 66 \\
\hline
\end{tabular}

Table 7. Actuarial survival of primary renal allografts from donors in different age groups, Eurotransplant 1990 to 1994

\begin{tabular}{|c|c|c|c|c|}
\hline \multirow{2}{*}{\multicolumn{2}{|c|}{$\begin{array}{l}\text { Donor age group } \\
\text { (years) }\end{array}$}} & \multirow{2}{*}{ Cases } & \multicolumn{2}{|c|}{$\%$ graft survival } \\
\hline & & & 1st year & 3rd year \\
\hline & -5 & 190 & 78 & 73 \\
\hline & -10 & 220 & 86 & 81 \\
\hline & -15 & 249 & 92 & 91 \\
\hline 16 & -25 & 1608 & 92 & 88 \\
\hline 26 & -35 & 1291 & 91 & 86 \\
\hline & -45 & 1482 & 89 & 84 \\
\hline \multirow[t]{2}{*}{46} & -55 & 1584 & 87 & 82 \\
\hline & $>55$ & 996 & 83 & 74 \\
\hline
\end{tabular}

from donors in the oldest group (>55 years) were $83 \%$ at one year and $74 \%$ at three years post-transplantation $(p<0.0001)$.

The survival rate of primary renal allografts from donors whose cause of death was cerebral trauma differed significantly between younger $(<55$ years) and older (>55 years) donors: $86 \%$ and $79 \%$, respectively, at three years posttransplantation ( $p=0.03$, [figure 1]). Graft survival rates of renal transplantations performed with organs from donors whose cause of death was CVA were also analyzed according to donor ages. Grafts from younger donors ( $<55$ years) did significantly better $(p=0.0001)$ than those from older donors (>55 years). The survival rates at three years were $85 \%$ and $72 \%$, respectively [figure 2].

\section{Results with grafts from single and multiple organ donors}

Multiple-organ donors (MODs) were mainly young, male donors who more often died as a result of cerebral trauma than the single-organ (kidneys only) donors (SODs). The MOD kidneys were transplanted into younger recipients with lower pre-transplant panel reactive antibody levels and shorter cold ischemia times, over a slightly less favorable DR mismatch gradient. These grafts were more often preserved with the University of Wisconsin (UW) solution than were SOD kidneys [2]. 


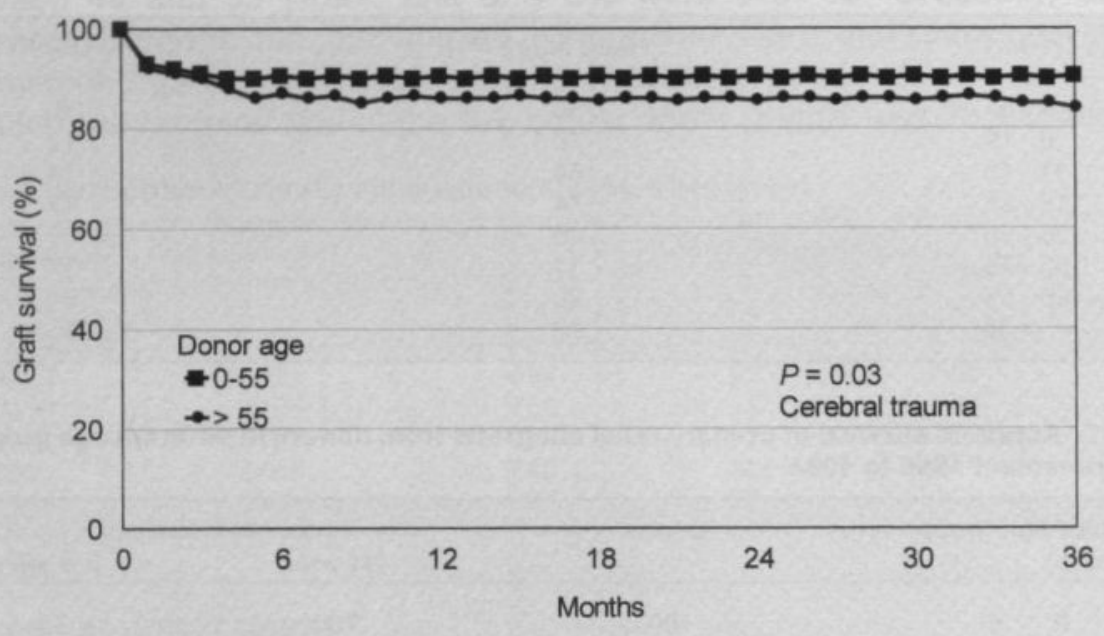

Fig. 1. Survival of primary renal allografts from donors whose cause of death was cerebral trauma (Eurotransplant 1990-1994)

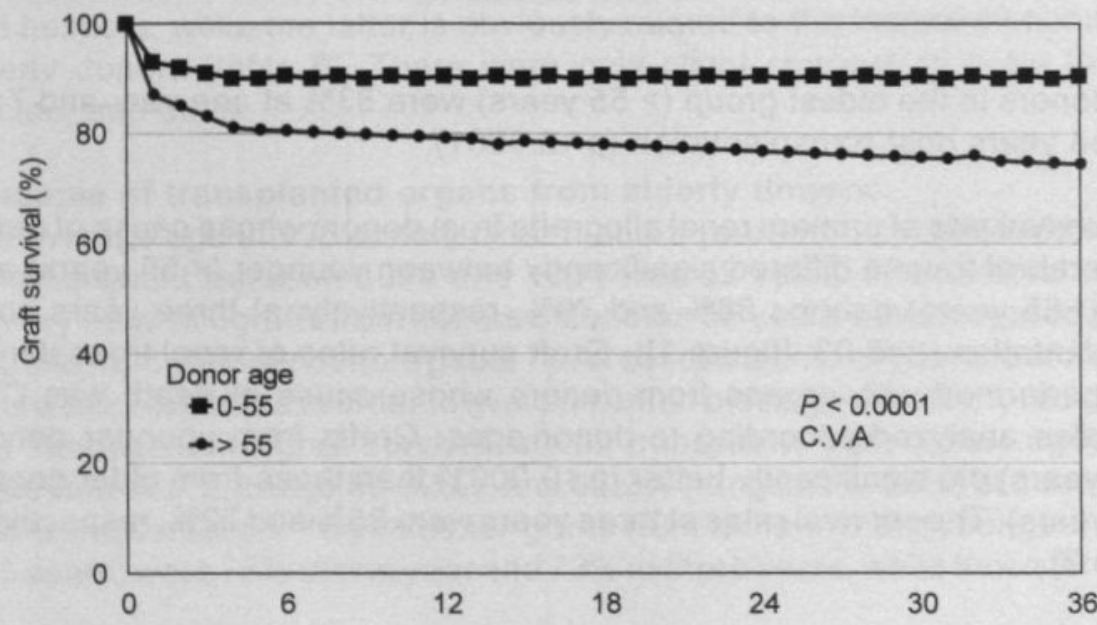

Fig. 2. Survival of primary renal allografts from donors whose cause of death was cerebrovascular accidents (Eurotransplant 1990-1994) 
An observational study was carried out by Smits et al on the results of 8746 MOD kidneys and 6610 SOD kidneys transplanted between 1988 and 1995 in the Eurotransplant community [7]. Renal allograft survival was significantly better for MOD kidneys $(85 \%, 75 \%$, and $58 \%)$ than for SOD kidneys $(78 \%$, $68 \%$, and $46 \%) ;(p=0.0001)$. A multivariate analysis using Cox's proportional hazards model was used to quantify the role of the two different procurement policies, MOD and SOD, on renal allograft survival after adjusting for other prognostic factors. Results showed that recipients of SOD kidneys had a 1.28 times higher risk of graft failure than recipients of MOD kidneys. The superior graft survival of MOD kidneys could not be explained by the fact that the MOD's were younger, male, and that UW was used as a preservation solution.

\section{Discussion}

In most fields of human endeavor, excess demands for a product or service are normally offset by increases in the production or availability of the service. Unfortunately, that natural process does not function in clinical transplantation. Consequently, the increasing disparity between the number of patients waiting for a transplant and the number of transplants performed is generating a large amount of attention from governmental and public organizations.

Between 1990 and 1994, there was a $27 \%$ increase in the number of patients waiting for a kidney transplant in Eurotransplant, while there was no increase at all in the number of kidney transplantations performed. That disturbing trend is evident not only in kidney but also in heart transplantation.

Renal transplantation continues to be the treatment of choice for patients with end-stage renal failure. Consequently, it is not surprising that patients continue to be placed on waiting lists for such transplantations. However, the number of organ donations still does not satisfy the requirements of those waiting lists, which continue to grow. Attempts have been made to counter that trend via the educational programs directed both at the general population and at the specific medical communities. Transplant coordinators have been appointed to expedite the numerous procedures involved in transplantation. There has also been a number of different organs that may be retrieved from a single donor as well as an increase in the acceptable age for organ donation.

The survival rate of kidneys transplanted from older donors $-83 \%$ at one year - is lower than that from donors aged 6-55 years, which ranges from $86 \%$ to $92 \%$ at one year. The survival rate of the older grafts is $74 \%$ at three years compared to $81-91 \%$ for the younger grafts. Obviously, since transplantation does not confer immortality on the graft, one should not be surprised by the poorer performance of older grafts which may have a lower functional reserve than younger grafts [3]. Thus, one might consider introducing donor age as a separate "match" criterion, especially for recipients over 55 years of age. 
The significantly better results with MOD kidneys, which are not attributable to the fact that MOD's were younger, male, and that their grafts were preserved with UW solution, may have been the result of the intensive surveillance that potential MOD's receive and the combined expertise of the multi-organ explantation teams. Smits et al [4] have suggested that "every donor should not only be considered as a potential multi-organ donor but, what is more important, every organ should be treated as one".

The shortage of non-renal organs may be partly due to the fact that the routine transplantation of these organs is relatively new and has not yet received the same degree of public acceptability as renal transplantation. As such, the number of patients awaiting such transplants may be expected to parallel the increasing availability of those transplants. Indeed, the number of patients on these waiting lists has almost doubled - from 897 in 1990 to 1736 in 1994 while the number of non-renal transplants only increased from 1399 to 1864 $(33 \%)$. Once again, we are observing a serious disparity between the numbers of waiting and transplanted patients.

Throughout Europe, many initiatives to increase organ donation rates, among them transplant legislation, publicity campaigns, distribution of donor cards, appointment of transplant coordinators and reimbursement of procurement costs. Although all of these initiatives may help to increase organ donation, none has been sufficient to make a significant impact on the supply of donor organs [5].

In light of the continuing organ shortage, it is time to re-examine our strategies to encourage organ donation. Two of the Eurotransplant member countries with presumed consent legislation, Austria and Belgium, are demonstrating that such a system is not only provides more donors, but also more organs per donor [3]. Nevertheless, abandoning the system that most European countries currently have, i.e. of voluntary, altruistic organ donation in favor of presumed consent legislation is unlikely to be introduced. Poor results have been achieved in France, whereas in some other countries, such as Spain, which uses informed consent [6], better results have been achieved. Since 1990, Spain has managed to dramatically increase the renal transplant rate - to 42 per million population in 1994 - and to provide more donors per capita than any other country. This has been achieved despite a continuing decrease in the number of deaths from road traffic accidents, and has been attributed to the coordination system and the support and training provided for transplant coordinators [7].

Still, many potential donors are lost, because hospitals lack a clear process for organ donation. Either potential donors are not detected or families are not given the option of donation, or the manner in which the donation request is made does not meet the family's emotional and informational needs. Despite evidence of considerable public support for organ donation, many countries still 
report significant refusal rates. In 1994, data from United Kingdom Transplant Support Service Authority (UKTSSA) and the Spanish Organización Nacional de Trasplantes (ONT) revealed national refusal rates of $26 \%$ and $24 \%$, respectively $[7,8]$. The Eurotransplant Foundation, concerned about the rise in organ donation refusals, has taken the initiative of addressing this particular issue. The European Donor Hospital Education Programme (EDHEP) was created in 1991 to meet the widely perceived need to help health professionals deal effectively with bereaved relatives of potential organ donors. Its highly interactive "skills awareness workshops" are moderated by qualified trainers who work to sharpen the communication skills of medical professionals, heighten their sensitivity to the needs of the bereaved relatives and teach them how to go about requesting organ donation. The workshops provide participants with guidelines for protocols for the care of the bereaved and for making requests for organ donation. Since its inception, EDHEP has been translated into 17 languages and is in use in over 30 countries [9] demonstrating the need for this kind of professional training. Several countries are now beginning to incorporate EDHEP into their national medical and nursing training programs. A statistically significant learning effect can be discerned in evaluations of the impact of EDHEP that are underway in the Netherlands and the United Kingdom. This EDHEP effect has also been shown in Israel and Japan. National Working Group from all countries confirm that EDHEP adapts easily to all national, religious, cultural, and educational needs. The program generates a more favorable attitude to organ donation among critical care staff and teaches those involved how to communicate more effectively and more confidently.

Recently, the Eurotransplant International Foundation (the Netherlands), ONT (Spain), and the Partnership for Organ Donation (US) decided to integrate their expertise into a program called "Donor Action", also designed to improve the hospital donation process and to make sure that potential donors are detected and families asked about donation in a sensitive and caring manner. This program, combined with the training and support of the professionals involved, is considered to be the most effective way to improve the donation situation in individual hospitals. Research confirms that, with better practices, hospitals can achieve a measurable increase in donation. Specific tools are provided to ensure that all potential donors are identified early enough and referred. Donor Action provides a comprehensive package of tools, resources, guidelines, and training to help a hospital diagnose its own potential for donation and improve its own organ donation procedures. The Donor Action program materials are designed in a modular

- Donor detection - early identification of all patients who may be potential donors.

- Donor referral - referral of all potential donors to transplant coordinators.

- Family care and communication - sensitive communication and support for families of potential donors.

- Donor maintenance - optimal clinical management of potential donors.

- Organ retrieval - optimal retrieval protocols. 
It is hoped that this cooperative effort will have a beneficial effect on our efforts to alleviate the organ shortage and help to provide treatment for patients with end stage organ failure.

\section{Conclusion}

The favorable graft survival results of MOD kidneys, which were significantly better than those obtained with SOD kidneys, confirm their suitability for renal transplantation.

The obtained results with grafts from donors older than 55 years were $5 \%$ lower than those obtained from donors aged 6-55 years at one year and $8 \%$ lower at three years. However, graft survival was much lower, and significantly so, for organs from donors whose cause of death was CVA than it was for organs from donors with cerebral trauma. Nevertheless, in view of the severity of the organ donor shortage, we should continue to accept these organs for transplantation. 


\section{References}

1. The new Articles of Association of Stichting Eurotransplant International Foundation 1994. Eurotransplant Newsletter; 120: October 1994, ISSN 0920-2366.

2. Cohen B, Persijn GG, De Meester J, eds. Eurotransplant Foundation Annual Report 1994, Leiden, the Netherlands.

3. Brenner BM, Cohen RA, Milford EL. In: Renal Transplantation, one size may not fit all. J Am Soc Nephrol 1992; 3: 162-9 (Erratum, J Am Soc Nephrol 1992; 3: 1038).

4. Smits JAM, De Meester J, Persijn GG, Claas FH, Van Houwelingen HC. The outcome of kidney grafts from multi organ donors and kidney only donors. Transplantation 62:1.

5. Cohen B. Finding a cure to dramatic fall in organ procurement rates, Neph. News \& Issues 1994; July/August: 21-22.

6. Land W, Cohen B. Post mortem and living donation in Europe: transplant laws and activities. Transpl Proc 1992; 24: 2165-7.

7. Stewart R, Buckley P, Matthewman E, Pearce J, Corrado M. UKTCA/BACCN/MORI Relatives' Refusal Study. UKTSSA User's Bulletin Winter 1994/5;14:11.

8. Matesanz R, Miranda B. The Spanish experience in organ donation. In: Chapman JR, Deierhoi MH, Wight C, eds. Organ and Tissue Donation for Transplantation. London: Edward Arnold; 1997: 361-372.

9. Wight C, Jager K, Blok G, Dalen J van, Cohen B. Overview of the European Donor Hospital Program. Transpl Proc, Vol. 28, No. 1, February 1996. 



\section{Chapter 5}

\section{Trends in organ donation}

Bernard Cohen, Stephen McGrath, Johan De Meester, Yves Vanrenterghem and Guido G. Persijn 


\section{Introduction}

Organs for transplantation are a scarce and precious resource. Although organ donation rates have improved considerably in recent years, much more needs to be done to reduce waiting lists and minimize loss of life. In this article we present data gathered from a variety of sources relating to renal and extrarenal transplantation for the period 1989-1996, and attempt to identify trends in donation and transplantation rates. We also consider the possible implications for future policy.

\section{Methods}

Countries where transplantation takes place were grouped into seven regions: Western Europe, Eastern Europe, Latin America, the Middle East, Asia, North America, and Australia, New Zealand, and South Africa as one region [table 1]. The number of renal and extrarenal (liver, heart, heart-lung, pancreas) transplants were recorded according to donor type (cadaveric or living). Data were compiled from both official sources, such as organ exchange organizations (OEOs), and various scientific publications and internal reports from pharmaceutical companies [1-4]. Data from all sources were cross-checked against one another.

\section{Results}

\section{Donation}

Published or well-corroborated estimates of numbers of organ donors for every year in the period 1989-1996 were available only for North America and Western Europe. The number of kidney donors available per annum increased in both these regions in the period 1989-1996. In Western Europe, numbers

Table 1. Countries included in each of the seven regions studied

\begin{tabular}{ll}
\hline Region & Countries included \\
\hline Western Europe & $\begin{array}{l}\text { Austria, Belgium, Denmark, Eire, Finland, France, Germany, Greece, Italy, } \\
\text { Luxemburg, the Netherlands, Norway, Portugal, Spain, Sweden, Switzerland, } \\
\text { UK }\end{array}$ \\
$\begin{array}{ll}\text { Eastern Europe } \\
\text { Latin America }\end{array}$ & $\begin{array}{l}\text { Byelorussia, Bulgaria, Croatia, Czech Republic, Estonia, Hungary, Latvia, } \\
\text { Lithuania, Poland, Romania, Russia, Slovakia, Slovenia, Ukraine }\end{array}$ \\
Middle East & $\begin{array}{l}\text { Cyprus, Egypt, Israel, Iraq, Iran, Jordan, Kuwait, Lebanon, Libya, Oman, } \\
\text { Qatar, Saudi Arabia, Syria, Turkey, United Arab Emirates }\end{array}$ \\
Asia & $\begin{array}{l}\text { Bangladesh, Hong Kong, India, Indonesia, Japan, Malaysia, Pakistan, China, } \\
\text { Philippines, Singapore, South Korea, Taiwan, Thailand }\end{array}$ \\
North America & USA, Canada \\
AusNZSA & Australia, New Zealand, South Africa \\
\hline
\end{tabular}




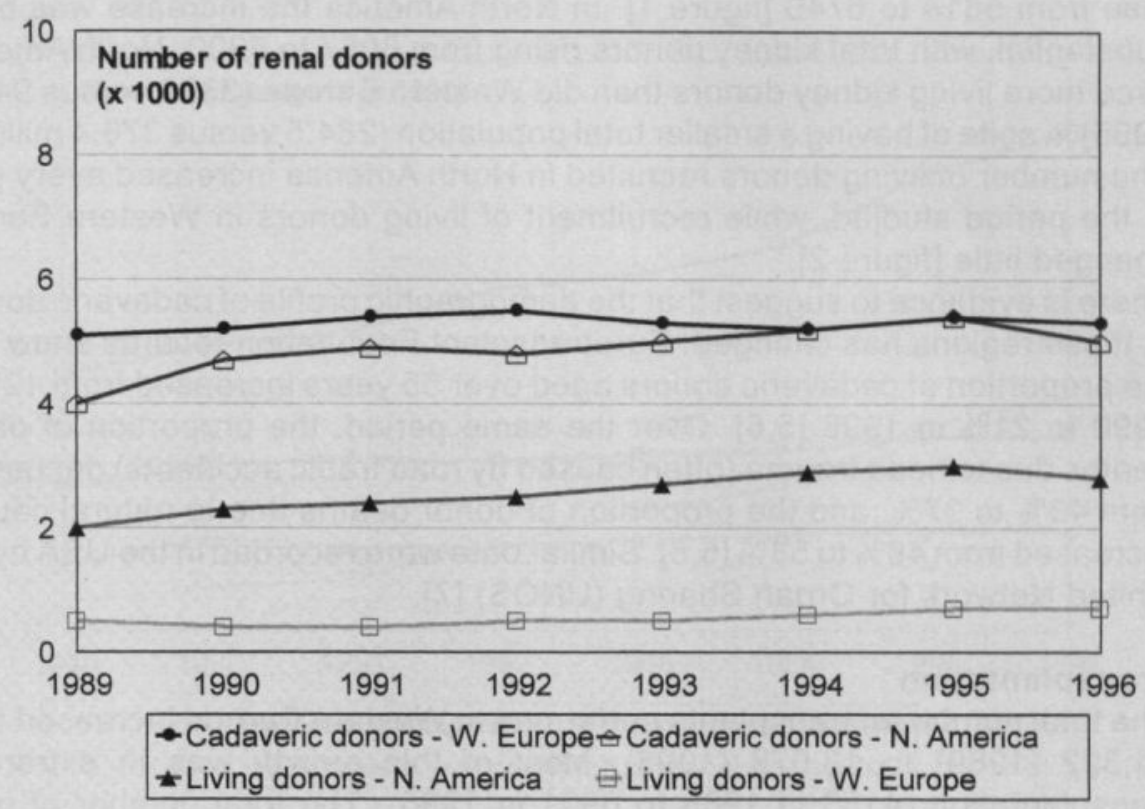

Fig. 1. Number of donors used for renal transplantation in North America and Western Europe between 1989 and 1996.

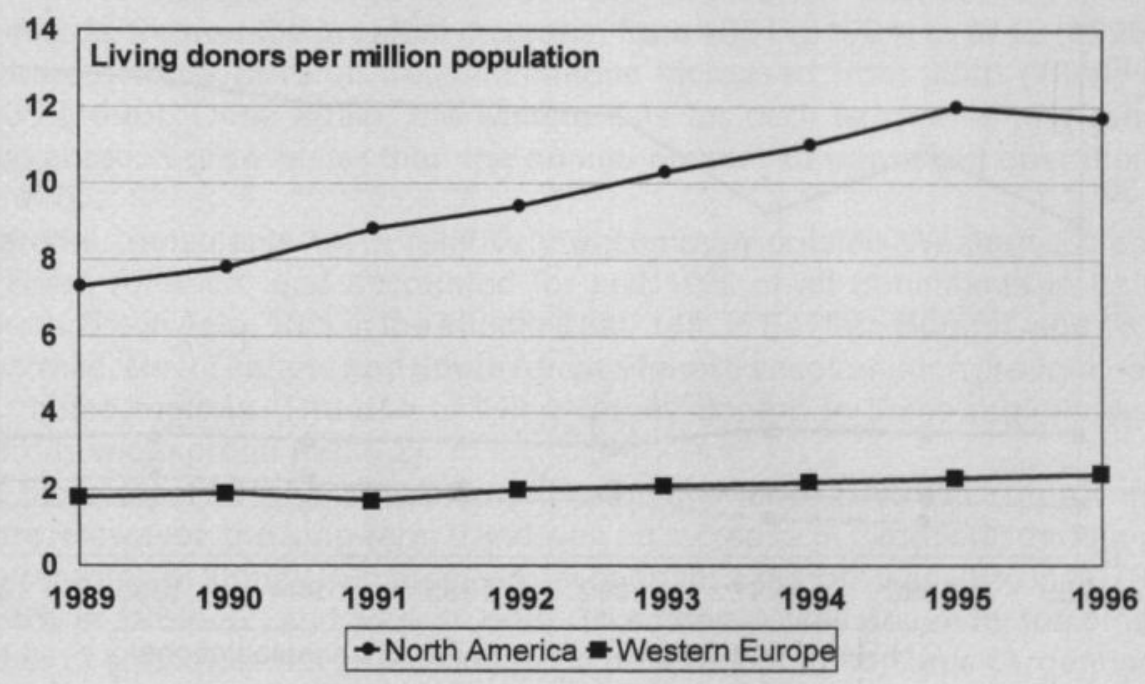

Fig. 2. A marked upward trend in the number of living donors was observed between 1989 and 1996 in North America. The number of living donors remained relatively stable during the same period in Western Europe. 
rose from 5814 to 6740 [figure 1]. In North America the increase was more substantial, with total kidney donors rising from 6057 to 8800 . North America used more living kidney donors than did Western Europe (3389 versus 943 in 1996 ) in spite of having a smaller total population ( 284.5 versus 378.4 million). The number of living donors recruited in North America increased every year in the period studied, while recruitment of living donors in Western Europe changed little [figure 2].

There is evidence to suggest that the demographic profile of cadaveric donors in these regions has changed. Eurotransplant Foundation records show that the proportion of cadaveric donors aged over 55 years increased from $12 \%$ in 1990 to $21 \%$ in $1996[5,6]$. Over the same period, the proportion of donor deaths due to head trauma (often caused by road traffic accidents) decreased from $43 \%$ to $37 \%$, and the proportion of donor deaths due to natural causes increased from $48 \%$ to $58 \%[5,6]$. Similar data were recorded in the USA by the United Network for Organ Sharing (UNOS) [7].

\section{Transplantation}

The total number of transplants performed in Western Europe increased from $14,322(1989)$ to 18,078 (1996). Most of this growth was in extrarenal transplantation (4153 in 1989 to 6901 in 1996). The total number of renal transplants changed little (from 10,169 in 1989 to 11,177 in 1996). In the period under review waiting lists for both renal and extrarenal transplants increased faster than annual transplantation rates [figure 3].

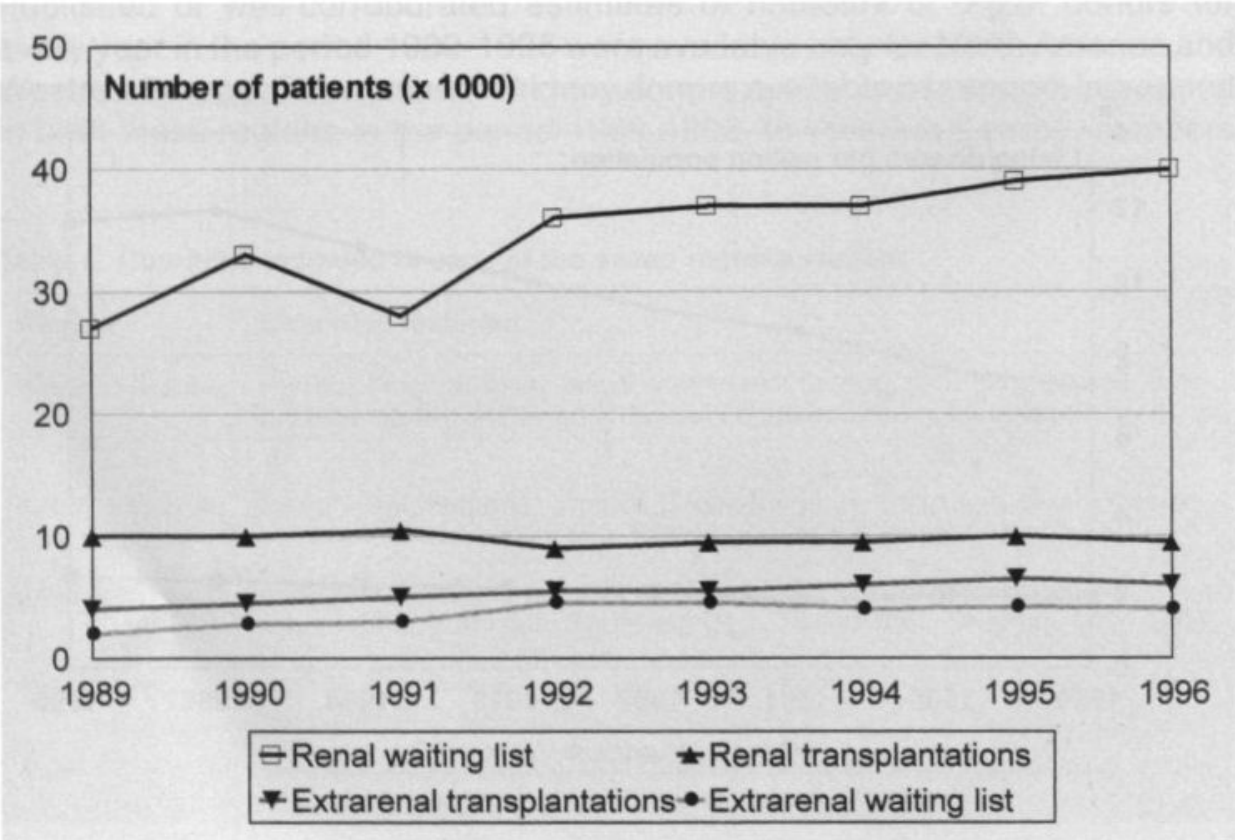

Fig. 3. Renal and extrarenal waiting lists and transplantations in Western Europe between 1989 and 1996. 


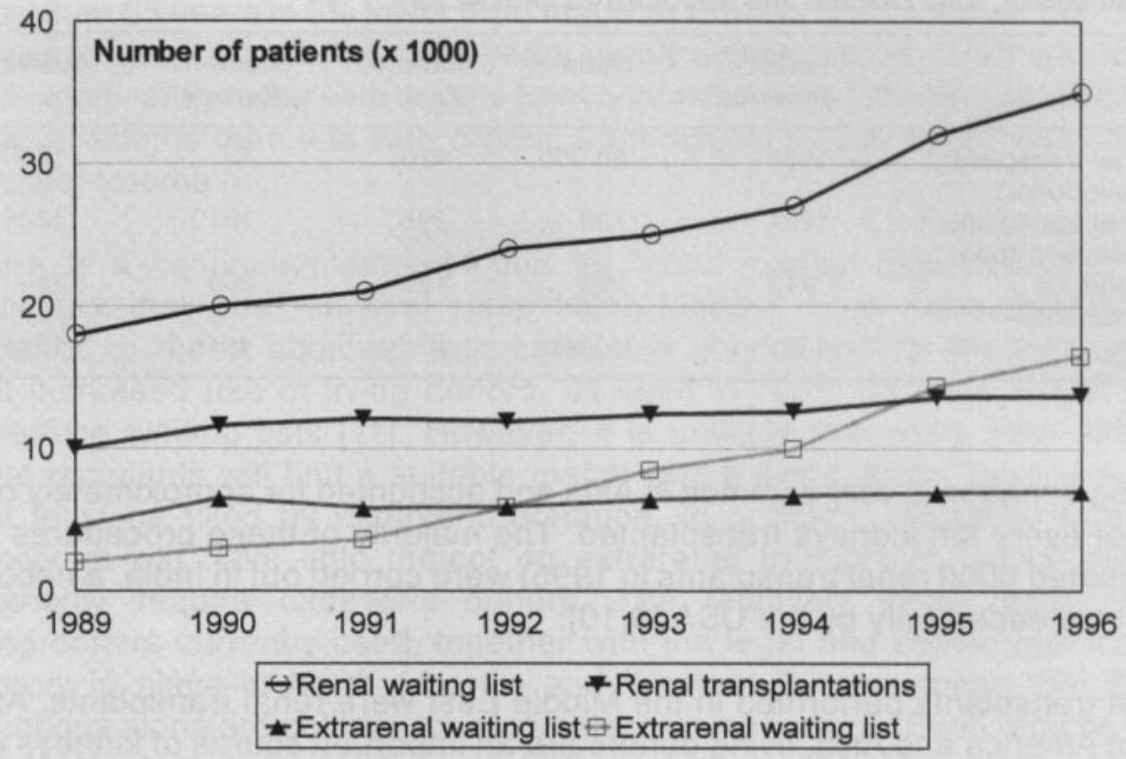

Fig. 4. Renal and extrarenal waiting lists and transplantations in North America between 1989 and 1996.

The number of transplants performed each year in North America increased from 14,677 (1989) to 21,613 (1996). As in Western Europe, extrarenal transplants showed the greatest increase, from 4831 (91989) to 8712 (1996). The total number of renal transplantations increased from 9846 (1989) to 12,901 (1996). Once again, the waiting lists for both extrarenal and renal transplantation grew faster than the annual number of transplant operations [figure 4].

Extrarenal transplants were relatively uncommon outside Western Europe and North America, and accounted for just $10 \%$ of all transplants in Latin America, 3\% in Asia, 15\% in the Middle East, 14\% in Eastern Europe, and 18\% in Australia, New Zealand and South Africa. Renal transplantation predominated in these regions. The use of living kidney donors in these regions was generally widespread [table 2].

More than half of all renal transplants in Latin America in 1995 were from living donors. However, the long-term trend was an increase in cadaveric donation: the proportion of kidney transplants from cadaveric donors was $29 \%$ in 1970 $88,35 \%$ in $1989-92$, and $51 \%$ in 1995 . This change was driven by the small number of countries that performed large numbers of transplants (Argentina, Brazil, Chile, Cuba, and to a lesser extent, Mexico) and reflected changes in government policy on transplantation, improvements in the structure of transplant programs, and the introduction of new laws relating to donor consent [8]. 
Table 2. Transplant activity (1995) in Latin America, Asia, the Middle East, Eastern Europe, and Australia, New Zealand and South Africa (AusNZSA)

\begin{tabular}{llllcc}
\hline & $\begin{array}{l}\text { Latin } \\
\text { America }\end{array}$ & Asia & $\begin{array}{l}\text { Middle } \\
\text { East }\end{array}$ & $\begin{array}{l}\text { Eastern } \\
\text { Europe }\end{array}$ & AusNZSA \\
\hline $\begin{array}{l}\text { Renal transplants } \\
\text { (living donor) }\end{array}$ & 1985 & 10,000 & 420 & 40 & 135 \\
$\begin{array}{l}\text { Renal transplants }) \\
\text { (cadaveric donor }\end{array}$ & 1924 & 700 & 295 & 1610 & 1005 \\
$\begin{array}{l}\text { Extrarenal } \\
\text { transplants }\end{array}$ & 442 & 281 & 123 & 260 & 244 \\
Total & 4351 & 10,961 & 836 & 1910 & 1384 \\
\hline
\end{tabular}

Living donation is very common in Asia and accounted for approximately nine out of every ten kidneys transplanted. The majority of these procedures (an estimated 6000 renal transplants in 1995) were carried out in India, a national total exceeded only by the USA $[9,10]$.

Most transplants performed in the Middle East were renal transplants. As in Latin America and Asia, living donors are an important source of kidneys and accounted for more than $50 \%$ of all transplant procedures. Many of these activities are unregulated, although Iran is reported to have a legal system of paid living donation [9].

Eastern Europe is unique in that virtually no renal transplants were carried out using living donors. Renal transplantation programs in this region were generally underdeveloped, but Hungary and the Czech Republic were notable exceptions with cadaveric renal transplantation rates of 25.2 and 37.7 per million population (PMP), respectively, in 1996. These figures compared well with rates in the UK (26.2 PMP) and the USA (33.5 PMP).

\section{Discussion}

The number of renal and extrarenal transplants performed each year in Western Europe and North America is increasing steadily. North America is striking in its use of living donors, which is high compared with Western Europe and is increasing every year. The reason for this may be partly economic, with the health insurance system favoring transplantation over dialysis as a less costly maintenance option for patients with end-stage renal failure. Ironically, the relatively low rate of living donation in Eastern Europe may also have an economic basis; under-investment prevents such procedures being performed.

The supply of organs in all regions is failing to keep up with demand, and waiting lists are continuing to grow year on year. Those patients lucky enough to receive a transplant are increasingly likely to find themselves with an organ from a so-called marginal donor - a donor aged over 55 years and possibly who has suffered stroke. Recent data indicate that such organs may carry an 
increased risk of graft failure. The graft survival rate with kidneys from donors older than 55 years is $5 \%$ lower than that with kidneys from younger donors at one year and $9 \%$ lower at three years post-transplantation. Graft survival is also significantly lower with organs from donors who die following cerebrovascular accidents than it is with organs from donors whose death was due to cerebral trauma [5].

There is a continuing, urgent need for 'good quality' organ donors. The discovery that graft survival rates using kidneys from living donors are superior to those obtained with cadaveric donors led to the suggestion that increased use of living donors, as seen in North America, could help to reduce waiting lists [11]. However, it is unlikely that more than $35 \%$ of renal recipients will find a suitable match with a living donor, leaving a gap that must be filled by cadaveric donation. In addition, increases in living donations will have little impact on extrarenal transplants, which almost invariably require cadaveric donors. The relatively small numbers of living donors currently used, together with the legal and ethical restrictions already in place in North America and Western Europe, mean that living donations alone are unlikely to resolve the organ shortage. Even regions with historically high levels of living donation, such as India and parts of Latin America, have enacted, or are in the process of enacting, legislation designed to limit the use of living unrelated donors and stimulate the search for cadaveric donors.

Transplant legislation is important because it provides a framework within which cadaveric organ donation can take place. In practice, this means the adoption of one of two basic forms of consent law: 'presumed consent' or 'informed consent'. Presumed consent allows individuals to record their objection to organ donation. If no objection is registered - mostly on a central computerized database - then the organs may be procured. It is not usually legally necessary to inform relatives of the intention to remove organs, and rates of objection using this system appear to be low $(0.5-24 \%)$ [12]. With informed consent, if an individual has not recorded his or her wish to be an organ donor, consent must be obtained from the next of kin. This is always a difficult interview for both the doctor and the recently bereaved relatives, and refusal rates in these situations remain understandably high [13]. As might be predicted, when ranked by cadaveric donation rate, four of the top six countries in Western Europe and North America practice presumed consent legislation [table 3].

These data should be treated with caution as the relationship between procurement legislation and the practice of organ procurement is not straightforward. Interpretation of the law varies between nations, hospitals, and even doctors. These variations can be so great as to effectively over-rule the legislation. Thus Spain, the country with the highest procurement rate, has chosen not to practice its presumed consent legislation and, instead, operates a de facto informed consent system, and France and Greece, which also have 
Table 3. The number of cadaveric donors in Western Europe and North America in 1996 and the prevailing donor legislation

\begin{tabular}{|l|c|l|l|}
\hline & $\begin{array}{l}\text { Cadaveric kidney } \\
\text { donors per million } \\
\text { population }\end{array}$ & $\begin{array}{l}\text { Donor's legal } \\
\text { situation }\end{array}$ & $\begin{array}{l}\text { Donor's situation } \\
\text { in practice }\end{array}$ \\
\hline Spain & 26.8 & presumed consent & informed consent \\
\hline Austria & 24.7 & presumed consent & presumed consent \\
\hline USA & 21.2 & required request & informed consent \\
\hline Belgium & 21.2 & presumed consent & presumed consent \\
\hline Portugal & 21.2 & presumed consent & presumed consent \\
\hline Finland & 19.5 & presumed consent & presumed consent \\
\hline Ireland & 17.7 & informed consent & informed consent \\
\hline The Netherlands & 15.1 & informed consent & informed consent \\
\hline Norway & 15.1 & presumed consent & informed consent \\
\hline France & 15.1 & presumed consent & informed consent \\
\hline Canada & 15.0 & informed consent & informed consent \\
\hline Denmark & 15.0 & informed consent & informed consent \\
\hline UK & 14.2 & informed consent & informed consent \\
\hline Germany & 12.7 & informed consent & informed consent \\
\hline Switzerland & 12.6 & $\begin{array}{l}\text { presumed consent, } \\
\text { informed consent, } \\
\text { or no law }\end{array}$ & $\begin{array}{l}\text { practice varies } \\
\text { per canton }\end{array}$ \\
\hline Sweden & 11.0 & presumed consent & practice varies \\
\hline Italy & 6.5 & presumed consent & informed consent \\
\hline Greece & presumed consent & informed consent \\
\hline
\end{tabular}

presumed consent laws, procure relatively few organs [2].

It is evidently important both for individuals to become organ donors and for consent, once asserted, not to lapse. If relatives are to be consulted following an individual's death, they should be aware of, and sympathetic to, the benefits that organ transplantation can bring to the recipient. The attitudes of potential donors and their relatives to transplantation medicine and ethics may have a crucial bearing on their decision to give consent for donation. There is some evidence to suggest that these attitudes may be influenced by transplantationrelated stories in the media. These stories include the alleged theft and murder of babies in Latin America so that their organs can be used for transplantation in North America and Europe, rumors of international organ trafficking, allegations that organs of executed prisoners are used for transplantation in the People's Republic of China [14]. Most of these stories remain entirely unproven [15], while others may be relatively well verified but have no bearing on transplantation as it is practiced in Western Europe and North America. However, the consequences of such stories may be far-reaching; for example, the transmission of the 1993 TV documentary Voleurs D'Organes that purport- 
ed to show evidence of child organ trafficking coincided with a significant reduction in levels of organ donation in France later that year [2].

Such stories are often linked to important ethical questions which must of course be openly debated. However, if the issues are not clearly defined and misinformation quickly denounced, public misunderstanding about organ transplantation will be encouraged and cadaveric donations may plateau or even decrease. We propose that the question of information management be addressed directly by a permanent international human donor surveillance committee comprising transplantation physicians and by OEOs. Using international human rights monitoring organizations as a model, the committee would have the following core activities:

To serve as a clearing house for information on organ donation activities. To this end, the committee would publish an annual survey of organ donation practices, containing basic information on demographics, donation rates, and legal issues. A separate report would focus on more problematic areas, such as the sale of organs, the use of organs from executed prisoners, allegations of organ theft and so on.

To review the positions of international organizations, and to discuss current ethical issues surrounding transplantation.

The key purpose of this review would be to highlight relevant ethical issues, and to act as a forum for subsequent debate.

To make recommendations to medical and human rights groups regarding appropriate strategies for enforcing international standards.

As a non-affiliated body, the committee would be well placed to offer advice to both national and international organizations. 


\section{References}

1. UNOS. 1996 Annual Report, Transplant Data 1988-1995.

2. Council of Europe. International figures on organ donation and transplantation 1996. Transplant Newsletter 1997; 2 (1).

3. Cecka JM, Terasaki PI. Worldwide Transplant Center Directory Clinical Transplants 1996: 519.

4. Smith S, Kontzalis P. A summary of the organ transplant figures from 1993-1995. Sandoz Internal Report. Switzerland, Basel, 1996.

5. Cohen B, D'Amaro J, De Meester J, Persijn GG. Changing patterns in organ donation in Eurotransplant, 1990-1994. Transpl Int 1997; 10: 1.

6. Cohen B, Persijn GG, De Meester J, eds. Eurotransplant Annual Report 1996, Leiden, the Netherlands.

7. Bennett LE., Glascock RF, Breen TY, Ellison MD, Daily OP. Organ donation in the United States: 1988 through 1992. Clin Transpl 1993: 85.

8. Santiago-Delpin EA, Duro-garcia V, Chameh O. Forty Thousand Organ transplants in Latin America. XVI Congress of the International Transplantation Society, Barcelona, August 25-30, 1996. Transpl Proc 1997; 29: 1586.

9. Daar A. An emerging transplant force - developing countries: Middle East and the Indian subcontinent. XVI Congress of the International Transplantation Society, Barcelona, August 25-30, 1996. Transpl Proc 1997; 29: 1577.

10. Takagi H. Organ transplants still too few in Japan and Asian countries. XVI Congress of the International Transplantation Society, Barcelona, August 25-30, 1996. Transpl Proc 1997; 29: 1580.

11. Terasaki PI, Cecka JM, Gjertson DW, Takemoto S. High survival rates of kidney transplants from spousal and living unrelated donors. N Engl J Med 1995; 333: 333336.

12. Roels L, Deschoolmeester G, Vanrenterghem Y. A profile of people objecting to organ donation in a country with a presumed consent law: data from the Belgian national registry. XVI Congress of the International Transplantation Society, BarceIona, August 25-30, 1996. Transpl Proc 1997; 29: 1473.

13. Wight C, Cohen B. The European Donor Hospital Education Programme (EDHEP). In: Chapman Yr, Deierhol M, Wight C, eds. London: Edward Arnold, 1997: 373.

14. Organ procurement and judicial execution in China. Human Rights Watch Asia 1994 (August 29); 6 (9).

15. Leventhal T. The child organ trafficking rumor: a modern 'urban legend'. United States Information Agency, December 1994. 


\section{Chapter 6}

\section{A European perspective on organ procurement - breaking down the barriers to organ donation}

Bernard Cohen and Celia Wight 


\section{Introduction}

Organ donation is a unique process that can take place only with the cooperation of the many parties involved, such as donors, families, and medical staff, as well as government and society as a whole. Even with such cooperation, the steady progress made in the last 10 years in the field of organ transplantation has been seriously hampered by one persistent problem: a worldwide shortage of donor organs. As the number of patients on transplant waiting lists continues to rise, the number of transplants performed in the US and most of Europe in recent years has levelled off [figure 1]. It is now imperative to organize the procurement of organs so that waste is minimized and the supply of organs is increased.

Many countries have developed national systems for organ procurement and allocation that comprise various combinations of legislation, organ exchange organizations (OEOs), the appointment of transplant coordinators, publicity campaigns, donor cards, and training programs. Although these measures have minimized organ waste, none has so far proved sufficient to solve the problem of donor organ shortage. OEOs play an important role in initiating donation programs and, we describe their role in the organ procurement process that precedes allocation and transplants and some of the methods used to increase organ supply.

\section{Development of OEOs}

The efficient use of donated organs depends on the pool of patients awaiting transplants; the larger and more diverse the waiting list, the higher the chance of using the available organs. However, most early transplant programs operated locally and maintained only short waiting lists, which often meant that suitable recipients could not be found for the available organs. As the number and type of transplant procedures increased, the problem grew, and the need for a centralized organization to coordinate organ procurement and allocation became evident. The OEOs were created in response to this need and now ensure that as many available organs as possible are transplanted. In addition, OEOs also oversee fair, transparent, and objective organ allocation policies that ensure the best possible match between donor and recipient and that patients in the most urgent need are given priority.

Initially, most OEOs were private initiatives based on the recognition of the special benefits widespread professional collaboration could achieve in transplantation. OEOs were voluntary associations between co-operating transplant programs. Each transplant program is comparable to a member of a club who agrees to abide by the club's rules, and the OEO, as the club secretary, is the custodian and implementor of the rules. As such, the OEO must strike a delicate balance between satisfying the demands of the individual transplant programs and maintaining the integrity of an organization that represents all its members [1]. 


\section{The Widening Gap 1993-1998 \\ USA}

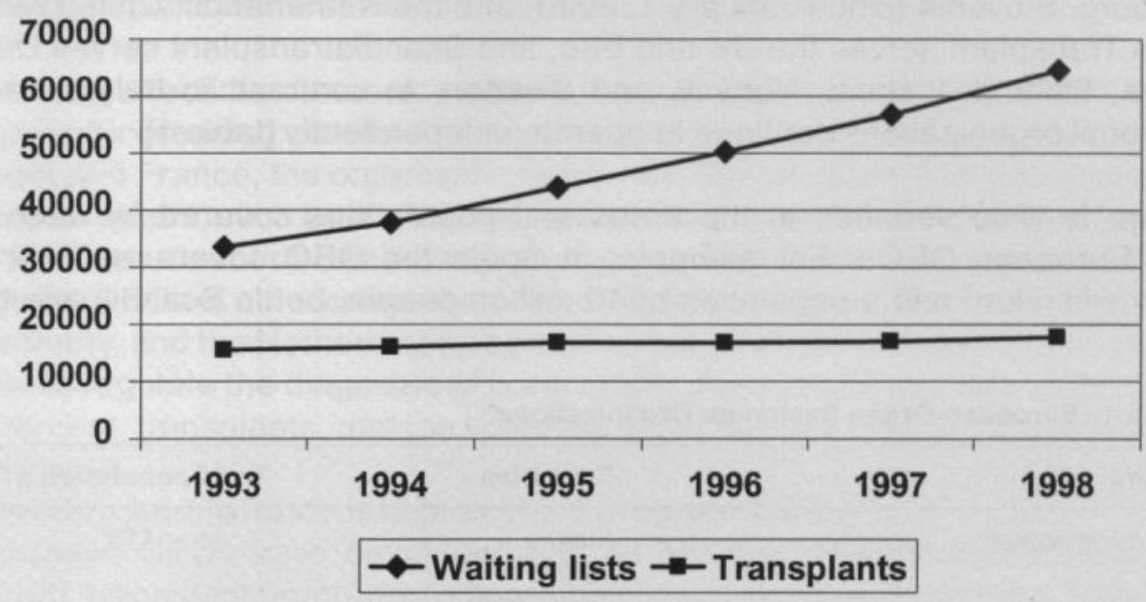

Source: UNOS

\section{Eurotransplant}

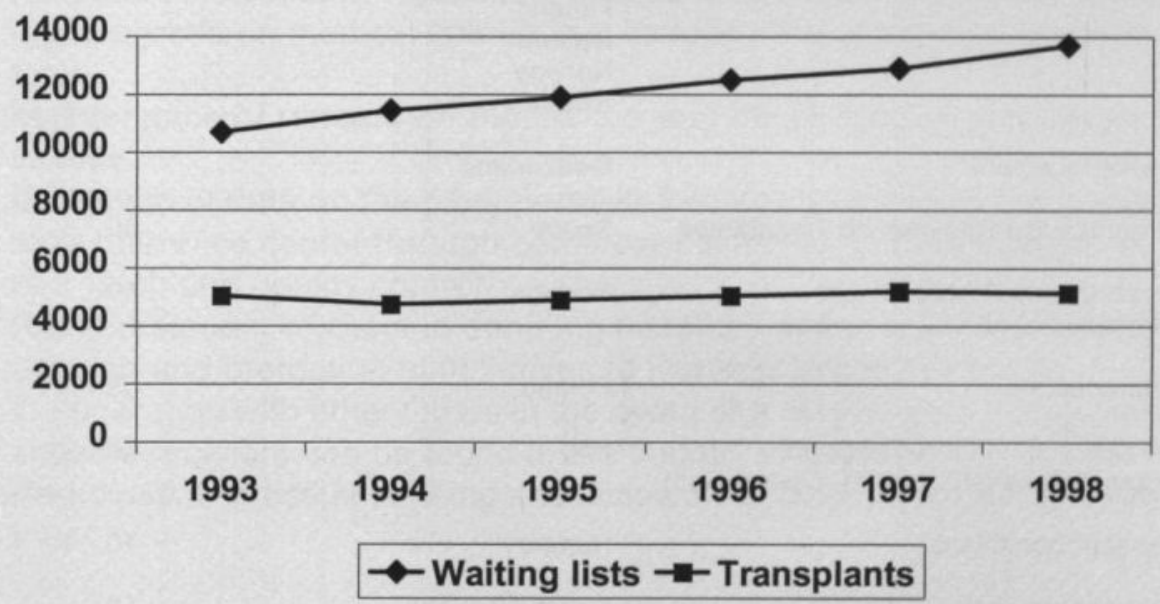

Source: Eurotransplant

Figure 1. Difference between organ supply and demand in the USA and Eurotransplant (Austria, Belgium, Luxemburg, Germany, the Netherlands) 1993 - 1998. 
Most OEOs operate on a national basis. In some countries, such as the US, the national organization is the result of an alliance between regional agencies. In Europe, for some organizations, cooperation has always been international, thus the Eurotransplant Foundation serves Austria, Belgium, Germany, Luxemburg, Slovenia (since January 1, 2000) and the Netherlands; United Kingdom Transplant serves the UK and Eire; and Skandiatransplant serves Denmark, Finland, Iceland, Norway, and Sweden. In contrast, in Italy several regional organizations continue to operate independently [table 1].

There is wide variation in the areas and populations covered by each of the European OEOs. For example, in Spain the OEO covers an area of 0.5 million $\mathrm{km}^{2}$ and a population of 40 million people, but in Scandinavia the

Table 1. European Organ Exchange Organizations*

\begin{tabular}{|c|c|c|}
\hline Name & Countries & Total population $\times 10^{6}$ \\
\hline Eurotransplant & $\begin{array}{l}\text { Austria } \\
\text { Belgium } \\
\text { Luxemburg } \\
\text { Germany } \\
\text { The Netherlands } \\
\text { Slovenia (since January } 1 \text {, } \\
2000 \text { ) }\end{array}$ & 118 \\
\hline Etablissement Français des Greffes & France & 60 \\
\hline United Kingdom Transplant & UK + Ireland & 62 \\
\hline Scandiatransplant & $\begin{array}{l}\text { Denmark } \\
\text { Finland } \\
\text { Iceland } \\
\text { Norway } \\
\text { Sweden }\end{array}$ & 24 \\
\hline Swisstransplant & Switzerland & 7 \\
\hline Organización Nacional de Trasplantes & Spain & 40 \\
\hline $\begin{array}{l}\text { Organizaçao Portuguesa de } \\
\text { Transplantaçao }\end{array}$ & Portugal & 10 \\
\hline Poltransplant & Poland & 39 \\
\hline $\begin{array}{l}\text { No national, but three regional } \\
\text { organizations (NITp, AIRT, Centro-Sud) }\end{array}$ & Italy & 58 \\
\hline Hungarotransplant & Hungary & 10 \\
\hline Czechtransplant & Czech Republic & 10 \\
\hline Hellastransplant & Greece & 10 \\
\hline Total population & & 448 \\
\hline
\end{tabular}

"No data available from the Republics that formed the former Yugoslavian Federation 
OEO is responsible for an area of 1.1 million $\mathrm{km}^{2}$ and a population of 24 million people. Eurotransplant is the largest OEO in Europe and serves an area of 0.5 million $\mathrm{km}^{2}$ and a population of 116 million people. This includes 64 renal transplant centers, 44 heart transplant centers, 15 lung transplant centers, 36 liver transplant centers, and 21 pancreas transplant centers.

In the last decade, donation systems, transplant programs, and OEOs have received increasing attention from government and, in some countries, such as Spain and France, the organizations are now formal, governmental organizations. In others, such as the UK, the OEO is a non-governmental body attached to the Department of Health. Although governments are not closely involved with the OEOs of other countries, such as Austria, Belgium, Denmark, Sweden, Germany, and the Netherlands, legislation has been introduced in these countries to regulate the diagnosis of brain death, the consent process, organ procurement, transplants, and the licensing of centers to perform transplants.

\section{Function and infrastructure of the European OEOs}

European OEOs have developed into an alliance between donor hospitals (input), transplant programs (output), and tissue-typing laboratories. They are non-profit bodies that act as service agencies to both donating hospitals and transplant units, and they all follow the same set of general policies, operating procedures, and organ allocation rules.

The main functions of the OEOs are diverse and vary from country to country. They include the following:

- Maintenance of patient waiting lists for all varieties of organ and tissue transplants

- Allocation of available organs and tissues to appropriate patients, according to agreed on medical criteria that include clinical urgency and waiting time

- Maintenance of records on the source and destination of all organs and tissues

- Collection of data on the postoperative transplant course and acting as a data reference center through continuous analysis of the database

- Research and quality control

- Reimbursement of costs to donating hospitals and procurement teams

- Support and promotion of initiatives to increase organ donation

- Co-operation with other OEOs in the event of a clinical emergency or if no suitable recipient can be found in the country of donation

- Participation in tissue banking and inclusion on bone-marrow donor registries

In general, OEOs have developed a hierarchical decision-making process that guarantees equal representation of all the geographical regions and transplant programs covered by the organization. Policy is overseen by medical advisory committees specializing in each type of organ or tissue transplant, tissue-typing, organ procurement, and ethics. Changes in policy initiated by 
the committees must be approved by the board of the OEO and government, if involved.

\section{Transplant coordinators}

An acknowledgment of the need for local as well as national and international organization of organ transplants led to the introduction of transplant co ordinators (TCs). Transplant coordinators first appeared in the US in the 1970s and were typically renal technicians and nurses who were already working in transplant units. As the demand for transplants grew, the responsibilities of TCs expanded and they were appointed in a full-time capacity to concentrate on the elaborate donation and procurement process, as well as community and professional education [2]. This initiative was quickly adopted in Europe, where the first TCs were appointed in the late 1970s. All European countries with transplant programs now employ TCs, and they have become the linchpin between transplant centers and intensive care units (ICUs).

The role of the TC involves the following:

- Developing professional links between transplant units and nearby ICUs

- Establishing hospital protocols and procedures for organ donation

- Helping hospital staff with the tasks involved in the process of organ donation, including approaching bereaved relatives to ask for permission to remove organs for transplants

- Providing professional and, to a lesser extent, public information on organ donation and transplants.

In most European countries, TCs are based in transplant units. In contrast, in the US, many procurement coordinators have removed themselves altogether from transplant centers and provide a service to donating hospitals and transplant units through independent organ procurement organizations [3].

\section{The organ procurement process}

Most countries recognize brain death, and it is usually defined as the total and irreversible loss of brain function. If organ donation is a possibility, brain death must be established by physicians not involved with the organ procurement team. Once the diagnosis of brain death is confirmed and consent to remove the organs and/or tissues has been obtained, the TC arranges a suitable time for this to occur. At this point 'patient care' becomes 'donor maintenance', and the aim is to maintain optimal organ function for the benefit of recipient patients. Donor management can be difficult, costly, and time-consuming, and organs may be 'lost' at this stage. A high standard of medical and nursing care, is therefore, essential. It is important to remember that this change in emphasis may be distressing for the ICU staff, and, as a result, the responsibility for donor management is frequently undertaken by procurement TCs.

TCs are responsible for the local organization of organ donation and communicate closely with the OEO throughout the process. When a potential donor becomes available, the TC, who may travel to the donating hospital, must 
determine whether the organ(s) and/or tissues are suitable for transplant. The donor's medical history is carefully examined and his or her current medical status is evaluated. This process frequently necessitates further investigations. Once collected, all relevant information is relayed to the OEO that will eventually allocate the available organs.

\section{Ethical and legal issues}

The ethical issues surrounding transplantation have come under close scrutiny in most countries, and legislation has gradually been introduced to regulate the transplant process and to protect donors. However, few countries have introduced legislation that comprehensively deals with organ or tissue donation by living or deceased donors. Most countries have introduced legislation to clarify the diagnosis of brain death and to control the consent process and the methods used to monitor the source and destination of donor organs and tissues [4]. In general, legislation also aims to ensure that living donors are not coerced to donate, especially if they are minors or if they are mentally ill, and that neither donors nor physicians gain financially from donation. In addition, measures to prevent 'transplant tourism' - the movement of prospective donors and recipients to other countries - are gradually being instituted.

Improvements in legislation on driving and health and safety at work has led to a reduction in accidental deaths [5]. This welcome change coupled with the steadily increasing number of patients requiring transplants has contributed to the worldwide shortage of donor organs that now exists. Furthermore, despite strong public support for organ donation, rates of refusal to donate remain relatively high. For example, in 1994, data from UK and Spain revealed national refusal rates of $26 \%$ and $24 \%$, respectively $[6,7]$.

A recent study in the Netherlands revealed refusal rates as high as even $73 \%$ $[8] !$

Families give many reasons for refusing organ donation, such as worries about the meaning of brain death and the integrity of the corpse, and religious and social objections. Differences need to be taken into account. In addition, wide differences in refusal rates between countries suggest that the method and timing of the request for donation probably also influences the outcome.

Efforts to reduce the barriers to organ donation include schemes in which individuals may register their objections to organ donation ('opt-out' or 'presumed consent' schemes) or schemes that require potential donors to carry donor cards indicating their wish to be an organ donor or register with a central computerized system ('opt-in' schemes). In general, despite such schemes, the families of potential donors who carry donor cards or have registered their desire to be an organ donor are still consulted before organs or tissues are removed. The system, therefore, relies heavily on good communication within families. In countries that operate opt-in schemes, the families of potential 
donors who do not carry donor cards are also approached and given the opportunity to donate.

Opt-out or presumed consent schemes enable either verbal or computer registration of an individual's objection to organ donation and, in some countries, the register is available to transplant units. Opt-out schemes do not usually require the relatives of the donor to be informed before the organs or tissues are removed from the body. Although opt-out schemes do seem to provide impressive donation rates in most, but not all, countries, it is difficult to compare donation rates between countries because individual hospitals and doctors often interpret the prevailing regulations differently [table 2] [9]. For example, Belgium operates a 'presumed consent' legislation and it consistently has one of the highest numbers of donated organs per million of the population [10]. Other countries, such as France, that have similar legislation have not achieved comparable donation rates [11].

In the US, refusal rates are reported as high as $38 \%$. Consent rates went up to $74 \%$ when the following three elements were present in the donation

Table 2. The number of cadaveric donors in Europe and the USA in 1997 and the prevailing donor legislation

\begin{tabular}{|l|c|l|l|}
\hline & $\begin{array}{l}\text { Cadaveric kidney } \\
\text { donors per million } \\
\text { population }\end{array}$ & $\begin{array}{l}\text { Donor's legal } \\
\text { situation }\end{array}$ & $\begin{array}{l}\text { Donor's situation } \\
\text { in practice }\end{array}$ \\
\hline Spain & 29.0 & presumed consent & informed consent \\
\hline Czech Republic & 23.2 & presumed consent & presumed consent \\
\hline Belgium & 22.5 & presumed consent & presumed consent \\
\hline USA & 21.3 & required request & informed consent \\
\hline Portugal & 20.5 & presumed consent & presumed consent \\
\hline Austria & 19.5 & presumed consent & presumed consent \\
\hline Finland & 16.3 & presumed consent & presumed consent \\
\hline Hungary & 15.4 & presumed consent & presumed consent \\
\hline Norway & 15.1 & presumed consent & informed consent \\
\hline France & 15.0 & presumed consent & informed consent \\
\hline UK + Ireland & 14.5 & informed consent & informed consent \\
\hline The Netherlands & 14.4 & informed consent & informed consent \\
\hline Switzerland & 14.3 & $\begin{array}{l}\text { presumed consent, } \\
\text { informed consent, or } \\
\text { no law }\end{array}$ & $\begin{array}{l}\text { practice varies per } \\
\text { canton }\end{array}$ \\
\hline Germany & 13.2 & informed consent & informed consent \\
\hline Sweden & 12.6 & presumed consent & practice varies \\
\hline Italy & 11.6 & presumed consent & informed consent \\
\hline Denmark & 11.4 & informed consent & informed consent \\
\hline Poland & 6.9 & presumed consent & informed consent \\
\hline Greece & 3.7 & presumed consent & informed consent \\
\hline
\end{tabular}


process: the family understood the concept of brain death before the request for organ donation was made, the request took place in a quiet place, and the TC participated in the request for donation [12].

In addition, in the US, in case of brain death in which the patient may be a potential donor, physicians are required to ensure that families are approached and given the opportunity to consider organ donation, a process known as 'required consent'. However, even in the presence of this mandatory process, not all families are approached and a high proportion of potential donors are missed.

Whichever system is used to increase organ availability, all relatives of donors must be reassured of the effectiveness and usefulness of organ donation. A special understanding of the religious and social beliefs of ethnic minorities is also needed to optimize donation rates among all people within a country. In addition, donation rates might increase if organ donation was focused on the ICU and regarded as a specialty in its own right. As such, it would attract increased funding for improved training and research.

\section{Improved training}

Training seems to play an important role in achieving high donation rates. With a renal transplant rate of 46.9 per million of the population (live and cadaveric), Spain had the highest rate in 1997 . This was achieved despite a continuing fall in deaths from road traffic accidents and was attributed to a combination of an effective procurement and allocation system and well-trained and supported TCs $[7,11]$. In contrast, lack of training in the US often leads to requests for donation not being made and high refusal rates because of poor support for donors' families [13].

To improve training and, therefore, reduce refusal rates, Eurotransplant created the European Donor Hospital Education Programme (EDHEP) in 1991. The aim of EDHEP is to help health professionals be more effective when dealing with bereaved relatives. Interactive workshops, moderated by qualified trainers, are available to all critical-care staff who wish to sharpen their communication skills, heighten their sensitivity to the needs of the bereaved, and learn ways of requesting consent for organ donation.

Since its inception EDHEP has been translated into 17 languages and is in use in over 30 countries and several countries have incorporated the program into national physician and nurse training. When questioned about the usefulness of EDHEP, both doctors and nurses who took part reported that they felt more confident in dealing with donors' families, were more willing to request donation, and were better informed about brain-death criteria and the legal and religious objections to organ donation in their countries [14]. When participants' knowledge was tested before and two weeks and 6 months after taking part in EDHEP, they showed improved knowledge, improved confi- 
dence in dealing with the bereaved and, most important, were more likely to make donation requests than professionals who had not taken part in the program. In addition, the program has also been shown to increase donor referral through increased national and international collaboration between professionals [14].

\section{The Donor Action Programme}

An example of effective international co-operation is the Donor Action Programme - a collaboration between the Eurotransplant Foundation (the Netherlands), Organización Nacional de Trasplantes (Spain), and The Partnership for Organ Donation (US). In 1993, these organizations agreed to pool their different areas of expertise in donation to alleviate the worldwide shortage of donor organs.

The Donor Action Programme provides tools, resources, and guidelines for hospitals to define their potential for donation and to develop an effective protocol to improve their donation practices. In the first phase, a hospitalbased committee performs a diagnostic review to collect information on its current donation situation. Diagnostic tools are a retrospective medical records review (MRR), a hospital attitude survey (HAS) of critical care staff, and a software package to analyze the data. In the second phase, the committee uses the database analysis to identify specific areas for improvement and education for key staff in the donation process. In the third phase, the Donor Action Programme modules are used to effect changes in one or more of the following specific stages in the donation process: donor detection, donor referral, family care and communication, donor maintenance, and organ retrieval. Data are then collected on an on-going basis to monitor progress.

Between 1994 and 1996, the Donor Action Programme pilot evaluations were undertaken in 11 hospitals in the Netherlands, Spain, the UK, and Canada. Data from the pilot diagnostic reviews showed significant potential for improvement in donation rates. Aggregated MRR results on the basis of 579 medical records of patients who died in ICUs showed no obvious contraindication to donation in $398(68 \%)$ patients. However, only $124(31 \%)$ of these individuals became donors. In all pilots, most problems occurred in donor identification and/or management (166 cases: $42 \%)$ and family or coroner refusals (104 cases: $26 \%$ ) [15].

Aggregated HAS data from 2129 critical-care medical and nursing staff reveal consistently strong support for organ donation. However, the surveys also reveal that many staff do not feel comfortable performing key tasks close to donation. Belief that organ donation saves lives (97\%), support for donation $(94 \%)$, and willingness to donate organs $(79 \%)$ were high in all country samples. However, significant differences exist between countries, hospitals, and individual ICUs in self-reported skills in donation-related tasks. For 
example, $77 \%$ of UK respondents reported themselves skilled or comfortable explaining brain death, compared with only $57 \%$ of Dutch respondents, $50 \%$ of Canadian respondents, and $12 \%$ of Spanish respondents. Similar variations were seen when staff were asked how they felt about requesting organ donation: in the UK $52 \%$ of staff felt comfortable requesting donation compared with $40 \%$ of Dutch respondents, $33 \%$ of Canadian respondents, and $13 \%$ of Spanish respondents [15]. It is interesting that fewer staff in Spain feel prepared to request donation than in the other countries, yet Spain has the highest donation rates. This may reflect the degree to which staff with a specialized role in donation have been successfully integrated into hospital practice.

Data from the Donor Action Programme pilot hospitals have identified a significant number of unused donors and also suggest that there may be important differences in attitudes and perceived skills and comfort between countries. The diagnostic review has proved useful in identifying problem areas in the hospital donation process and providing a baseline against which to monitor progress. In addition, the MRR can effectively identify untapped donation potential and, when matched with the HAS, can be used to customize the Donor Action Programme to individual hospital requirements. To date, there has been a lack of information on the attitudes of hospital staff to organ donation to enable comparisons between countries to be made and to support targeting of strategies to the specific needs of different countries. The Donor Action Programme pilot results demonstrate the feasibility of collecting and comparing data across national systems. The pilot data and medium-term results from Spain and the UK also suggest that the program will offer longterm benefits.

\section{Other factors}

Other factors that influence organ availability include media reports and costs. The media play an important role in influencing attitudes towards organ donation, in both negative and positive ways and may also influence legislation. Dramatic newspaper stories revealing, for example, the sale of organs or the removal of organs without permission, inevitably adversely affect donation rates. However, stories on, for example, the plight of children requiring liver transplants boost transplant programs and donation rates and the need to cooperate with the media is now well understood.

A greater awareness among physicians of the costs and quality of life benefits of transplants may help improve the likelihood of families being offered the opportunity to donate after the death of a relative and increase donor organ availability. Transplants are costly procedures, but increasingly, they compare favorably with the cost of other forms of treatment, such as dialysis, nursing seriously ill patients, and patients not being able to work. One study in the US found that a 20 -year savings of $\$ 11,000$ per patient could result from renal transplants [16]. 


\section{Conclusion}

Transplants are now an accepted form of medical treatment and, since the first transplants were performed, many thousands of lives have been saved or improved. However, the process leading from donation to transplant is complex and influenced by many factors, such as legislation, training, public attitudes, and costs. Such factors also influence organ donation, and the worldwide shortage of donated organs is the major challenge currently facing transplant programs around the world.

Several attempts have been made to improve donation rates, such as presumed consent legislation and more effective training programs to improve the way bereaved families are approached and, therefore, increase the likelihood of obtaining permission to remove organs or tissues from the deceased relative. In addition, the transplant community itself has taken steps to ensure that procurement and allocation criteria are efficient, fair, objective, and transparent. However, organ donation rates remain too low, and difficult questions such as the following need to be answered if the supply and demand for transplantable organs are to be better matched:

- Should transplants be limited by age or disease?

- Should re-transplantation be an option for patients whose first graft fails?

- Should the lives of living donors be endangered in the quest for organs?

- Should we encourage donation from living relatives and friends of the potential recipient?

- Should organ donation be rewarded in some way?

- Should organs or tissues from other species be transplanted into patients?

The problems associated with transplants are international and, until alternative forms of treatment become available, the aim of health professionals must be to join forces in an international effort to share initiatives aimed at optimizing the donation process. An example of effective international cooperation is the Donor Action Programme. The program provides an opportunity to change donation practices and create appropriate education strategies in hospitals. Such a co-operative effort will help alleviate the organ shortage and help provide the best possible chance of treatment for patients requiring transplants. 


\section{References}

1. Meester De J. Organization of donation and allocation. In: Chapman JR, Deierhoi $\mathrm{MH}$, Wight C, eds. Organ and Tissue Donation for Transplantation. London: Edward Arnold, 1997; 226-338.

2. Elick BA. Transplant coordinators. In: Chapman JR, Deierhoi MH, Wight C, eds. Organ and Tissue Donation for Transplantation. London: Edward Arnold, 1997; 325-343.

3. Wight C, Cohen B. Legal and Organisational Issues in Organ Transplantation. In: Klink J, Lindop M. eds. Anaesthesia and Intensive Care for Organ Transplantation. London: Chapman Hall; 1998: 57-68.

4. Fluss SS, Dickens BM, King AR. Legislation on organ and tissue donation. In: Chapman JR, Deierhoi MH, Wight C, eds. Organ and Tissue Donation for Transplantation. London: Edward Arnold; 1997: 95-119.

5. Land W, Cohen B. Post mortem and living organ donation in Europe-transplant laws and activities. Transpl Proc 1992; 24: 2165-2166.

6. Stewart R, Buckley P, Mattewmane E, Pearce J, Corrado H. UKTCA, BACCN, MORI relative's refusal survey. UKTSSA User's Bulletin Winter 1994/5; 14:11.

7. Matesanz R, Miranda B. The Spanish experience in organ donation. In: Chapman JR, Deierhoi MH, Wight C, eds. Organ and Tissue Donation for Transplantation. London: Edward Arnold; 1997: 361-372.

8. Kranenburg J, Willems L, Sieber-Rasch MH, Geertsma A, Ploeg RJ. The Don Quichot investigation, Spring Communications Amsterdam, ISBN 90-5252-010-0.

9. Cohen B. Finding a cure to dramatic fall in organ procurement rates. Nephrology News and Issues (Europe) 1994; July/August: 21-22.

10. Roels L. Legislative aspects of organ and tissue donation in Belgium. Ann. Transplant 1996, 1 (4): 39-43.

11. Council of Europe. International figures on organ donation and transplantation 1997. Transplant Newsletter 1998; 3 (1):5-11

12. Gortmaker SL. Improving the request process to increase family consent for organ donation. Journal of Transplant Coordination 1998; 8.

13. Beasley CL, Blaustein JD. The Partnership for Organ Donation: a strategic approach to solving the organ donor shortage. In: Chapman JR, Deierhoi MH, Wight C, eds. Organ and Tissue Donation for Transplantation. London: Edward Arnold; 1997: 389-399.

14. Wight C, Cohen B. The European Donor Hospital Education Programme (EDHEP). In: Chapman JR, Deierhoi MH, Wight C, eds. Organ and Tissue Donation for Transplantation. London: Edward Arnold; 1997: 373-381.

15. Wight C, Cohen B, Beasley C, Miranda B, Deblander G. Donor Action: A Systematic Approach to Organ Donation. Transpl Proc 1998; 30: 2253-2254.

16. Washington DC: Health Resources and Services Administration US Department of Health, 1988. 



\section{Chapter 7}

\section{The European Donor Hospital Education Programme (EDHEP)}

Celia Wight and Bernard Cohen 


\section{The origins of EDHEP}

The Eurotransplant Foundation (ET) is an Organ Exchange Organization (OEO) based in Leiden, the Netherlands. ET provides a service for the Netherlands, Germany, Austria, Belgium and Luxemburg, which covers a population of over 116 million people. In 1990, the ET region experienced a fall in organ donation that resulted in a further increase in the gap between the supply and demand for donor organs.

Seeking a reason for these trends, researchers in ET discovered that many medical professionals within the five countries were still unaware of the needs of transplantation and in many hospitals protocols and procedures for organ donation were not available. Additional data show that as many as $30 \%$ of potential donors were lost because of a refusal by the family [1]. This was often the result of difficulties in understanding the concept of brain death and misconceptions about the procedures of organ donation. The researchers felt that part of these misconceptions may have been the result of inadequate communication between the doctor and nurse and the relatives.

Following this train of thought a literature search was undertaken on the attitudes of doctors and nurses towards this subject. This review revealed that the difficulties staff say they have can be grouped under three headings:

1. The important role that the professional's own feelings towards death and organ donation can have in inhibiting the donation request.

2. Worries about intruding on a family's grief.

3. Lack of experience and training in approaching bereaved relatives.

These findings are supported by research from the United States [2].

\section{The development of EDHEP}

Eurotransplant wanted to tackle the problem of the growing donor shortage and is the driving force behind the development of EDHEP. In 1991, with the generous support of the Dutch Kidney and Heart Foundations, ET developed a professional education program for the Netherlands. Later, appreciating the value of a prototype that could eventually be adapted for use throughout Europe, Sandoz Pharma in Basel, Switzerland also agreed to support the development of what became EDHEP. The program is part of a multifaceted process aimed at closing the gap between the supply and demand for organs and tissue for transplantation. It was created to meet the widely perceived need to help doctors and nurses feel effective in dealing with the bereaved and in requesting organ donation. EDHEP was produced by professionals from different specialties including medical doctors and clinical psychologists from the University of Maastricht, transplant coordinators (TCs) and communications specialists in close collaboration with The Rowland Company [figure 1]. The prototype was designed to be easily translated into different languages, adjusted to meet national circumstances and cultures and to complement other existing educational programs. With the help of the regional TCs a Dutch 


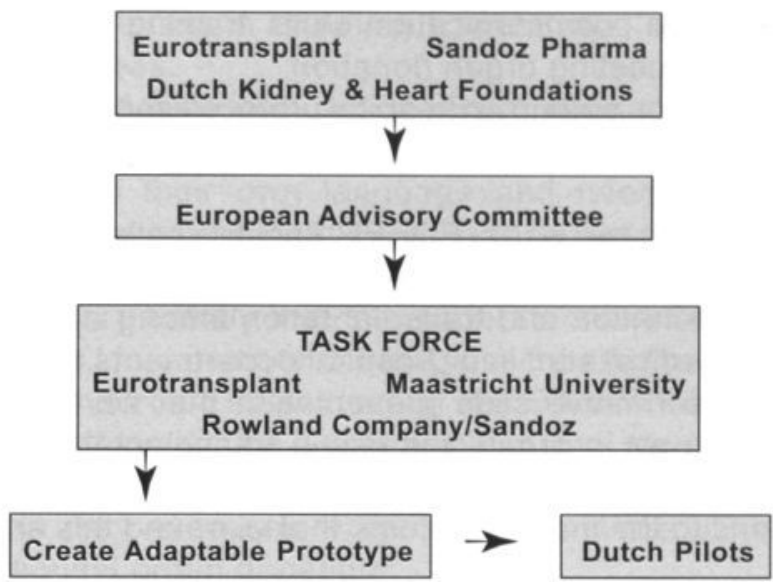

Figure 1 EDHEP-development

version of the program was piloted in three regions in the Netherlands in 1991. The participants were relatively experienced doctors and nurses, although some had never been involved in requesting organ donation. Following minor adjustments EDHEP was introduced as a professional educational tool in the Netherlands and in 1992 was made available to other interested countries [figure 2].

\section{Program objectives and content}

The objectives of EDHEP are to:

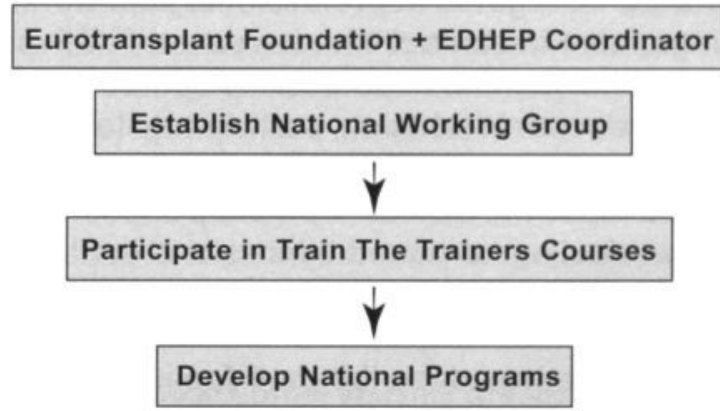

Figure 2 EDHEP-national implementation

1. Raise professional awareness of the problem of the donor shortage and to provide some possible solutions.

2. Develop an awareness of the needs of the bereaved between medical professionals and the needs of the professional in dealing with the bereaved. 
3. Provide "hands-on" communication skills training in dealing with grief reactions and requesting organ donation.

4. Provide guidance on setting up hospital protocols for dealing with bereaved relatives.

EDHEP is produced in two parts. EDHEP Part 1 is called "Meeting the Donor Shortage". The aim of Part 1 is to raise the awareness and understanding of organ and tissue donation and transplantation among all levels of medical, nursing and paramedical staff in all hospital departments. "Meeting the Donor Shortage" is an informative slide presentation that covers the history and current state of the art in organ and tissue transplantation. It also outlines some reasons behind the growing donor shortage and puts forward some possible solutions to the many problems that surround this area of medicine.

Many countries already have TCs who regularly provide this type of information to hospital staff. The material is available both to those countries who wish to supplement their existing educational programs and countries who are not yet providing this type of educational service. Slides and suggestions for overhead transparencies, which can also include statistics and information of local interest, are provided. The presentation takes about one hour and is intended to be given in hospitals, at an appropriate time, by TCs or other transplant personnel.

EDHEP Part 2, is named "The Grief Response and Donation Request". Part 2 takes the form of a highly interactive one-day skills awareness workshop, conducted outside the hospital setting, well away from bleeps and telephones. "The Grief Response and Donation Request" workshop is organized and introduced by the local TCs but is moderated by communications skills experts. The workshop is targeted at professional staff working in any area of medicine that brings them in contact with bereaved relatives. It aims to help participants improve their communication skills and heighten their sensitivity to the needs of the bereaved. In addition, participants learn ways to break bad news and discuss organ donation with the bereaved. With the help of exercises and teaching video tapes the EDHEP workshop encourages participants to:

1. Examine their own feelings aroused by loss and separation.

2. React to different grief reactions with an appropriate professional response.

3. Listen to bereaved relatives describe their feelings of loss and donation.

4. Analyze problems of miscommunication.

5. Participate in skills training with simulated bereaved relatives.

6. Discuss ways of establishing hospital protocols for dealing with the bereaved.

\section{Adaptation and implementation of EDHEP}

To ease the national adaptation and implementation of EDHEP a coordinator was appointed in 1992, based at ET. The role of the coordinator is to identify 
countries with an interest in adopting EDHEP and to provide advice and assistance in five areas:

1. The formation and composition of national working groups. The national working groups [table 1] are responsible for adapting the EDHEP educational material to their own language and needs. The group is also responsible for the national setting up and evaluation of the program.

2. The acquisition of workshop moderators and simulated bereaved relatives. It is not necessary initially that the moderators are familiar with donation procedures, the ideal moderator being described in table 2. However, this knowledge is important when running the EDHEP Part 2 workshops and can be provided under the supervision of the national working group. Simulated bereaved relatives are used to enhance the authenticity of the separate role play exercises when participants are asked to break bad news and request organ donation.

3. Organize "Train The Trainers" (TTT) courses. The TTT courses are international training courses for national working group members and potential EDHEP workshop moderators. The courses are run, in English, by the EDHEP international coordinator and clinical psychologists from the University of Maastricht, the Netherlands. The main purpose of these courses is for participants to gain familiarity with the content and format of the program. Training in moderating the different modules is provided for potential EDHEP Workshop moderators. National working group members are made aware of the variety of activities needed to adapt and set up the program in their national environment. Finally, the TTT course aims to establish a close dialogue between EDHEP national working groups and the EDHEP international working group.

4. Guidance and assistance with the national adaptation of the EDHEP educational material.

5. Ensure a degree of program quality assurance. Countries are asked to sign a contract with ET. The purpose of the contract is to preserve the spirit and quality of EDHEP during its adaptation and implementation and to ensure that adequate training, help and guidance is provided by the international EDHEP coordinator.

The costs involved in the translation, adaptation and application of EDHEP have, for the main part, been borne by the national Sandoz affiliates. Additio-

\section{Table 1. Composition of National EDHEP Working Groups}

The ideal working group could comprise members of the following organizations:

- National Transplant Societies

- Intensive care/neurosurgical societies

- National medical/nursing associations

- Transplant coordinators' organizations

- Communications skills trainers

- Public Relations specialists

- Religious advisors/community leaders 


\section{Table 2. Workshop moderators and simulated bereaved relations}

The ideal EDHEP Workshop Moderator should have the following background experience:

- Knowledge of behavioral skills

- Experience in communication skills training

- Familiarity with the psychological aspects of bereavement

- Familiarity with the nature of the medical professional's work in a hospital environment

- Familiarity with donor procedures

- Experience with using a variety of educational material

Suitable EDHEP Moderators can be found among:

- Bereavement counselors

- Clinical psychologists

- Crisis Care counselors

- Educational psychologists

- Communication skills training experts

Simulated Bereaved Relatives:

The University of Maastricht has a tradition of using local volunteers as simulated patients during the training of medical students. A simulated bereaved relative is a non-professional actor, trained in playing a prescribed role and giving feedback. Countries who do not have such a pool of volunteers available to them have chosen to use amateur actors as simulated bereaved relatives.

nally, some countries have from the beginning sought financial support from other sources. All countries hope that once EDHEP has become a regular part of professional education programs the running costs of the EDHEP workshops will be funded from local budgets.

\section{Evaluation of EDHEP}

Since 1992, over 330 participants have attended sixteen international EDHEP TTT courses held, either at Eurotransplant's home base in Leiden, or another host country. By the end of 1995 EDHEP was running in over 33 countries in Western Europe [figure 3], the Middle and Far East and Latin and South America. National Working Groups from these countries confirm that EDHEP adapts easily to all national legal, religious, cultural and educational needs. The program generates a more favorable attitude among critical staff to organ donation, teaches more confident communication, stimulates national and international professional collaboration and increases donor referral. Participants in the EDHEP workshops report that as a result they feel more confident in their ability to talk with the bereaved and are more willing to do so.

Countries operating in a "presumed consent" system have also found the major elements of the EDHEP workshop very relevant. Communication skills are always needed when informing a bereaved family of the intention to remove organs from a deceased loved one. Specific evaluations of 163 participants in pilot programs in Israel show an increase in knowledge on brain death criteria, the law, the supposed negative position of the Jewish religion in organ donation and the criteria for donation. These data also showed a 


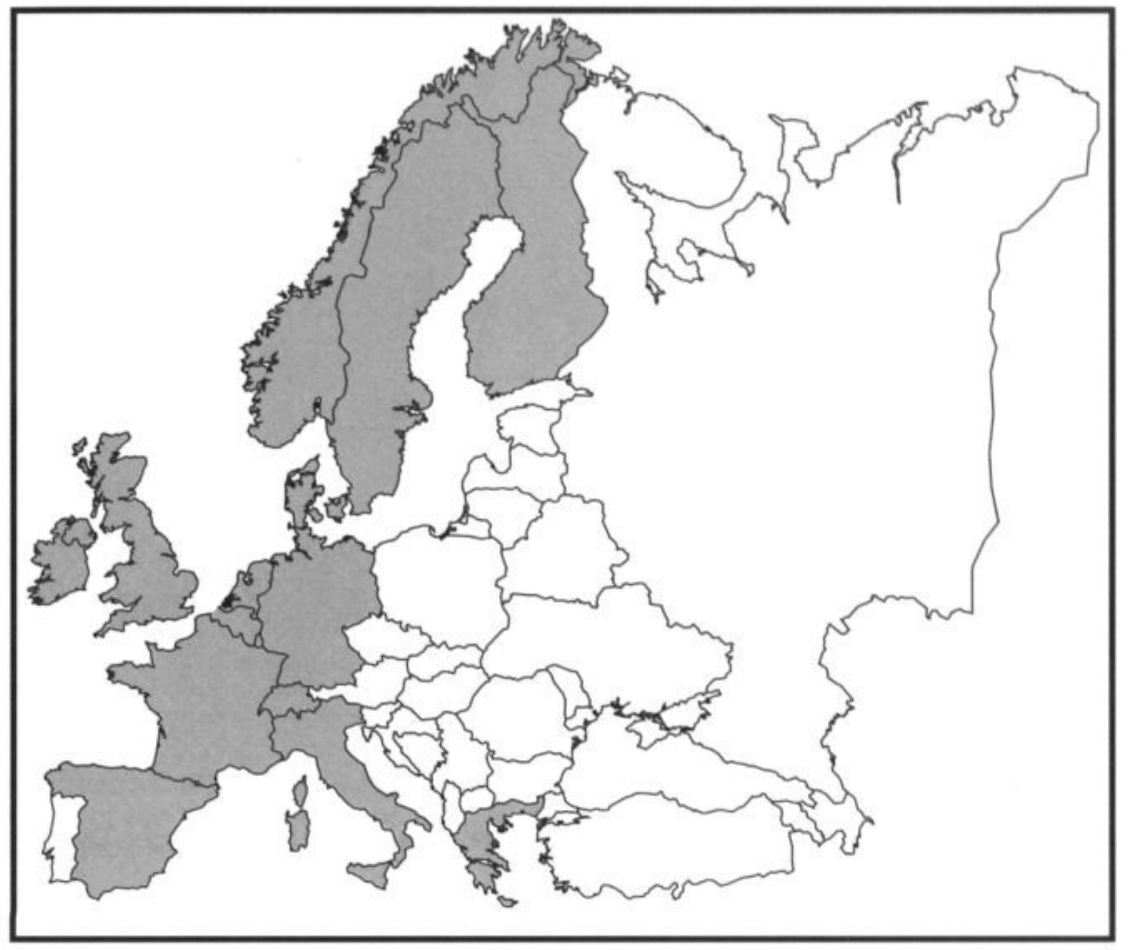

Figure 3. European Donor Hospital Education Programme 1995.

significant improvement in participants' ability and willingness to approach bereaved relatives for organ donation [figure 4]. Results from Japan show that $95 \%$ of doctors and $92 \%$ of nurses felt they had learned how to better communicate with the bereaved and $90 \%$ and $88 \%$ respectively felt that EDHEP was a useful educational tool [figure 5]. A one year controlled research project of matched professionals has been carried out in the Netherlands. Both groups were tested two weeks before the experimental group participated in an EDHEP workshop. Both groups were retested at two weeks and six months following the experimental group's participation in the workshop. The results show an increase in knowledge of the experimental group on grief reactions, communication skills and donation procedures. In addition, participants show an increase in self-confidence in dealing with the bereaved. The experimental group demonstrated a reduction in the perceived difficulty in requesting donation and at six months follow up had made more donation requests that the control group [figure 6]. All EDHEP participants rated the contribution of EDHEP to their current practice positively. EDHEP seems to have a positive effect on current practice in general not only relating to the care of the bereaved and donation procedures, but also to working together as a team [figure 7]. A controlled evaluation by the Universities of Liverpool and Maastricht is underway that will, in addition to the above, analyze relatives' satisfaction in the professional care they receive. 


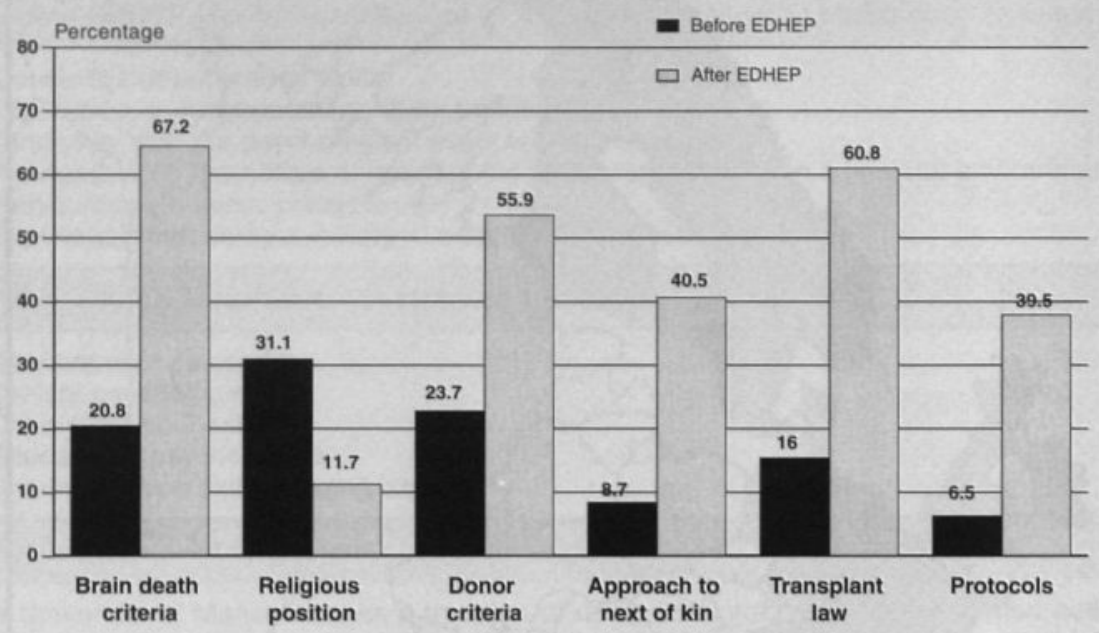

Figure 4. EDHEP-evaluation of participants knowledge: (Source: Dr Pierre Singer, Director ICU, Beilinson Medical Centre. Peta-Tikva, Israel.)

\section{Do you think you learned how to communicate with grieving families?}

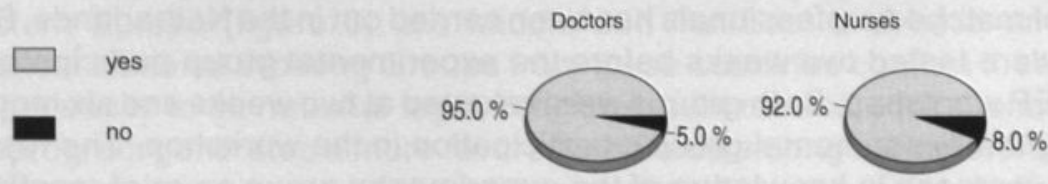

Is this programme useful in your workplace?
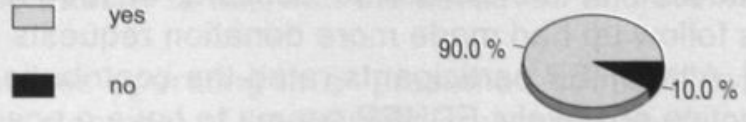

Doctors

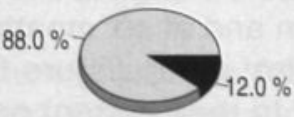

Nurses

Figure 5. Pilot evaluations of EDHEP Kobe, Inuyama, Fukuoka: Japan: (Source: Ushida et al. Development and assessment of methods to educate medical professionals and increase organ transplantation in different prefectures. Japan.) 


\section{Effect on Reduction in Difficulty with Donation Request}

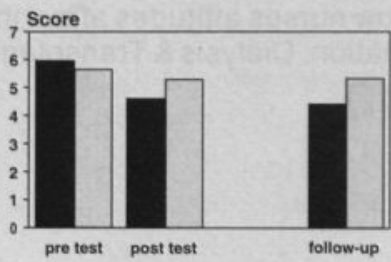

Experimental Group

口Control Group

$p<.0001$

\section{Number of People making Donatation Requests}

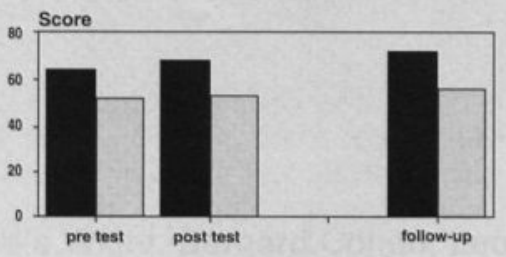

Experimental Group

$\square$ Control Group

$\mathrm{p}<.05$

Figure 6. Effect of EDHEP on participants self-confidence: the Netherlands. (Source: Blok GA et al. Effect of the European Donor Hospital Education Programme, University of Maastricht, the Netherlands.)

Current practice:

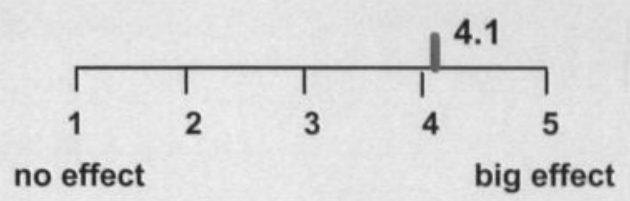

\section{Teamwork relating to donation:}

\section{Care for bereaved} relatives:

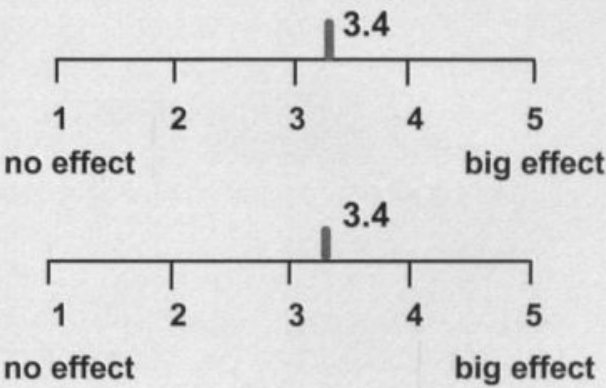

Figure 7. Effect of EDHEP on current practice: the Netherlands. (Source: : Blok GA et al. Effect of the European Donor Hospital Education Programme, University of Maastricht, the Netherlands.) 


\section{References:}

1. Gore S, Taylor RMR, Wallwork J. Availability of transplantable organs from brain stem dead donors in intensive care units. BMJ 1991; 302: 149-153.

2. Malecki MS Hoffmann MC. Getting to yes: How nurses attitudes affect their success in obtaining consent for organ and tissue donation. Dialysis \& Transplantation 1987; 276-278. 


\section{Chapter 8}

\section{Donor Action: A quality assurance program for intensive care units that increases organ donation}

Celia Wight, Bernard Cohen, Leo Roels and Blanca Miranda 


\section{Introduction}

Improvements in standards of health, advances in medical therapies and legislation on driving, health, and safety at work have all been successful in saving young lives. However, coupled with the increased number of patients registered on transplant waiting lists, such improvements may have added to a world-wide shortage of donor organs and underline the importance that all potential donors in Intensive Care Units (ICUs) are identified and families are given the option to consider organ donation.

Since the 1970's, many countries have introduced initiatives to increase organ donation. These include legislation, publicity campaigns, distribution of donor cards, appointment of transplant co-ordinators (TCs), introduction of donor protocols in hospitals, reimbursement of procurement costs, donor registries, review of donor referral procedures, and educational programs. Although these isolated initiatives may help to increase organ donation initially non have been sufficient to make a sustained impact on the supply of donor organs [1]. Only the introduction of specifically trained staff responsible for organ donation, working in the hospitals at the "grass roots", has proven to be consistently effective [2]. Estimates are that the average hospital misses about one third of its potential for organ donation mainly because not all donors are identified and many families are not presented with the option of donation [3-7].

This continued shortfall in organ donors has led to the development of a variety of different national [8] and state [9] initiatives to increase organ donation. Those institutions tasked with organ procurement have been placed under increasing pressure to improve their performance $[10,11]$. This in turn has led to a major evaluation of the processes of organ procurement [12] and allocation [13].

Donor Action (DA) is the result of collaboration between three organizations. Eurotransplant International Foundation (the Netherlands), has spearheaded the European Donor Hospital Education Program (EDHEP), an initiative to provide health professionals with the communication skills to break bad news and present the option of organ donation, now used in many countries throughout the world $[14,15]$. Organización National de Trasplantes (Spain) has been particularly successful in increasing organ donation rates in Spain through support programs for hospital-based TCs as responsible for the overall donation process $[16,17]$. The Partnership for Organ Donation (United States), in collaboration with Harvard University, has developed methodologies to assess the donation potential of ICUs $[6,18]$. These organizations agreed to pool their expertise on an initiative to help hospitals increase their donation rates through improved donation practices. DA takes a systematic approach toward achieving quality assurance in donation. Experience in Europe and the US indicates that a consistent hospital protocol built on multidisciplinary consensus can lead to a significant increase in donations [18-20]. 
Such a protocol supports teamwork toward a common goal: to identify all potential donors and provide optimal care for families.

The program is designed to help hospitals develop the improved donation practices that are tailored to meet the identified needs of the ICU. DA aims to streamline the roles and responsibilities of professional staff involved in the donation process and focus responsibility on dedicated and trained individuals. The program provides a comprehensive package of tools, resources, and guidelines to help an ICU determine its potential for donation, develop appropriate donation protocols, and establish a team with clearly defined roles and responsibilities in donation. In addition, it allows targeted and consistent education and performance monitoring systems.

This article describes in detail the methodology employed by DA and reports the results of its introduction into pilot hospitals with a two-year follow up.

\section{Program design and methodology}

Local implementation requires a multi-disciplinary, hospital-based team to assess the current situation in organ donation and identify specific areas for improvement and staff educational needs, then to put in place the appropriately adapted DA Core Program Modules. These modules correspond to the five major steps in the donation process and are used to effect changes in one or more specific areas of the process: donor identification, donor referral, family care and communication, donor organ maintenance and retrieval [figure 1]. Implementation of DA is divided into several phases: 1. gaining hospital support, 2. performing the diagnostic review, 3. program tailoring, 4 . introducing the core program module(s), 5. monitoring and evaluating progress and 6 . program management.

\section{Gaining hospital support}

The introduction of DA into a hospital can only be successfully achieved with the support of the senior hospital staff. Such a group can form the basis of a permanent DA committee. The DA committee is a hospital-based, multi-

\section{Figure 1}

The Critical Donation Pathway

- Severe brain damage

- Identify potential donor

- Diagnose brain death

- Refer potential donor to TC

- Present option for donation

- Maintain organ viability

- Retrieve organs
DA Program Modules

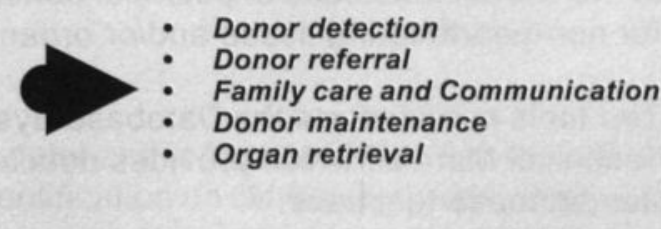

Five Donor Action Program Modules match the Critical Donation Pathway. The modules provides concepts and examples of corrective measures that correspond to the critical steps in the donation process and come as a "tool kit" for daily use in ICUs. The modules can be used alone or in any combination according to specific identified needs. 
disciplinary team of senior staff committed to improving donation practices and is well placed to inform appropriate colleagues about DA and clarify its relevance in the workplace. The committee can give authority to the hospital's efforts to ensure that all potential donors are identified and referred to the procurement transplant coordinator (PTC)/organ procurement organizations (OPOs), all families are approached in a caring and sensitive manner, and an appropriate "quality" donation protocol is introduced. The DA committee acts as custodian of the program and helps gain ICU support for the project. This Committee also supervises the Diagnostic Review and, following analysis of the data, helps identify areas for improvement, gain support for any recommendations for improvement and, assign specific staff roles and responsibilities in the donation process. A critical appointment is a DA Link(s), probably a well-respected member of the ICU staff who can serve as the hospital's focal point/in-house coordinator for donation. Such an appointment can focus responsibility for the donation process proactively and independently of the transplant team and establish an in-hospital partner for the TC. The program materials include guidelines on establishing an official DA Committee and information and presentation packages to help the hospital and ICU staff understand the potential value of DA within their own environment.

\section{The diagnostic review}

The Diagnostic Review provides baseline information on an ICU's donation performance and has three components: a Medical Record Review (MRR), a Hospital Attitudes Survey (HAS), and a system database to analyze and report on the findings.

\section{DA system database}

A software package has been developed to analyze and report on the findings from the MRR and HAS. This relational database can be installed on any PCbased computer. The system features user-friendly screens for entering hospital data and a series of push-button reports that retrieve and analyze the data according to several predefined formats: raw figures, aggregated synthetic figures and graphs. Since the DA System is based on a Microsoft (MS) Access database, data stored in the system can also be retrieved and analyzed using software packages such as MS Access or Excel. When analyzing, the MRR users can set the upper age limit for potential organ donation according to local criteria or, exclude or include non-ventilated cases in the overall outcomes of potential donors if users wish to track the potential for non-heartbeating tissue and/or organ donation.

The tools provided are the Database System on diskettes or CD-ROM and a Technical Manual, which provides detailed instruction how to install and use the database functions.

\section{MRR}

This validated computer-based analytical tool has been developed to measure 
gaps between potential and actual donors, indicating when and where in the process potential donors are missed. While the program provides simple pushbutton reporting systems, it also provides for detailed and sophisticated analysis of the data both aggregated and by individual ICU. For example, cause of death by ICU, cause of death of patients determined to be brain dead, refusal rates before or following confirmation of brain death, cases with documented signs of brain death but treatment was withdrawn, cases determined to be brain dead where families were not presented with the option for donation, reasons for exclusion of brain dead cases as potential donors, conversion rate of potential donors to actual donors, and the rate of organ recovery can be accessed [table 1].

\section{Table 1}

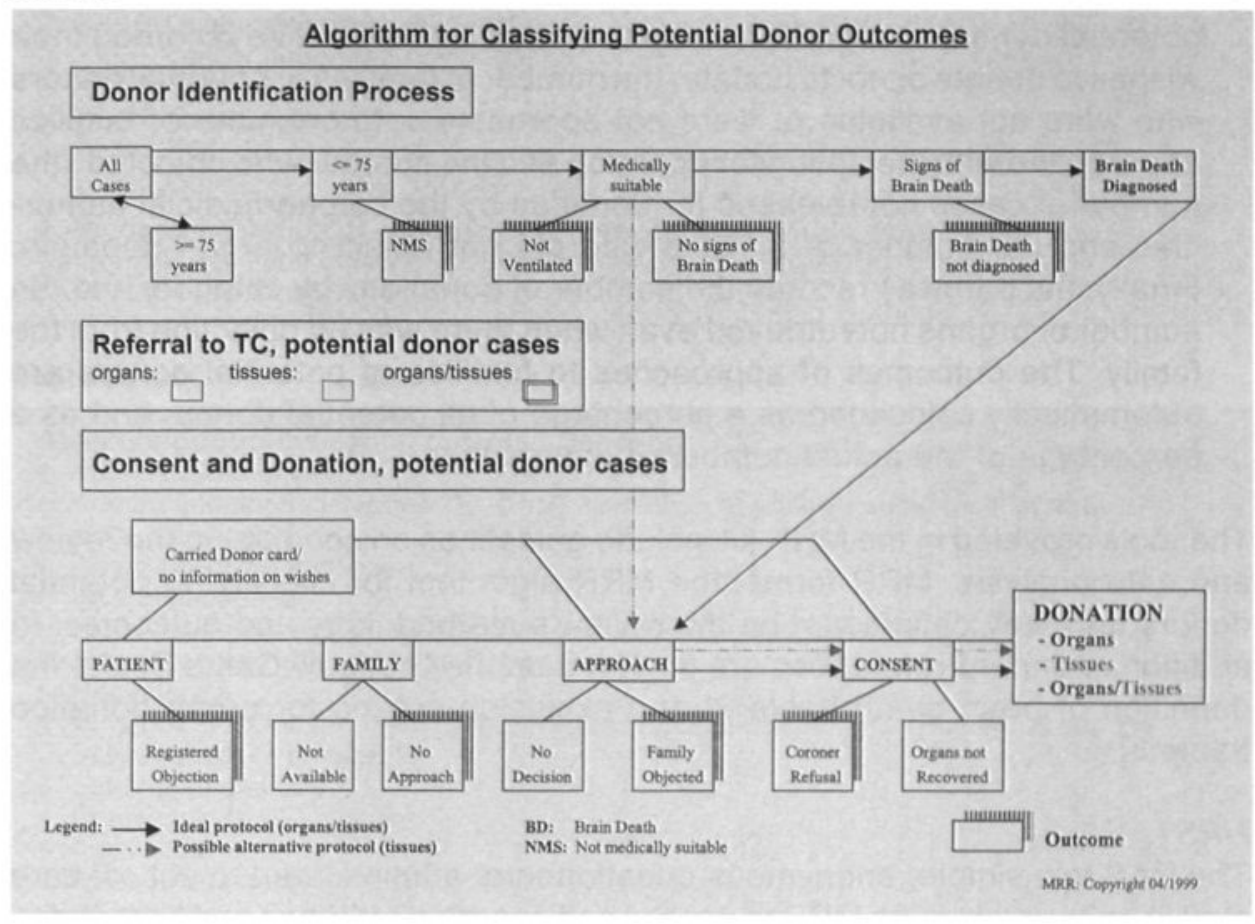

A retrospective MRR establishes a baseline against which to monitor improvements. Success relies on co-operation and support from the ICU Directors and the hospital Medical Records department to identify and retrieve relevant medical notes.

\section{MRR algorithm}

The MRR algorithm upon which the database is founded follows three essential elements for potential donors: identification on clinical evidence, referral to the appropriate agency, and the consent and donation process, leading to a predefined outcome as defined in the MRR "key" definitions. 
1. Identification of potential donors on clinical evidence starts with all cases where the cause of death and/or concurrent disease was not a known contraindication to organ donation [table 1]. Medically unsuitable cases, non-ventilated cases (see DA system database above), cases where no signs of brain death were documented, and cases where signs of brain death were documented but brain death was not diagnosed are analyzed by specific pathways. Cases where brain death was diagnosed are directed to the consent and donation pathway. A further pathway tracking potential tissue donors leads all medically suitable cases to the consent and donation algorithm [table 1].

2. The referral section records the number of cases referred to the TC/OPO as potential organ, tissue, or organ and tissue donors.

3. The consent and donation pathway records evidence on the number of potential donors who carried a donor card or had otherwise recorded their wishes to donate or not to donate, the number of families of potential donors who were not available or were not approached, the number of families approached with the option for donation and the number who objected, the number of cases not released for donation by the coroner/judicial authorities and the number of families who did not object to organ donation. Finally, the pathway records the number of donations by category and the number of organs not retrieved even when there was no objection from the family. The outcomes of approaches to families of potential donors are automatically calculated as a percentage of all potential donors and as a percentage of the actual number of approaches.

The tools provided in the MRR kit include guidelines on conducting the review and data analysis, MRR forms, the MRR algorithm for classifying potential donors and "key definitions" on the review's methodology and outcomes. In addition, standard references are provided on the Glasgow Coma Scale, the definition of brain death [table 2] and exclusion criteria for organ donation [table 3].

\section{HAS}

The HAS is a simple, anonymous questionnaire administered to critical care staff in units undergoing MRR to assess self-reported attitudes and knowledge about donation and transplantation, involvement, skills/self-confidence in donation-related activities and support provided in the donation process. Finally, ICU staff are asked how much education they have received on donation-related matters and how much more education they feel they need, in what format, and the most convenient time of day. The process relies on cooperation and support from the ICU medical and nursing directors, who need to be well informed about the DA program, the purpose of the HAS, and its relevance to the ICU staff. For a valid assessment of staff attitudes a questionnaire return rate of more than $60 \%$ is a minimum requirement. It is therefore worthwhile to invest time in holding informal seminars and provide supplementary literature about DA before starting the HAS. Experience has 


\section{Table 2}

International brain death definition

Definition for "consistent with brain death"

1. Documentation of the following pre-existing conditions:

a. Known mechanism of injury

b. Absence of toxic CNS depression

c. Absence of metabolic CNS depression (i.e. severe hypothermia)

2. Documentation of at least one of the following categories (a. and/or b.) consistent with brain death:

a. Clinical findings including 5 of the following 6

(may or may not be documented in one note)

ii. Pupillary reflex - negative

iii. Corneal reflex - negative

iv. Oculocephalic reflex - negative

v. Oculovestibular reflex - negative

vi. Gag or cough reflex - negative

b. One of the following studies

i. Cerebral blood flow studies

ii. EEG

iii. Other

3. No documentation of conditions inconsistent with brain death.

Reference: definition based on "Guidelines for the determination of Death".

JAMA 1981: 2462184-2186

\section{Table 3}

Absolute Contra-indication to Organ Donation:

- Active tuberculosis

- Human Immunodeficiency Virus (HIV) - infection or positive serological or viral culture findings

- Jakob-Creutzfeldt disease

- Viral septicaemia

- Extra-cerebral malignancy or $>5$ year history of treated malignancy

Relative Contra-indications to Organ Donation:

- Hepatitis C

- Hepatitis B surface antigen (unless organs are to be used for a Hepatitis B surface antigen positive patient)

- Extreme immaturity

- Connective tissue disease

- Agranulocytosis

- Aplastic anaemia

- Hemophilia

In all cases a careful examination should be made of the past medical and social history and the current medical situation.

shown that when ICU staff take ownership of the distribution and collection of the questionnaires, a higher response rate is achieved. Once the HAS forms are collected, the data are entered into the database. When reviewed with the MRR, the HAS database reports create a profile of the unit's donation practices.

The tools provided in the HAS kit include guidelines on conducting the survey and data analysis, HAS questionnaires, and an ICU sampling plan. 


\section{Program tailoring}

Program tailoring is the bridge between analysis of the results of the Diagnostic Review and implementation of the DA Core Program in the ICU. It provides a way to adapt the program to meet the special needs of an ICU based on the assessment of existing strengths and weaknesses provided by the results of the MRR and HAS analysis. The tailoring process can be broken down into four steps:

\section{Determining the potential for donation through MRR}

The database allocates an outcome for each medical record entered into the system. It is therefore possible to use the database reports to evaluate the number of cases unsuitable for donation as a percentage of the total number of charts reviewed, the number of potential donors as a percentage of the medically suitable cases, and the number of actual donors as a percentage of the potential. Finally, the database reports the reasons for and number of failed donations as a percentage of the medically suitable cases.

\section{Analyzing the HAS}

Using the database reports, assess staff attitudes, knowledge, self-confidence, satisfaction, and educational needs in the donation process.

\section{Identifying areas for improvement}

Make correlations between the DA System MRR and HAS reports and prioritize areas for improvement in the donation process: donor detection, donor referral, family care and communication, donor maintenance, and organ retrieval.

\section{Customizing the "Core" Program Modules to fit identified needs}

Match the Diagnostic Review results to the Modules, create an action plan, adapt and introduce the appropriate modules to the ICU, and implement the improvement program.

\section{Introducing the Core Program modules}

Factors influencing donor identification and management success have been identified as the following: a specific point of potential donor identification, established protocols for declaring brain death, specific points of contact with a PTC/OPO, communication with the family of potential donors, management policies, monitoring systems and role definition and acceptance of responsibilities. The Core Program provides concepts and examples of corrective measures in the form of five modules that follow the donation process and come as a "tool kit" for daily use in ICU. The modules can be used alone or in any combination.

\section{Donor detection}

The first step toward building an effective donation protocol. The goals in donor detection are to create a new or improved detection protocol that 
identifies all potential donors. Tools included in the module include sample protocols to establish a starting point to monitor potential donors and define the role of the DA Link and when the DA Link becomes involved in the donation process. A Medical Tracking Tool is used to record all relevant clinical information.. The DA Link initiates the tracking tool at the pre-determined point; the data can be used when informing the TC of a potential donor and can be used by the PTC/OPO on arrival in ICU. The Medical Tracking Tool is included in all program modules.

\section{Donor referral}

The goals in donor referral are to refer all potential donors to the right person at the right time and with all the appropriate information. Tools included in the module include sample protocols to establish when the PTC/OPO becomes actively involved in the process, who will convey the information to the PTC/ OPO and what role the PTC/OPO will take.

\section{Family care and communication}

The goals in this module are to communicate sensitively and to identify the right people to communicate with the family, separating the communication of brain death from presenting the option for donation. Tools included in the Family Care and Communication module include sample protocols and guidelines to help communicate regular and consistent information in a sensitive and timely manner and a Communication Tracking Tool. This tool is used by the DA Link to follow information given to the family and record the family's understanding of events. The tool is initiated by the DA Link following a diagnosis of severe brain damage and used throughout the donation process.

\section{Maintenance module}

The goals are to achieve optimal clinical care in donor organ management. The module provides sample protocols to maintain optimal organ function in the potential organ donor.

\section{Organ retrieval}

The goals in the organ retrieval module are to establish optimal hospital practices in organ and tissue retrieval. Feedback to hospital staff and donor families is the final step in building a total donation protocol.

Practical training workshops are included in the donor detection, family care and communication and maintenance modules.

\section{Monitoring and evaluating progress}

Implementation of DA in hospitals is an on-going process that does not happen overnight. Like any process of change, the program involves an investment of time, personnel, and resources on an institutional as well as an individual level. A multi-disciplinary team, working steadily, may require as little as 6 months, or as much as one year or more to fully implement changes in practice. Initially, the program will require an investment of time from DA Committee 
members and other key people in getting started, the diagnostic review phase, establishing a donation infrastructure and the implementation of the appropriate program modules. Time requirements will significantly decrease as the improvement practices are put in place, streamlining the donation process. Once the initial Diagnostic Review has been analyzed, performance targets can be set. The DA system database is then used as a prospective monitoring tool by immediately entering details of the patients who die in ICU and storing the data for future analysis. Using tools provided in the Program Modules, data is collected on an on-going basis to monitor progress.

\section{National program management}

In countries with highly centralized systems for donation, it is recommended to convene a National Working Group. In countries with more decentralized systems for donation, program management may represent a state, province, region, organ procurement organization, hospital, or a group of hospitals. The specific role of the Group is to facilitate and oversee the introduction of DA. The Group can adapt the program materials to fit the national situation, appoint and train Project Manager(s), and provide ongoing support for the program. In addition, this Working Group can facilitate the collection of local, regional, and national data on donation potential and practices where such information is not yet available. The Project Manager can evaluate the current national/ regional donation protocols, introduce DA to hospitals, recruit members for the hospital DA Committees, help train and support hospital personnel, and monitor the effectiveness of the improvement program. In summary, national implementation of DA requires a management structure, training in the concept and use of the program, adaptation of the program materials for local use, the support of suitable pilot hospitals and potentially, project managers to oversee the application of the DA program.

\section{Results}

\section{Pilot Evaluations}

Between 1995 and 1997 international pilot evaluations of the DA Diagnostic Review took place in ICUs in the Netherlands [2], Spain [2], the United Kingdom [1] and Canada [6]. Program tools, as described in the program design and methodology section of this article, were used to conduct a 12- to 18-month retrospective review of deaths in the pilot ICUs. The ICU staffs were asked to complete the HAS questionnaire. The DASystem database was used to analyze these data.

Aggregated data of the MRR results based on 579 medical records of patients who had died in ICUs showed that $181(31 \%)$ of the cases were medically unsuitable for donation. In the remaining $398(68 \%)$ cases there was no obvious contraindication to donation [figure 2].

Of the total 579 cases, $220(55 \%)$ were determined to be brain dead. One hundred and eighteen (54\%) of these patients died as a result of a cerebral 


\section{Medical Record Review}

\section{Aggregated Data}

Charts Reviewed: 579

Potential Donors: 398

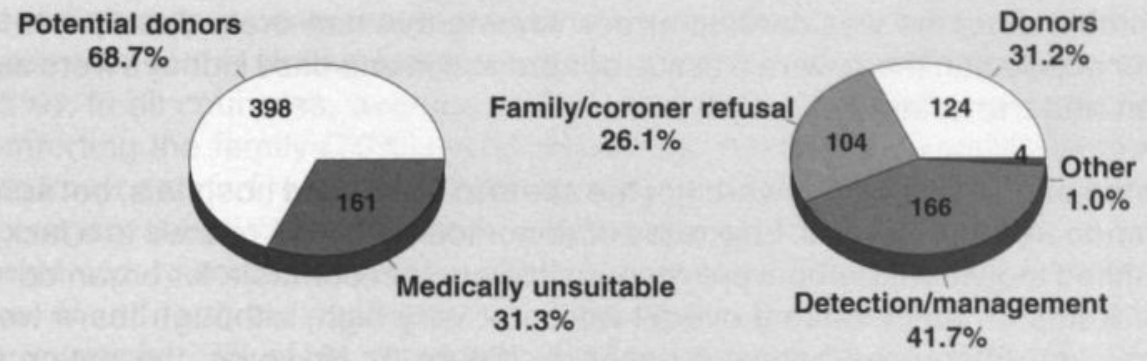

Figure 2

vascular accident (CVA) and $68(31 \%)$ as a result of a road traffic accident (RTA) or other head trauma (OHT). The remaining 34 deaths $(15 \%)$ broke down as follows: 6 cases of anoxia second to cardiac arrest, 6 primary brain tumor (PBT), 9 gunshot injuries, 5 asphyxia, and 8 "other" causes. Of these 220 brain dead cases $50(23 \%)$ were lost to donation following an objection from the family and in another two cases, the coroner/judicial authorities refused to release the body for donation. In $23(10 \%)$ cases brain death was formally diagnosed but the families were not given the option to consider donation. In a further 2 cases the family was not available and organ donation did not take place. Twenty ( $9 \%$ ) potential donors became medically unsuitable for donation at some stage of the process and were excluded from the potential donor population. Organ donation was successfully achieved in $119(54 \%)$ cases determined to be brain dead, an overall conversion rate of brain dead suitable potential donors to actual donors of $59 \%$. Of these actual donors, $65(55 \%)$ died as a result of a CVA and in three of these cases, the organs were determined to be unsuitable and tissues were donated. Forty-four $(37 \%)$ of the donors died as a result of RTA or OHT. Of the 6 cases of PBT, three came to donation although in one case the organs were deemed to be unsuitable and only tissues were donated. There were 5 "other" causes of death in the donating group. Overall in this donor population, in only one case were organs removed and not transplanted. .

In 178 cases brain death was not diagnosed. This represented $45 \%$ of the medically suitable cases and, of these, $35(20 \%)$ never displayed signs of brain death. In $53(30 \%)$ cases, signs of brain death were documented and medical treatment was reduced or withdrawn. The major cause of death in this group was CVA (17 of 32 ). In $50(28 \%)$ cases, brain death was well document- 
ed and the families were approached for organ donation before a formal diagnosis of brain death. In all cases, consent was denied. In addition, in two cases the coroner/judicial authorities were approached at an early stage and refused to release the case for donation, again the major cause of death in this group was CVA ( 30 of 58 ). In the final $35(20 \%$ ) cases signs of brain death were documented in the medical notes, there was no documentation implying deescalation of medical care, and the relatives were not approached. The inevitable outcome was cardiac arrest. Among this non-brain dead potential donor population there were 5 tissue donors and in one case kidneys were also taken and transplanted.

The major points of failure were not the same in all studied hospitals, but some common trends emerged. Low rates of donor identification related to a lack of identified individuals, who were responsible and accountable for organ donation. Rates of family refusal overall were not very high, although there were significant differences between hospitals [figure 3]. However, the option for donation was not even presented to families in $50 \%$ of the potential donor cases.

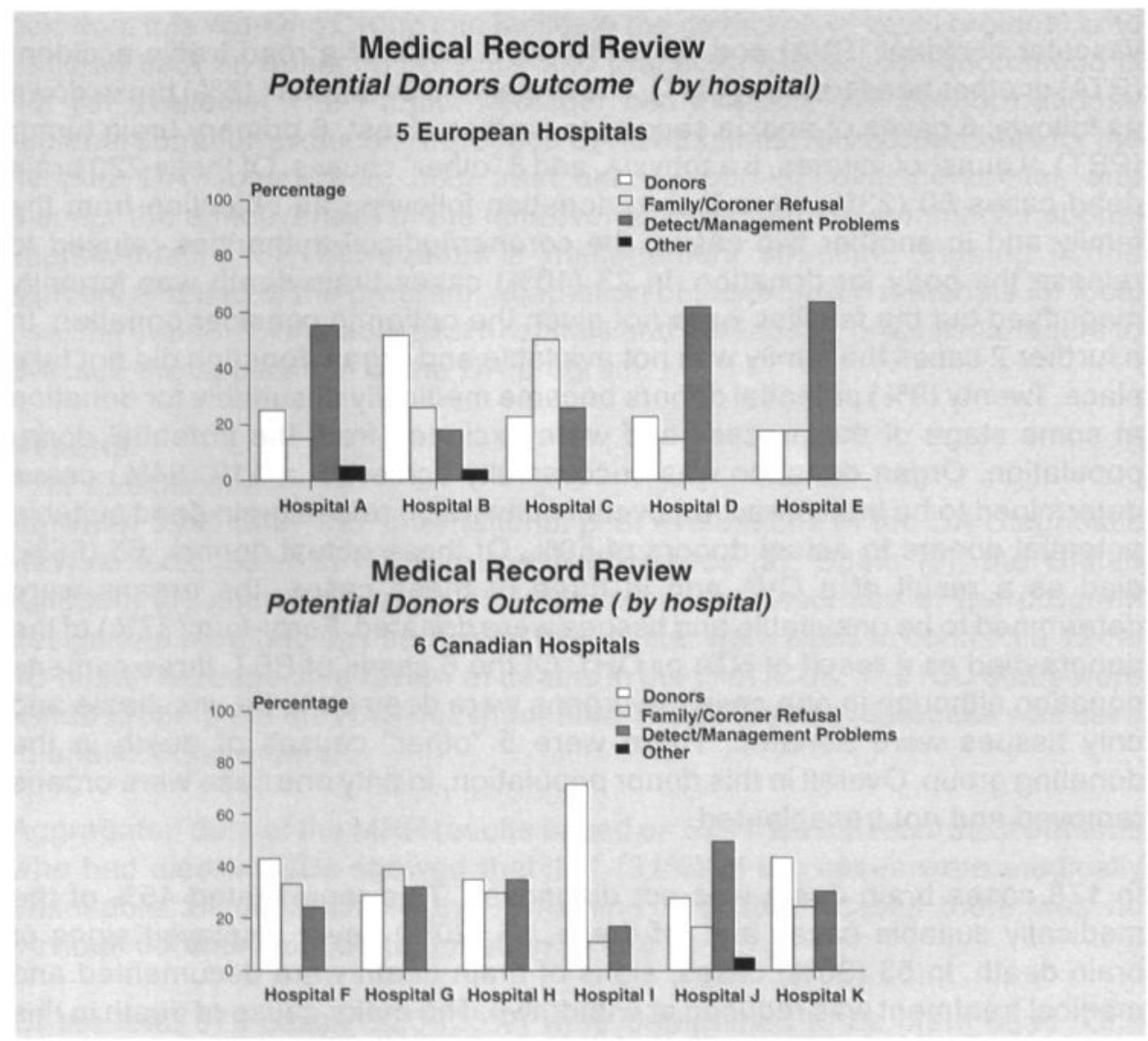


Aggregated HAS data from 2129 critical care medical and nursing personnel revealed consistently strong support for organ donation, but that many staff do not feel comfortable when performing key tasks close to donation. Belief that organ donation saves lives (97\%), support for donation (94\%) and a willingness to donate one's own organs $(79 \%)$ were high in all country samples. Significant differences in belief were observed when respondents were asked whether they agreed that organ donation helps families with their grief. The Canadian respondents were more likely to agree $(72 \%)$, with lower levels of agreement in the United Kingdom (57\%), Spain (47\%), and the Netherlands $(28 \%)$. In all countries, average ratings of skills/confidence were highest for comforting the family $(70 \%)$ and notifying the transplant co-ordinator $(60 \%)$, with lower comfort reported regarding explaining brain death (44\%), introducing organ donation $(38 \%)$, and requesting organ donation $(31 \%)$. Ratings varied widely across countries, with UK respondents expressing the highest level of self-reported confidence, and Spanish respondents the lowest levels. For example, $77 \%$ of UK respondents reported themselves as skilled/comfortable with explaining brain death, versus $57 \%$ of Dutch respondents, $50 \%$ of Canadian respondents, and $12 \%$ of Spanish respondents. Similar variations were seen regarding requesting organ donation: United Kingdom $52 \%$, the Netherlands $40 \%$, Canada $33 \%$ and Spain $13 \%$, respectively [figure 4]. It is noteworthy that the sense of staff preparedness was lowest in Spain. This may reflect the degree to which role specialization in donation has been successfully integrated into hospital practice [17].

\section{Immediate, short-term and sustained effect}

Of the 4 original pilot countries completing the MRR and HAS retrospective diagnostic analysis, national re-evaluations of donation and transplant practices and modification or introduction of transplant legislation retarded implementation of the identified corrective modules in two countries (Canada and the Netherlands). In the UK centers (expanded from the original pilot centers) short- term follow-up data (6 months-one year) are available. Follow-up in the original Spanish pilot centers now exceeds two years.

Immediate (6 months), short-term (one year) and sustained (two years) effects of the DA program on donation rates can be demonstrated. Causes of death in these donation populations were essentially the same as seen in the retrospective review.

In the United Kingdom, three of 27 regional ICUs took part in the international pilot evaluations. Following analysis of the Diagnostic Review data, corrective measures based on guidelines and references provided in the DA Detection, Maintenance, and the Family Care \& Communication modules plus a series of communication skills training courses were introduced into the pilot ICUs. In addition, many of the measures were adopted in the other 24 regional ICUs. A $122 \%$ increase in organ donation was achieved regionally in the 6 months following the start of the Diagnostic Review compared to the same 6 months in the previous year. One year after the initial introduction of DA, donation rates 


\section{Hospital Attitude Survey ICU Medical \& Nursing Staff Attitudes to Donation}

$\square$ OD saves lives $\square$ Support OD Donate own organs

- OD helps with grief

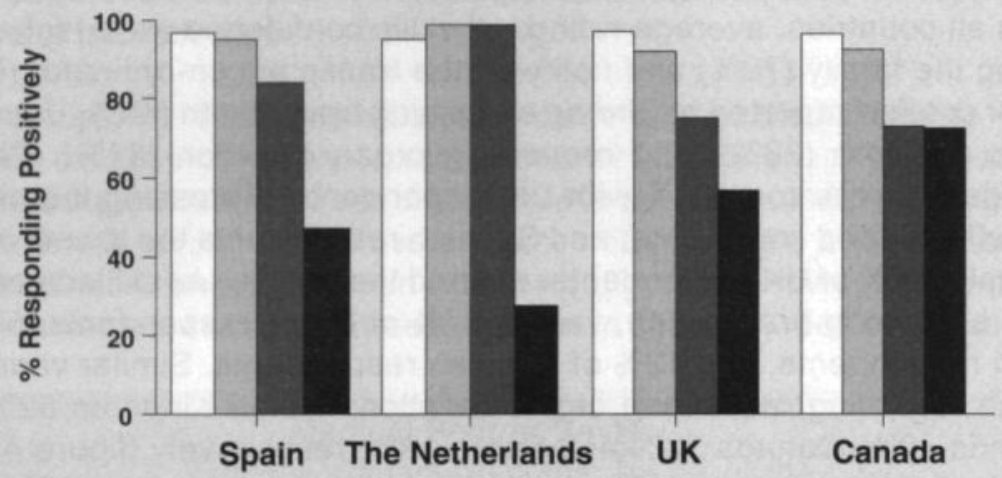

Hospital Attitude Survey ICU Medical \& Nursing Staff Skills/Self Confidence in Donation Practices

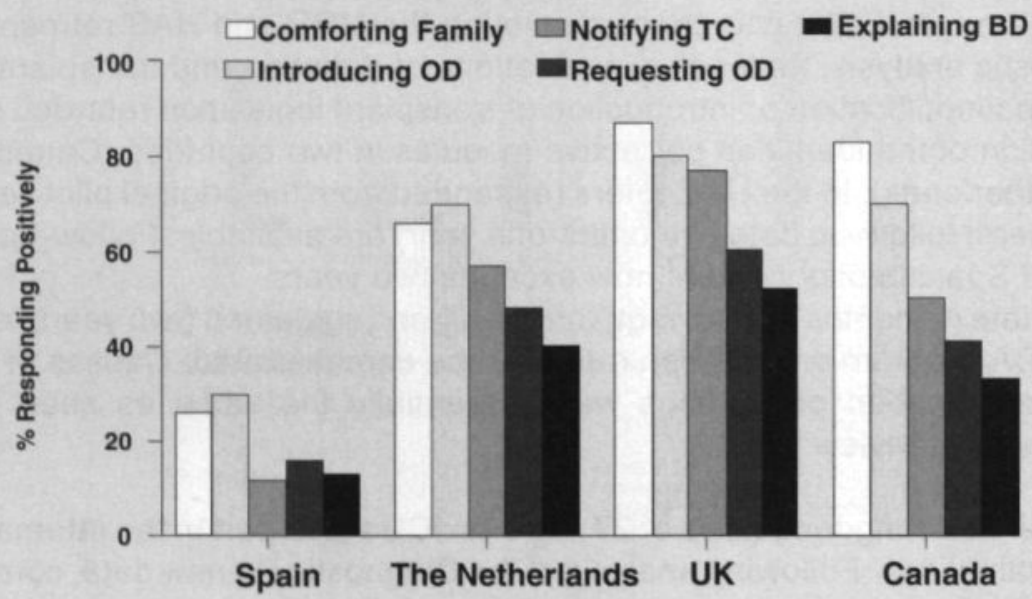

Figure 4 Key:

OD - Organ Donation

TC - Transplant Co-ordinator

throughout the region settled at a $40 \%$ increase over the year before the introduction of DA [21]. This compared with a $2 \%$ national decrease in the same period. 
A sustained effect (two years) has been demonstrated in Spain, the pilot country with the longest follow-up experience. The retrospective MRR in two major ICUs showed that $21 \%$ of the cases reviewed were medically unsuitable for organ donation. Of the medically suitable potential donor cases, $19 \%$ were not identified. In $18 \%$ of cases consent was denied, $2 \%$ were missed following an incorrect decision on suitability for donation by the ICU staff, and $2 \%$ of the medically suitable cases did not come to donation because of organizational problems. In $5 \%$ of the cases, despite aggressive medical care it was impossible to maintain haemodynamic stability and cardiac arrest occurred before donation could take place. A $44 \%$ conversion rate of potential to actual donors was achieved. Following the Diagnostic Review and introduction of the DA Donor Detection, Family Care and Communication and Donor Maintenance Modules and associated practical training a 33\% increase in donation rates was sustained over two years. Analysis of MRR and HAS data two years after the introduction of the program showed that despite a drop in donation potential ( $4 \%$ ), $98 \%$ of potential donors were now identified and no potential donors were lost as a result of inadequate donor management or organizational problems. This represents a conversion rate of potential to actual donors of $65 \%$ [figure 5]. The ICU staff declared an important increase in confidence in performing donation-related tasks [figure 6]. However, in these units there has been no significant effect on the family refusal rate, which remains at $18 \%$, and professional training in interaction with the bereaved continues.

\section{Two Year Effect of Donor Action on Donation Rates from 2 ICUs: (Spain)}

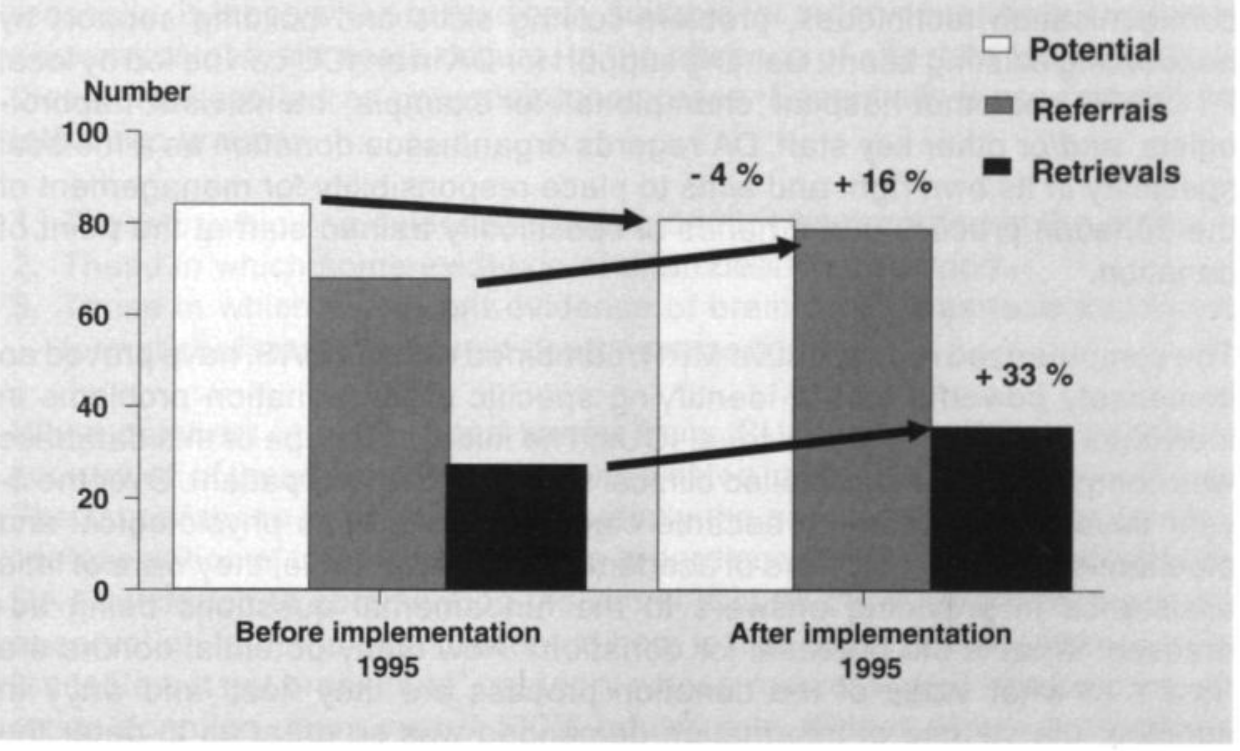

Figure 5 


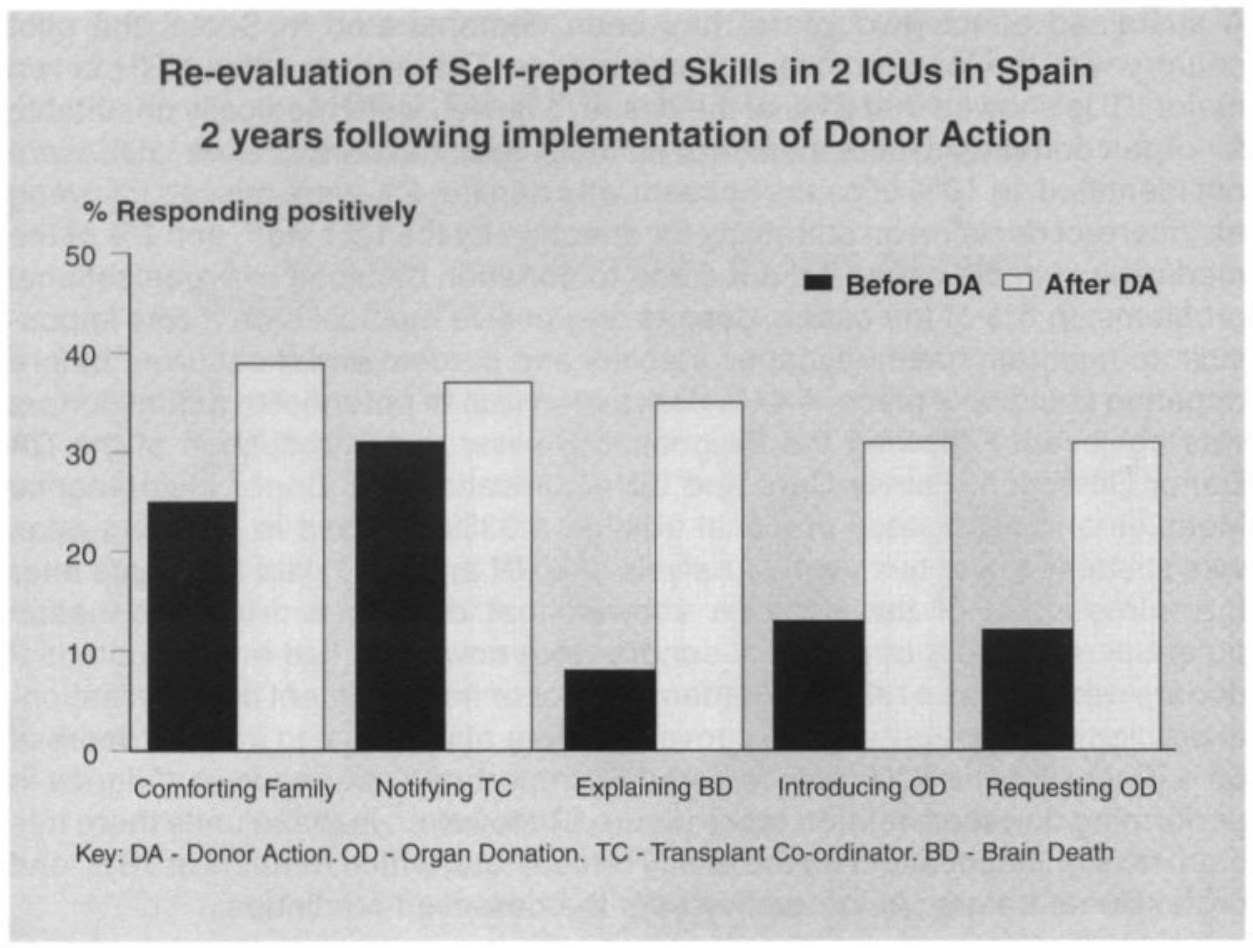

Figure 6

\section{Discussion}

Gaining support for quality improvements in donation depends on good communication techniques, problem-solving skills and building support by negotiating existing talent. Gaining support for DA in an ICU can be led by local PTC/OPO and other hospital "champions", for example, intensivists, nephrologists, and/or other key staff. DA regards organ/tissue donation as a medical speciality in its own right and aims to place responsibility for management of the donation process in the hands of specifically trained staff at the point of donation.

The computerized retrospective MRR, combined with the HAS, have proved an immensely powerful tool in identifying specific organ donation problems in individual countries and individual ICUs. The initial prototype of this database was complex; gathering detailed clinical results from every patient. Over the 5year development phase it became clear that while such physiological and biochemical parameters were of academic and medial value, they were of little assistance in providing answers to the fundamental questions being addressed. What is the potential for donation? How many potential donors are "lost"? At what stage of the donation process are they "lost" and why? In addition, the volume of information demanded was so great as to deter the regular use of the database as both a retrospective and prospective monitoring 
tool. The program finally introduced has the unique advantage of being based on a relational database; for example, links can be made between staff attitudes and skills to donation failures such as family refusals. Thus, the reporting mechanism will identify the major problem areas in the donation process without any recourse to complicated, sophisticated, or analytical skills.

For those of a more enquiring nature, built-in features allow detailed interrogation of the relational database so that specific questions can be addressed. For example, one might wish to know how many patients diagnosed with brain tumors progressed to donation; in this study it was $50 \%$. How many donors were under 40 years of age and, of these, how many were female? How many respondents by professional group support organ donation? In the United States in particular, the detailed gathering of data from ICUs has become an obligatory process. However, this highly sophisticated data banking process should not be compared or confused with the simplistic yet focused aims of the analytical tools developed by the DA Foundation.

While the underlying algorithm used in the MRR process is complex, the basic principle on which it relies is simple. Was this individual who died in the ICU medically suitable to be a donor, were they a donor and if not, why not? Within this simplistic notion dwells many complexities and sub- divisions, for example, tissue donors versus organ donors and organs taken from patients who suffered a cardiac arrest in the ICU (there was one such case in our pilot study). The database is hopefully robust enough to deal with all such idiosyncrasies, although the learning process continues thanks to feedback from the many countries now adopting the DA program.

Undoubtedly the most difficult patient population, which the program must reconcile, is those who are medically suitable for organ donation but no formal declaration of brain death occurs. In the absence of any data to the contrary, these are identified as potential donor cases. Essentially these patients fall into three groups.

1. Those in which no evidence of brain death was recorded in the notes.

2. Those in which some evidence of brain death is recorded.

3. Those in which significant evidence of brain death was recorded but no formal confirmation of brain death was performed.

While numbers in each group varied from ICU to ICU and from country to country, all of these patient populations existed in all the pilot groups analyzed. The fate of these patients was essentially the same, either cardiac arrest or "de-escalation of treatment" resulting in cardiac arrest. It is not the remit of the DA Foundation to comment on individual ICU practice. However, a relevant observation from the data presented here is that of the $50(28 \%)$ cases in the "suitable but not brain dead" category whose relatives were approached with organ donation, there was a $100 \%$ refusal rate. This is clearly a practice of benefit to no one and should be discontinued [22]. 
The retrospective data presented here identified 398 potential donors. More detailed case reviews may well have identified anomalous in the suitability for donation of some, in particular those in whom formal diagnosis of brain death was never established. The fact remains, however, that these 398 potential donors produced 119 brain-dead donors and 5 non-heartbeating donors, less than one-third of the potential. Given the desperate need for organs within the patient population with end-stage organ failure this represents a significant loss of life, loss of quality of life, and excess expenditure of health care money. The results of the DA program reported here point to a possible way of correcting this problem.

The data from DA pilot hospitals showed that ICU's starting points and needs differ. The pilot data identified a significant number of unrealized donors and also suggested that there may be important differences in attitudes and perceived skills/confidence across countries. The Diagnostic Review has proved useful in identifying problem areas in the ICU donation process and providing a baseline against which to monitor progress. The MRR can effectively identify untapped donation potential and, when matched with the HAS, can be used to customize the program to individual hospital requirements. There has been a lack of data about hospital staff attitudes and skills to allow for comparison across national systems and to support the targeting of specific strategies to the needs within different countries. The results reported here show the feasibility of collecting and comparing data across national systems. The pilot findings also suggest that there may be important differences in attitudes and self-perceived skills/comfort across and within countries. Although data are only available over two years, the results of the effect of DA on donation rates from Spain, which already has the highest donation rates in the world, are encouraging. Even in a country with a national donation rate of more than 30 donors per million population, DA was able to increase and sustain organ donation from the pilot ICUs by $33 \%$ and significantly improve all ICU staffs' skills and confidence in donation related tasks.

While the program described above was designed with the primary motivation of improving the donor recruitment rate from ICUs, one observation requires specific comment. Analysis of the cause of death of potential donors showed a high incidence of CVA (50\%) compared to RTA or OHT (25\%). This probably reflects improvements in road safety, car design, crash helmets and safety at work legislation. However, the implications of this observation are important. As therapeutic measures to deal with hypertension improve, the overall donation pool will decline. This makes it all the more important that programs such as DA are in place which can successfully identify every potential donor although a $100 \%$ recruitment rate is probably impossible.

\section{Conclusion}

Donor Action provides an opportunity for ICU staff to take control and actively contribute, where necessary, to changes in donation practices and create 
appropriate education strategies within their own environment. The introduction of the DA program allows points of failure to be identified and corrected. Implementation of DA can contribute to an increase in organ donation rates by up to $33 \%$, sustained over two years. Since 1996, critical care and transplant professionals from over 14 countries have attended specifically designed DA training courses. These courses not only familiarize participants with the program's aims, objectives and materials but also includes workshops dealing with the many skills required when introducing change in the difficult area of organ donation. In addition to the pilot countries (Canada, Spain, the Netherlands, and the United Kingdom), hospitals in Australia, Belgium, Finland, France, Germany, Hungary, Italy, Poland and Switzerland are now at various stages of implementing the program nationally. These countries have begun to see a similar early DA effect with a $30 \%-100 \%$ immediate increase in organ donation. 


\section{References.}

1. Wight C, Cohen B. Legal and Organisational Issues in Organ Transplantation. In: Klink J, Lindop M. eds. Anaesthesia and Intensive Care for Organ Transplantation. London: Chapman Hall; 1998: 57-68

2. Miranda M, Gonzalez-Posada JM. Cadaver kidney procurement. In: Makowka L, Sher LS. eds. Current Opinion in Organ Transplantation: Baltimore: Lippincott Williams \& Wilkins, 1998; 3: 197-204.

3. Gore S, Taylor RMR, Wallwork J. Availability of transplantable organs from brain stem dead donors in intensive care units. BMJ 1991; 302: 149-53.

4. Nathan $\mathrm{H}$ et al. Estimation and characterisation of the potential renal organ donor pool in Pennsylvania. Transplantation 1991; 51: 142-149.

5. Gravel MT, Szeman P. Increasing referrals and donations using the transplant center development model. Journal of Transplant Co-ordination 1996; 6: 32-36.

6. Beasley CL, Blaustein JD. The Partnership for Organ Donation: a strategic approach to solving the organ donor shortage. In: Chapman JR, Deierhoi MH, Wight $\mathrm{C}$, eds. Organ and Tissue Donation for Transplantation. London: Arnold; 1997: 389-399

7. Matesanz R, Miranda B. The Spanish Model of Organ Donation: The National Organisation of Transplants (ONT) Registry Report 1994. In: Cecka and Terasaki eds. Clin Transpl 1995. UCLA Tissue Typing Laboratory. Los Angeles, California.

8. McDonnell MC et al. Development of a national initiative to increase the number of kidneys for transplant purposes in Canada. Transpl Proc 1997; Dec. 29 (8): 3234-6

9. Hospital Conditions of Participation for Organ, Tissue and Eye Donation. HHS (HCFA) June 22, 1998; 63 Fed. Reg. 33856

10. Beasley CL. After a decade of progress, a real need to re-energise the organ donation movement. Nephrol News Issues 1997; Feb.11 (2): 56-7

11. Luskin RS et al. An alternative approach to evaluating organ procurement organisation performance. Transpl Proc 1999; Feb-Mar 31(1-2): 353-5

12. Kootstra G. et al. The non-heart-beating kidney donor: of any help in developing countries? Transpl Proc 1992; Oct. 24 (5): 2040-1

13. Lefell MS et al. Impact of changes in the UNOS renal allocation system. Transpl Proc 1997; Dec. 29 (8): 3435-6

14. Blok GA, van Dalen J, Jager KJ et al. The European Donor Hospital Education Program (EDHEP): addressing the training needs of doctors and nurses who break bad news, care for the bereaved, and request donation. Transpl Int 1999; 12: 161-167

15. Van Dalen J, Blok GA, Morley MJ et al. Participant's judgements of the European Donor Hospital Education Program (EDHEP): an international comparison. Transpl Int 1999; 12: 182-187.

16. Miranda B et al. Organ donation in Spain. Nephrol Dial Transplant 1999; 14 (Suppl. 3): $15-21$.

17. Miranda B et al. The Spanish model of organ donation for transplantation. Current opinion in Organ Transplantation 1999; 4.

18. Gortmaker SL, Beasley CL, Bergham LE. et al. Organ donor potential and performance: size and nature of the organ donor shortfall. Crit Care Med 1996; 24: 423-439.

19. Matesanz R, Miranda B, Felipe C. Organ procurement and renal transplants in Spain: the impact of transplant coordinators. Clin Transpl 1994; 8:281-286).

20. Roels L. Donor hospital development in non-university hospitals. In: Collins GM, Dubernard JM, Persijn GG, Land W, eds. Procurement and Preservation of Vascularized Organs. NL: Kluwer; 1997: 255-262.

21. Trafford J, Hooker A, Wellington F. Donor Action - Is it a unique opportunity to increase organ donation? A pilot center experience. Organs and Tissues 1997; Dec. 9-12.

22. Linyear AS, Tartaglia A. Family communication co-ordination: a program to increase organ donation. Journal of Transplant Coordination. 1999; 9 (5): 165-174. 


\section{Chapter 9}

\section{Future trends in organ allocation}

Bernard Cohen and Jacqueline Smits 


\section{Introduction}

Transplantation provides benefits to society as a whole as well as to the individuals who receive transplants. It is often the most cost-effective form of treatment for end stage disease patients and offers the opportunity for patients disabled by illness to play a fuller and more active role in society, thus reducing the costs of healthcare and social care.

However, this form of treatment is limited by the availability of human organs suitable for transplant. In part, the shortage is the result of the success of transplantation and the consequent increase in potential transplant recipients.

Changes in donor demographics also contribute to persistently low numbers of donor organs [1]. The ideal donor is someone aged between 16 and 45 , who died as a result of cerebral trauma probably caused by a road traffic accident. However, this profile does not fit the average donor. Potential donors these days are more likely to be older than in previous years and are more likely to have died following a stroke than cerebral trauma. In addition, graft survival rates for organs from these donors are significantly worse than from other donors $[1,2,3,4,5]$.

In addition, as the population ages, more and more older patients are entered on to transplant waiting lists, thus increasing pressure on transplant programmes [table 1]. If all potential transplant recipients are to be treated in an equitable way, there is no room for discrimination on the grounds of age or social worth, although most clinicians would probably prefer to allocate organs to those with the longest potential lifespan $[6,7]$. Thus, the transplant community, which is under a moral obligation to make the best possible use of donated organs, is faced with a dilemma: how to balance the needs of the potential recipient with the need to allocate organs fairly [6].

Table 1: More elderly kidney transplant recipients on the Eurotransplant waiting list as per December 31.

\begin{tabular}{|l|c|c|c|c|}
\hline & 1996 & 1997 & 1998 & 1999 \\
\hline Age group $(\mathrm{N}=)$ & 10855 & 11165 & 11789 & 12089 \\
\hline $0-56$ & $76 \%$ & $73 \%$ & $69 \%$ & $68 \%$ \\
\hline$>56$ & $24 \%$ & $27 \%$ & $31 \%$ & $32 \%$ \\
\hline
\end{tabular}

Chi - square test $p<0.0001$

In this article we consider one approach to this dilemma - expansion of the donor pool - that is currently being investigated by Eurotransplant.

\section{Organ allocation}

In simple terms, Eurotransplant attempts to identify the best recipient for each available donor organ (table 2). In reality, this decision is not that simple and 
a balance must be achieved between optimal use of all available organs, including those from marginal donors such as the elderly and optimal life expectancy of all transplant candidates. In the day-to-day reality of organ allocation and in the face of donor shortages, this can mean achieving maximal outcome under marginal conditions.

Table 2

Eurotransplant aims to:

- Achieve optimal use of available donor organs and tissues

- Secure a transparent and objective selection system based on medical criteria

- Assess the importance of factors that have the greatest influence on transplant results

- Support donor procurement to increase the supply of donor organs and tissues

- Further improve the results of transplantation through scientific research

- Promote, support, and coordinate organ transplantation in the broadest sense of the term

Allocation algorithms that take into account factors such as age, HLA match, waiting time, clinical urgency, and so on have been developed using computer models based on sound outcome data and scientific judgment. These algorithms enable difficult allocation decisions to be made efficiently and without delay to the transplant process [8].

Such allocation algorithms are, by necessity, not set in stone. Rather, they are flexible schemes that can be altered to accommodate, for example, changes in donor or recipient profiles and the latest outcome data. The structure of Eurotransplant and its decision-making process enables adaptations in the algorithm to be based on scientific data. Each organ-specific advisory committee wishing to change an algorithm can develop a recommendation to the Eurotransplant board. The board members, like advisory committee members are democratically elected, make the final decision to accept or refuse the proposed change to the algorithm.

\section{Expanding the donor pool}

Thanks to fewer road traffic accidents, and improved intensive care facilities, donors are more likely to have died as the result of a stroke rather than cerebral trauma [1], hence the donor pool has changed qualitatively. In addition, the transplant community is faced with an increasing donor shortage. Therefor, ways to expand the donor pool have been sought and the reasons for rejecting donors have come under close scrutiny. The worldwide trend is now to identify sub-optimal donor populations, such as donors aged over 65 years $[3,4,5,9,10]$ or to introduce new initiatives such as the use of asystolic, or nonheart beating, donors [11]. In the latter protocol organs are procured when the heart -and thus the circulation- of the donor has come to a standstill. Kootstra et al have greatly contributed to widen the acceptance of this new approach, which -in fact- is the reinstitution of an old practice.

Before the concept of brain death became sufficiently accepted, asystolic donors were the only source of organs. Recent publications revealed that transplant survival with kidneys from non-heart beating donors was similar to 
that of transplants with kidneys from heart beating donors [12]. These encouraging results will undoubtedly lead to an increased number of transplant centers introducing a non-heart beating protocol. The potential contribution of this category of donors to the pool remains subject of debate, but is considered to be substantial $[13,14]$.

Eurotransplant is currently investigating the possibility of using organs from expanded-criteria donors, in particular kidneys from donors aged over 65 years [15].

Until recently, it was accepted wisdom that as organs lose functional capacity with age, organs from older donors would not be suitable for transplant. However, studies now suggest that the chronological age of a donor does not necessarily give an indication of the condition of that person's organs. Provided that transplant conditions are optimized, organs from older donors can survive as long as organs from other donors $[5,10,16,17]$. Moreover, while a kidney that is functioning at less than its peak physiological capacity may not be the best solution for a young patient on dialysis, it may be suitable for an older patient with a shorter life expectancy.

A study carried out at Eurotransplant demonstrated that although kidneys from older donors (over 55 years of age) produced lower graft survival rates at one year than those from donors aged $6-55$ ( $83 \%$ versus $90 \%$ ) the difference did not reach statistical significance until three years post-transplant $(85 \%$ versus $74 \%)$.

Improvements in immunosuppression and organ preservation techniques in recent years have also increased the chances of success for such transplants. Studies in the USA and Spain demonstrate that while kidney transplants from older people do carry a greater risk of reduced survival and poorer renal function than those from younger donors, excellent outcome can be achieved with a combination of careful donor and recipient selection, good surgical and organ preservation techniques and, if necessary, transplant of both donor kidneys into a single recipient $[3,4,10]$.

\section{Eurotransplant Senior Programme}

The Eurotransplant Senior or 'old for old' Programme (ESP) is a natural response to the universal trend extending the donor criteria. The programme is currently undergoing evaluation in a pilot programme that began in January 1999. It aims to:

1. achieve more efficient use of kidneys from elderly donors

2. offer transplantation in elderly patients

The programme is restricted to:

- donors and recipients aged 65 years or older

- first transplants only

- only recipients who are non-immunized at the time of match 
The rationale for the recipient age restriction is that a kidney graft that outlives the recipient is considered a success. If donor organs are physiologically slightly sub-optimal, as is more likely with older donors, the graft has a greater chance of surviving an older than a younger recipient. In addition, a prerequisite of the study is to reduce the cold ischaemia time as much as possible to maximize the outcome in these recipients.

Only preliminary results from ESP are available. So far, of the 521 kidneys included in the study, 403 were transplanted into recipients aged over 65 years. When compared with 118 non-ESP recipients, the cold-ischaemia time was significantly less $(11,27$ hours compared with 18,10 hours in the non-ESP group; $p<0.0001)$. While it is too soon to draw conclusions about kidney function, graft survival and patient survival, it is hoped that by optimizing transplant conditions, such as patient profiles and cold ischaemia time, outcome for recipients will be maximized.

If the programme is successful, the kidney allocation algorithm will be updated to accommodate the new data and consequently, increase the donor pool available in the Eurotransplant region. Moreover, future studies will, undoubtedly, consider the possibility of transplanting kidneys from old donors into younger patients, as such transplants have already produced good results $[3,4]$.

With programmes such as ESP, elderly patients will have a more equitable chance of transplantation. In the past, elderly recipients were omitted from waiting lists because of the shortage of organs and because of their increased vulnerability to perioperate complications with consequently lower success rates. [16]. The ESP program not only offers these patients a chance of receiving a transplant, but also allows for the best possible transplant conditions.

\section{Conclusion}

The continuing shortage of human donor organs has forced the transplant community to look carefully at the restrictions previously placed on potential donors. In addition, they have also been forced to check the validity of these restrictions. The use of kidneys from elderly donors was thought to be an option with a sub-optimal outcome. Yet, the evidence suggests that kidneys from older donors, even those with a slightly reduced functional capacity, appear to do well in both older and younger patients $[3,4,5,10]$. It therefore seems likely that other factors, such as those relating to the recipient, may be more influential on final outcome than donor kidney quality alone. Nevertheless, outcome from transplants in older people should be optimized, for example, by reducing cold ischaemia time and/or by using a double kidney transplant $[18,19]$.

However, as the clinical needs of patients must be constantly weighed against the need to allocate organs in a just way, restrictions must be lifted with caution 
and only on the basis of sound scientific research. The decision to use kidneys from donors aged 65 years or older may increase the pool of donors, but it may also increase risk for individual patients.

Allocation algorithms employed by organ exchange organizations such as Eurotransplant need to be updated regularly to take into account developments such as the use of sub-optimal donor organs. If they are not adapted, organs will not be allocated in the fairest possible way. Even so, no single allocation algorithm will be accepted by the entire transplant community and there will always be objections to the criteria on which they are based. Objections are inevitable but, within a democratic system, they can be minimized or overcome.

Eurotransplant has responded to the continuing shortage of organ donors and the changing characteristics of donors, by adapting its kidney allocation algorithm to include donors aged 65 years or older in ESP. Preliminary data from ESP in conjunction with data from other studies suggest that provided transplant conditions are optimized and donor and recipient are carefully selected, there is a good chance of maximizing outcome. 


\section{References}

1. Cohen B, D'Amaro, De Meester J, Persijn GG. Changing patterns in organ donation in Eurotransplant, 1990-1994. Transpl Int 1997; 10: 1-6.

2. Schwab PM. Closing the organ referral gap. Dialysis \& Transplantation Nov. 199; Volume 28; 11: 678-700.

3. Sànchez-Fructuoso AI, Prats $D$, Naranjo $P$, Fernàdez $C$, Aviléz $B$, Herrero JA, et al. Renal transplantation from sub-optimal donors. Transpl Proc 1998a; 30: 22722273.

4. Lee CM, Scandling JD, Pavlakis M, Markezich AJ, Dafoe DC, Alfrey EJ. A review of the kidneys that nobody wanted. Transplantation 1998; 65 (2): 213-219.

5. Lewis DM, Gorrie M, Bingham C, Nichols AJ, Beaman M, Riad H. Elderly donors in renal transplantation: a worthwhile venture? Transpl Proc 1998; 30: 2279.

6. Gutmann T, Land W. The ethics of organ allocation: the state of debate. Transplantation reviews 1997; 11(4): 191-207.

7. Horina JH, Holzer H, Reisinger EC, Neugebauer JS. Elderly patients and chronic haemodialysis. Lancet 1992; 339: 182.

8. De Meester J, Persijn GG, Wujciak T, Opelz G, Vanrenterghem Y. The new Eurotransplant kidney allocation system. Transplantation 1998; 66 (9): 1154-1159.

9. Ferraresso M, Berardinelli L, Bellapi A, Vegeto A. Long-term function and survival rates of kidneys from extreme-age donors in the cyclosporine era. Transpl Proc 1998; 30: 2274-2275.

10. Guirado L, Sola R, Agraz I, Diaz M, Vila A, Parades D et al. Elderly donors (60 to 87 years) in renal transplantation: good results after 5 years. Transpl Proc $1998 ; 30$ : 2276.

11. Kootstra G. The asystolic, or non heart-beating, donor, Transplantation 1997; 63 : 917-921.

12. Wijnen RMH, Booster MH, Stubenitsky BM, de Boer J, Heineman E, Kootstra G. Outcome of transplantation of non-heart beating donor kidneys. Lancet 1995; 345: 1067-1070.

13. Hauptman P, O'Connor K. Procurement and allocation of solid organs for transplantation. N Engl J Med 1997; 336: 422-431.

14. Cho YW, Terasaki PI, Cecka M, Gjertson W. Transplantation of kidneys from donors whose hearts have stopped beating. N Engl J Med 1998; 338: 221-225.

15. Eurotransplant Newsletter February 1999; 151: 7.

16. Sànchez-Fructuoso AI, Prats $D$, Naranjo $P$, Fernàdez $C$, Aviléz $B$, Barrientos $A$. Renal transplantation in elderly patients. Transpl Proc 1998b; 30: 2277-2278.

17. Lloveras J. Elderly and other suboptimal renal grafts and transplant outcome. Transpl Proc 1998; 30: 2269 - 2271.

18. Dafoe DC, Alfrey EJ. Dual renal grafts: expansion of the donor pool froman overlooked source. Transpl Int 1998; 11: 164-168.

19. Hesse UJ, Vermassen F, Lameire N, Vanholder R. Expanded criteria donors and dual kidney transplantation. Transpl Int 1998; 11: 457-458. 



\section{Chapter 10}

\section{Concluding discussion}




\section{Concluding discussion}

Organ transplantation is a unique human enterprise that has no parallel in nature, with the possible exception of pregnancy. An adequate supply of cadaveric donor organs requires the active participation of members of a community, either directly through their personal consent or indirectly through the consent of their relatives.

The acceptance of solid organ transplantation as the treatment of choice for end-stage organ failure by both the medical profession and patients has led to an increased demand for transplantation. Just as with any other venture that provides a desired product or service, transplantation is governed by the market mechanism of supply and demand. However, it differs from other ventures in that supply does not increase in line with demand and a price mechanism is completely lacking.

As donor organs are a scarce resource, organ transplantation is directly dependent upon the level of cooperation within a community and the number of individuals willing to donate their organs. The success of organ transplantation has resulted in a marked increase in the number of patients on waiting lists for transplantation. Unfortunately, that expansion has not been matched by the necessary increase in the supply of organ donors. In their attempts to resolve that problem, organ exchange organizations (OEOs) have expanded their aims to include activities associated with the procurement of donor organs [1].

Donor organ shortages are not resolved by OEOs but by the members of the communities they serve. Nevertheless, OEOs play a pivotal role in the resolution of this problem. OEOs carry out publicity campaigns to inform members of the public as well as healthcare professionals of the seriousness of the problem. The general public must also be informed of the benefits of transplantation; they must be willing to make altruistic decisions that affect their loved ones. Such decisions are often difficult in the face of long-term cultural traditions. Medical professionals must also remain alert to the possibility of organ donation by terminally ill patients and be willing to request permission for donation from relatives.

Many potential organ donors are treated in intensive care units (ICUs) and this fact was the motivation for the establishment of the Donor Action Programme, an international effort aimed at improving donation rates from patients in ICUs. This quality assurance initiative uses core program modules that correspond to each of the critical steps in the donation process. The aim is to customize the donation process within each ICU and to provide intensivists with a systematic method to improve donation rates [2].

OEOs also have a fundamental educational role, but educating the public and healthcare professionals is a slow process that requires persistence. It also 
demands that OEOs constantly evaluate transplantations and identify reasons for success or failure. Such information is essential in justifying any changes in the operational policies of the allocation process. Improved transplantation results lead to a reduction in the number of patients who require retransplantation and, therefore, the size of the waiting list and length of waiting time. Waiting time is especially important as appreciable numbers of patients waiting for a transplant die before they are allocated donor organs.

Organ donors are normally classified into two main groups: cadaveric and living. Road traffic accident victims are the one source of cadaveric donor organs. These donors are usually younger than donors who have suffered a fatal cerebrovascular accident, the largest source of cadaveric organ donors. The decrease in road traffic fatalities, due to maximum speed reductions and seat-belt regulations, has significantly reduced the number of high quality donor organs. The acceptance of elderly donors over the past decade has compensated for this decline, with a consequent increase in the proportion of donors whose cause of death was a cerebrovascular accident [3].

Prior consent is required before an organ may be removed for use in transplantation. Legislation in many countries recognizes two methods for obtaining such consent. Under the system of 'presumed consent', which operates in Belgium, Austria, and France, everyone is assumed to agree to donation and a centralized computer database stores a record of individuals who object to their organs being donated after their death. If such a record cannot be found at the time of death, the organs may be removed and used for transplantation. In systems that use 'informed consent', for each individual who has not recorded his or her informed consent to organ donation before death, consent must be sought from the next of kin before organs can be removed and used for transplantation.

The use of donor cards and central registration of donor information might eventually help to improve donation rates but these measures are a long-term investment as it can be many years before individuals become donors. The short-term solution to this problem rests in the hands of medical professionals, who must be constantly alert to the possibility of organ donation by their terminally ill patients and be ready to inform the transplant coordinator of that possibility. These professionals are also the logical people to request permission for donation from the patient's relatives, although they can be unwilling to carry out this task. The European Donor Hospital Education Program (EDHEP) was set up in 1990 to counteract the lack of training and experience within the medical profession in dealing with the bereaved and in requesting organ donation [4]. The objective of the EDHEP is to improve understanding among medical professionals of the various issues related to organ donation and transplantation and to assist them in communicating effectively and sensitively with bereaved family members. Transplant coordinators and local liaison officers are available to assist in this task. Once permission has been 
given for donation, the transplantation team takes over and is, therefore, not involved in the organ request procedure.

Further attempts to resolve the shortage of donor organs have led to the acceptance of non-heart beating donors, donors older than the long-standing limit of 55 years of age, and extended donor criteria (such as hepatitis Cpositive donors), en-bloc transplants, domino hearts and livers, split liver procedures, etc. [5]. Living donors are another source of organs for transplant. These donors are usually related to the potential recipients, either genetically or emotionally (spouses, partners, and friends). In some cultures, such as the Middle East and Asia, this is the major form of donation [6].

There is a considerable degree of ethical uncertainty about the acceptability of using organs from living-related donors for transplantation. It arises from the uncertainty about whether or not the organs have been donated freely. Should relatives of patients, whose organ failure has been the result of diseases that have a strong genetic predisposition be accepted as donors? Does doing so endanger the donor? The publication by Terasaki et al, which demonstrated that graft survival rates using kidneys from spousal and living unrelated donors are superior to those obtained with cadaveric donors, led to an increased use of living donors in Eurotransplant [7] [figure 1]. The newest innovation in the attempts to resolve the shortage of donor organs, however, involves the use of non-directed donations. They are provided by living individuals who are neither genetically nor emotionally related to the eventual recipient. This approach has been followed only in a few centers and it is the subject of

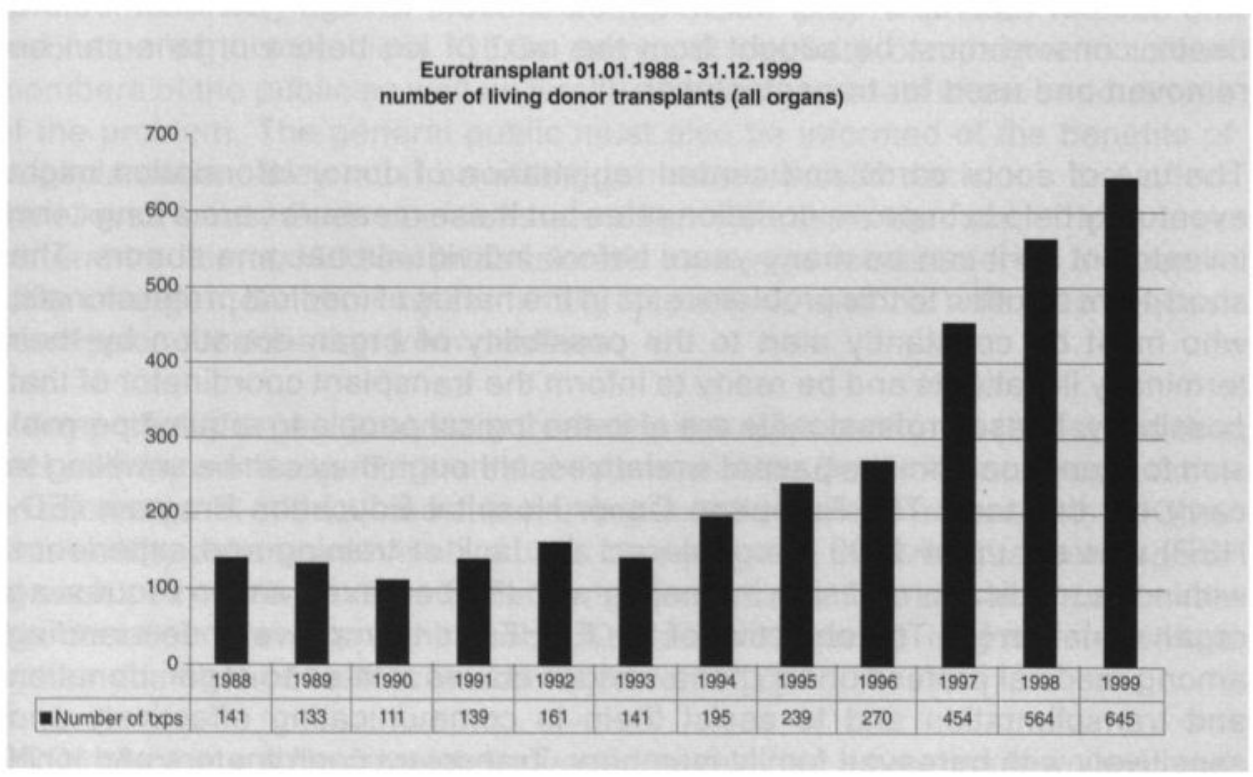


considerable ethical controversy. Such ethical dilemmas will naturally be resolved when adequate numbers of unrelated, cadaveric donors become available [8].

The continuing shortage of donor organs has led to the exploration of the possibility of breeding genetically modified animals, such as pigs, to enable their organs to be used in human transplantation. However, this is also affected by ethical constraints and questions about animal rights that must be resolved before xenotransplantation is taken seriously as an option for resolving the persistent donor-organ shortage problem. The concern about the potential biological hazard of transmitting foreign bacterial or viral pathogens to human recipients, whose immune response may be uncertain, especially as they receive immunosuppressive therapy after transplantation, must also be resolved before this option receives further consideration [9].

Allocation policies are developed on the basis of utility, justice, and equity of a procedure. The selective allocation of donor organs is an inevitable aspect of transplantation that aims to allocate organs to the best recipients. There are technical and ethical constraints on the definition of 'best recipient'. The definition might be based on the patient's clinical urgency, age, waiting time, size, degree of matching with the potential donor, number of previous transplants, and so on. Donor factors might also contribute to the definition and thus to the selection process. Should organs from older donors, with their reduced physiological functional capacity $[10,11]$, be allocated only to older recipients with a relatively restricted life expectancy rather than to those with a longer potential lifespan? Similarly, should organs from young donors be allocatedpreferentially to young recipients with a long life expectancy?

The admission of patients from immigrant populations to transplantation waiting lists also confronts us with a controversial ethical dilemma. We cannot refuse to register them but we might also expect their community to donate organs. When patients come from countries whose genetic and cultural backgrounds are markedly different from those of the host countries, the probability of being allocated a well-matched donor organ might initially be small. The chances rise only after the immigrant community has been adequately educated about the transplantation process and motivated to participate. The duration of this transition may be prolonged, especially if cultural traditions do not approve of cadaveric organ donation.

An important technical constraint on organ allocation is relatedto HLA tissue types, which must be matched between donors and recipients. This creates an automatic selection bias, without which the graft could be rejected. The risk of rejection can be reduced with immunosuppressants but the use of such drugs confers serious additional risks, such-as the induction of malignant tumors [12]. Matching, therefore, is not only a technical but also an ethical problem. 
Such considerations and new initiatives to increase organ donation play a key role in public and professional discussions of the organ shortage problem. Fortunately, most transplantation organizations, such as the International Transplantation Society and Eurotransplant, have medical ethics committees to supervise the actions of their members and to make sure that their policies and practices do not violate acceptable ethical constraints. In some countries, however, one class of serious ethical violations of normal transplantation practices has developed: commercial activity in organ donation and organ trafficking. Such activities are not sanctioned by the international transplantation community to whom they seem abhorrent and unethical [13].

A commercial donor pool usually consists of poor individuals, while the recipient pool is wealthy, a clearly unethical situation. A central clearing house for reports on such undesirable commercial practices - an International Donor Surveillance Committee - could be used to compile and distribute reports of commercial activity in transplantation. Such reports would stimulate the investigation of these practices and they would help to detect trends in organ donation commerce. Publication of such reports would also help to reduce the transient reduction in organ donation rates, which usually follow the publication of stories of commercial malpractice in the media. The desirability, structure, and advantages of such a committee was discussed at the last meeting of the Transplantation Society in Rome (August 26, 2000) and the Council endorsed the initiative of the establishment of such an organization. It would be expected to function completely independently of any transplantation-oriented organization, such as OEOs or organ procurement organizations. The naming of the organization and the funding of its activities awaits the decision of the international transplantation community.

The efficiency of organ donor procurement is affected by the level of financial support that governments and health insurers are willing to invest. Such levels vary between countries. In Spain, for example, the Government has taken the initiative to establish a sound reimbursement system for cadaveric organ donation. This policy, together with a centralized education system, has resulted in the highest level of organ donation in the world, as measured by the number of donors per head of population [14]. Historically, the USA has also been one of the leaders in this field. Several different initiatives have been undertaken to increase organ donation, such as required-request [15]. The geographic organization of organ donation programs through organ procurement organizations and the high level of funding by the Government and health insurers has also contributed to an increased number of organ donors in North America. In contrast, the governments of Germany and the Netherlands have reacted late to the need for legislation to promote organ donation. As a result, we must wait to see if the new laws will lead to any improvement in the donor situation in these countries. 
The shortage of donor organs is a direct result of the acceptance of transplantation by the medical profession and by patients as the treatment of choice for end-stage organ failure. The search for solutions for the persistent shortage of donor organs requires not only the constant efforts of medical care and scientific professionals but also the cooperation of the general public. Those solutions must be sought on educational, logistical and technical levels.

\section{Educational programs}

OEOs must constantly inform the general public of the possibility of transplantation, provide reports of its results and advances in the field and of the importance of their registering as potential donors in the event of their demise. Healthcare professionals must also be targeted by specific educational programs. Ideally, such programs should be part of professional training in medical or nursing schools. Healthcare professionals should be informed about the prerequisites for transplantation, specifically the timely reporting of potential organ donors and the proper technique for communicating with relatives to obtain permission for donation. Hospital staff should be aware of their hospital s donation policy and how to contact the local transplant coordinator, who will assist them in the early, critical stages of the donation process.

Education programs must be customized for each group of professionals. The Donor Action Program is an example of such a specialized program. It is a quality assurance program to increase donation rates in ICUs. Between 1995 and 2000, the Donor Action methodology has been introduced in pilot centers in 17 countries. Although the implementation of the program is at different stages in each country, sufficient data were available from 10 countries to analyze the impact of the program on donor referral and donation rates. Comparisons between one year before and one year after implementation of the program shows an average and significant increase in donation rates of $51 \%$ (paired t-test: $p=.0009$ ) [figure 2].

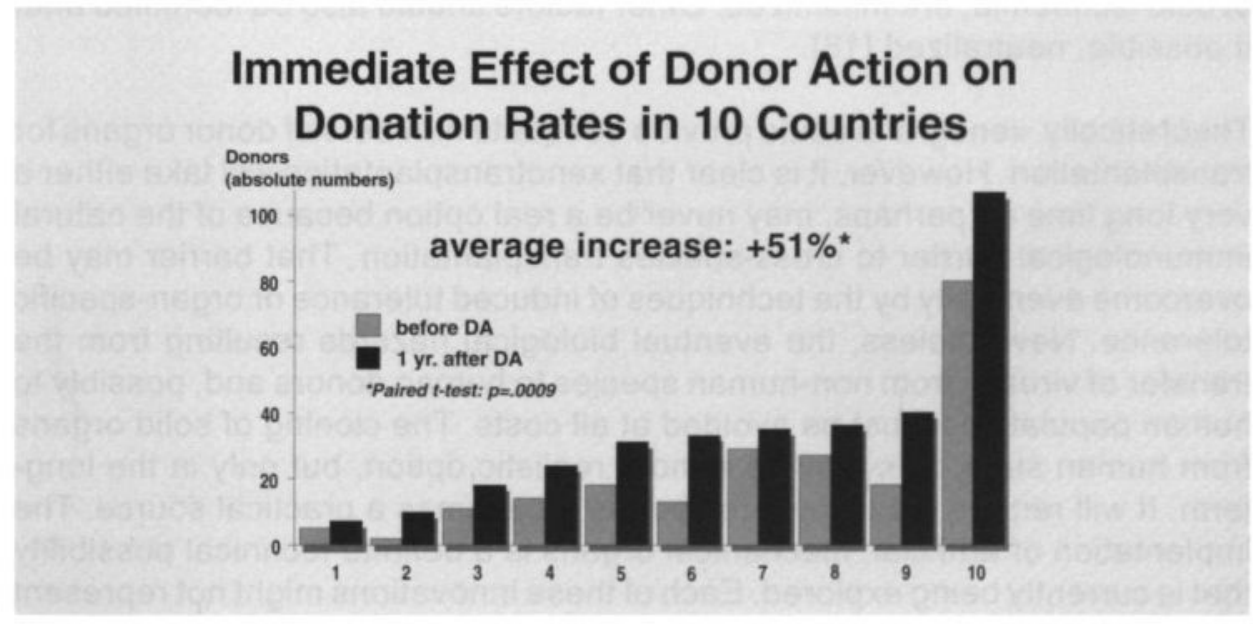

Figure 2 


\section{Logistical developments}

The use of cadaveric donors and of living related donors was not sufficient to adequately meet the demand for donor organs. The introduction of the practice of multi-organ cadaveric donation helped reduce the magnitude of the shortage but did not resolve it. Consequently, additional sources of donors had to be found. One source has been derived by the acceptance of so-called expandedcriteria donors. These donors are individuals in the lower and upper age groups, with a history of diabetes or hypertension, are haemodynamically unstable, have abnormal organ function, are non-heart beating (i.e. cardiopulmonary rather than brain dead), are hepatitis $B$ or $C$ seropositive, have systemic infections, or who have a history of malignancy $[16,17]$. In some cases, the use of dual kidneys from these sub-optimal donors, to compensate for their physiological function, has been advocated, especially, for elderly patients. Although the risks of such transplants are higher than those from other donors, their use can be justified by the improvement in the length of life or the quality of life of recipients as compared with, for example, life on haemodialysis.

The use of non-directed living donors is one of the latest innovations in the search for donor organs. Those altruistic individuals are neither genetically nor emotionally related to the potential recipients of their organs.

\section{Technical innovations}

These innovations for transplantation are provided by healthcare professionals and by the scientific community. They must continue to focus on prolonging the functional life of transplanted organs. Since a rejected graft is a wasted graft, the number of patients who must be returned to waiting lists for a retransplant should be avoided. The matching of donors and recipients should be carried out so that the adverse effects of immunological factors, such as the degree of HLA-mismatches and level of panel-reactive antibodies, as well as of non-immunological factors, such as the age of the donors and the duration of cold ischaemia, are minimized. Other factors should also be identified and, if possible, neutralized [18].

Theoretically, xenografts could provide adequate numbers of donor organs for transplantation. However, it is clear that xenotransplantation will take either a very long time or, perhaps, may never be a real option because of the natural immunological barrier to cross-species transplantation. That barrier may be overcome eventually by the techniques of induced tolerance or organ-specific tolerance. Nevertheless, the eventual biological hazards resulting from the transfer of viruses from non-human species to human donors and, possibly to human populations must be avoided at all costs. The cloning of solid organs from human stem cells may be a more realistic option, but only in the longterm. It will require many decades before it becomes a practical source. The implantation of artificial, mechanical organs is a definite technical possibility that is currently being explored. Each of these innovations might not represent a long-term solution but, nevertheless, each must be explored. 
Finally, it is clear that the solution of the shortage of donor organs for transplantation will require the constant, concerted effort, not only of OEOs and members of the various healthcare organizations but also of governmental bodies, health insurance organizations, and of the general population. No single approach will achieve the goal of a balance between supply and demand of organs for transplantation. Experiences in Spain of support programs for hospital-based transplant coordinators, in Austria and Belgium of presumed consent legislation, and in the USA of regional procurement organizations, provide valuable experience which could lead to a more systematic approach towards helping hospitals improve their donation practices. In addition, new activities, such as expanding the donor pool, will contribute to further increases in organ donation rates. Those efforts will generate many new ethical questions that will continue to require our careful consideration. 


\section{References}

1. Cohen B, Persijn G. Twenty-five years of Eurotransplant: a truly European collaboration. Clin Transpl 1992: 109-117.

2. Wight C, Cohen B, Beasley C, Miranda B. Donor Action, a quality assurance programme for intensive care units which increases organ donation. Journal of Intensive Care Medicine, 2000; 15 (2): 104-114.

3. Cohen B, D'Amaro J, De Meester J, Persijn GG. Changing patterns in organ donation in Eurotransplant, 1990-1994. Transpl Int 1997; 10: 1-6.

4. Cohen B, Wight C. A European perspective on organ procurement - breaking down the barriers to organ donation. Transplantation, 1999; 68 (7): 985-990.

5. Hauptman P, O'Connor K. Procurement and allocation of solid organs for transplantation. N Engl J Med 1997; 336: 422-431.

6. Cohen B, McGrath SMC, De Meester J, Vanrenterghem Y, Persijn GG. Trends in organ donation. Clin Transpl 1998; 12: 525-529.

7. Terasaki PI, Cecka JM, Gjertson DW, Takemoto S. High survival rates of kidney transplants from spousal and living unrelated donors. N Engl J Med 1995; 333: 333-336.

8. Matas J, Garvey CA, Jacobs CL, Khan JP. Nondirected donation of kidneys from living donors. N Engl J Med 2000; 324: 433-436.

9. Cohen B, D'Amaro J. Some contemporary ethical considerations related to organ transplantation. Transpl Int 1995; 8: 238-243.

10. Brenner BM, Cohen RA, Milford EL. In renal transplantation, one size may not fit all. J Am Soc Nephrol 1992; 3: 162-9 (Erratum, J Am Soc Nephrol 1992; 3: 1038).

11. Halloran PE. Non-immunologic tissue injury and stress in chronic allograft dysfunction. Graft 1998; 1: 25-31.

12. Penn I. Cancers following cyclosporine therapy. Transplantation, 1987; 43: 32.

13. Cohen B, Persijn GG, Vanrenterghem Y. Commerce in transplantation: how does it effect European legislation? Clin Transpl 2000; 14: 28-31.

14. Matesanz R, Miranda B, Felipe C. Organ procurement in Spain: Impact of transplant coordination. Clin Transpl 1994; 8: 281-286.

15. Caplan AL, Virnig BA. Is altruism enough? Required request and the donation of cadaver organs and tissues in the United States. Crit Care Clinics 1990; 6:1007.

16. Kootstra G. The asystolic, or non-heart beating, donor. Transplantation 1997; 63: 917-21.

17. Gridelli B, Remuzzi G. Strategies for making more organs available for transplantation. N Engl J Med 2000; 405: 404-440.

18. Smits JMA, van Houwelingen HC, De Meester J, le Cessie S, Persijn GG, Claas FHJ, Frei U. Permanent effect of nonimmunological factors on long-term renal graft survival. Transplantation 2000; 70: 317-323. 


\title{
Chapter 11
}

\author{
Summary
}

Samenvatting

Acknowledgements

Curriculum vitae 


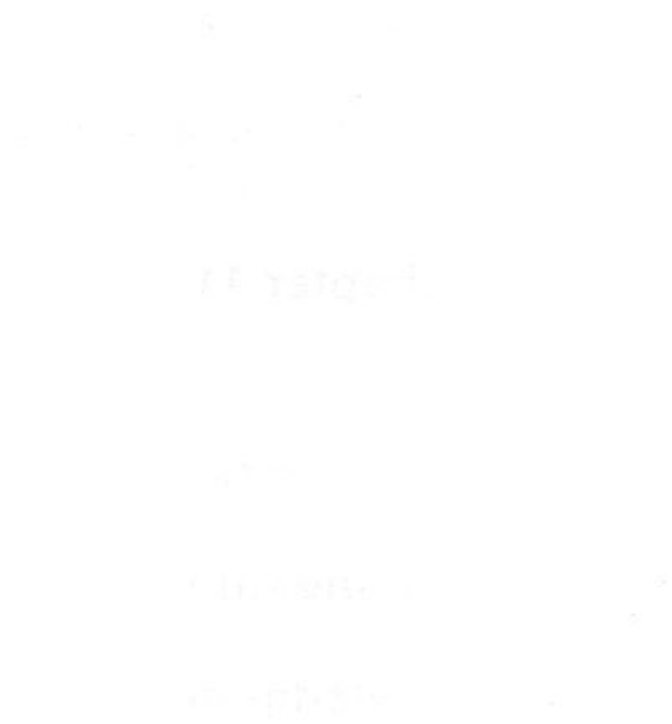


Summary 


\section{Some contemporary ethical considerations related to organ transplanta- tion}

With the increasing number of transplantable organs, as well as improvements in transplantation results, has come a severe shortage of organ donors. Consequently, new ethical dilemmas, related to the fair allocation of available organs and the use of alternative sources of donor organs, are of growing concern and are outlined in chapter 2. Establishing fair allocation priorities is a serious problem in organ transplantation. Ethically, they should be defined by society as a whole rather than exclusively by the medical profession. Proposed solutions for the organ donor shortage, each with their unique ethical constraints, include the use of related donors, partial organ transplantation, cell transplantation using fetal tissue, and the use of animal organs ("xenotransplantation"). Commercial trading in donor organs must be regarded as an unethical activity rather than an ethical dilemma since the donors are motivated by monetary rather than by humanitarian reasons. These ethical dilemmas could be largely avoided by an effective reduction in the severe shortage of postmortal organ donations.

\section{Commerce in transplantation}

Commerce in transplantation is well known, if not well defined. Although, the word commerce suggests an exchange of money, in reality it often simply signifies a non-profit-making transaction. Nevertheless, money, and therefore profit, may be involved in some human organ transactions, and the buying and selling of organs for transplantation remains common in too many countries. Clearly, if such transactions were allowed to continue only those who could afford to pay would benefit. They would probably also lead to an increase in the number of media horror stories. A number of such stories have appeared in the past and are illustrated in chapter 3 . Although they are rarely based on hard evidence, they do influence politicians and, as a consequence, affect legislation and the availability of organs for transplantation. They may also diminish the willingness of the general public to become organ donors and contribute to the persistent poor supply of organ donors. Organ exchange organizations, such as Eurotransplant, have made many efforts to prevent unethical transactions. Nevertheless, stories of such transactions continue to appear and are unlikely to abate while there is a high demand and poor supply of organs for transplantation. An international donor surveillance committee a clearing house for information on malpractice - could be one solution to the problem as it would prevent doctors from taking part in unethical transplant procedures.

\section{Changing patterns in organ donation}

Organ transplantation has become the treatment of choice for patients with end-stage organ failure and its success has led to progressive increases in the size of waiting lists over the past decade. Unfortunately, from 1990 to 1994 , the number of organ donors remained stable while the number of organs transplanted from these donors increased by only $10 \%$ as is described in chapter 
4. In view of the severity of the current organ shortage, elderly individuals are increasingly being accepted as organ donors. The graft survival rate with kidneys from donors older than 55 years is $5 \%$ lower than that with kidneys from younger donors at one year and $9 \%$ lower at three years post-transplantation. Graft survival is also significantly lower with organs from donors who die from cerebrovascular accidents than it is with organs from donors whose cause of death is cerebral trauma. The number of patients waiting for a nonrenal donor organ has increased rapidly in the past 5 years, and an increasing number of donor kidneys are now being provided by multi-organ donors. The favorable graft survival rate with multi-organ donor kidneys, which is significantly better than that obtained with single organ donor kidneys, confirms their suitability for renal transplantation.

\section{Trends in organ donation}

Renal and extrarenal transplant data were collected for seven geographical regions for the period 1989-1996 and are given in chapter 5. In Western Europe and North America the number of kidney donors increased by 926 and 2743 , respectively. The total number of transplants also increased in both regions by 3756 and 6936, respectively. Renal transplants accounted for approximately $60 \%$ of the total number of transplants and, although the number of renal transplants did not alter in Western Europe, the number rose by 3055 in North America. Outside these regions the number of extrarenal transplants was $3-18 \%$ of the total. The number of living kidney donors in North America increased each year and was higher than the number recruited in Western Europe (3389 versus 943 in 1996). With the exception of Eastern Europe, where virtually no renal transplants were carried out using organs from living donors, the number of living kidney donors rose in other regions: for example, in Latin America, the proportion of living kidney donors rose from $29 \%$ in $1970-88$ to $51 \%$ in 1995 , and, in Asia, $90 \%$ of kidneys were donated by living donors.

As the quality of cadaveric donor organs is often sub-optimal, the use of living donors is likely to increase in both Western Europe and North America, but is unlikely to become the most important source of organs in these regions.

\section{A European perspective on organ procurement}

A worldwide shortage of donor organs has led to the development of national and international systems for organ procurement and allocation and are described in chapter 6 . These systems promote organ donation and ensure fair distribution of available donor organs through a combination of legislation, organ exchange organizations (OEOs), transplant coordinators, publicity campaigns, donor cards, and professional training programs. The development of national and international OEOs is central to this process because they maintain waiting lists and allocate organs in the most appropriate way. Most countries also employ transplant co-ordinators whose role involves promoting links between transplant centers and intensive care units, establishing protocols for organ donation, and helping hospital staff deal with the 
sensitive issues involved in organ donation. An educational initiative, such as the European Donor Hospital Education Programme developed by Eurotransplant is now used in over 30 countries worldwide. The program aims to improve professionals' understanding of the legal and ethical issues involved in transplantation, to help them communicate effectively and sympathetically with bereaved families, and to increase organ donation rates. Other initiatives include programs such as the Donor Action Programme, which was set up by professional organizations in the US and Europe aiming to help hospitals establish tailor-made organ procurement policies to ensure that all potential donors can be identified and reported and the needs of unfortunate families can be met in a caring and sensitive manner.

\section{EDHEP}

EDHEP is a bold initiative designed to tackle the lack of training or experience that exists within the medical profession in dealing with the bereaved and requesting organ donation. Its primary function is to establish and monitor a nationally appropriate education program throughout Europe that will teach relevant medical staff to become confident, if not comfortable, in requesting organ donation from distressed relatives. The outstanding international interest in EDHEP displays almost universal concerns over the shortfall in donor organs and the lack of communication skills training in medical and nursing schools. There can be no doubt that the skills awareness workshop goes some way towards meeting the current needs of professionals working in critical care areas of hospitals. The long term goal of EDHEP is that these staff should acquire a positive attitude towards the benefits of transplantation that will, perhaps, help mitigate the distress of the relatives and increase the rate of organ donation.

\section{Donor Action}

Donor Action (DA) is an international initiative that helps Intensive Care Units (ICUs) improve donation and is further described in chapter 8. Existing best practices from around the world have been incorporated into this quality assurance program. Following a validated Diagnostic Review, areas of weakness in donation practices are identified and the appropriate changes introduced. Corrective measures have been developed in the form of five "Core" Program Modules which correspond to critical steps in the donation process and can be used together or alone according to specific identified needs. Medical records review (MRR) and hospital attitude surveys (HAS) were performed in $11 \mathrm{ICU}$ in Spain [2], the Netherlands [2], the United Kingdom [1] and Canada [6]. Baseline data were gathered on the units potential for donation, staff attitudes towards donation and, self-reported, skills/confidence in performing a range of donation roles. Analysis of these data was used to customize the program to individual ICU requirements. MRR data from 579 cases showed a $69 \%$ (398) potential for donation from which only $31 \%$ (124) were realized. Detection and management failures $(166 ; 42 \%)$ and refusal to donate $(104 ; 26 \%)$ were the major reasons for loss of potential donors. The 
HAS returns from staff (2129) showed consistently strong perceptions that organ donation saves lives (97\%). Support for donation (94\%) and willingness to donate their own organs (79\%) were high in all country samples. Ratings of skills/confidence were highest for comforting the family $(70 \%)$, with much lower comfort levels reported on explaining brain death $(44 \%)$, introducing organ donation $(38 \%)$, and presenting a family with the option for donation $(31 \%)$. Following introduction of the appropriate program modules a sustained (two-year) effect of a $33 \%$ increase in donation rates is demonstrated. The Donor Action HAS and MRR are useful tools in identifying problems within the donation process and lead to the introduction of improvement strategies integral to the Donor Action program that result in an increase in organ donation.

\section{Future trends in organ allocation}

The continuing shortage of donor organs has forced the transplant community to look carefully at the restrictions previously placed on potential donors. In addition, they have also been forced to check the validity of these restrictions. Alternative strategies are now being explored such as the usage of non-heart beating donors, compromised donors, elderly donors, etc. In addition, new surgical approaches such as the split-liver technique and en-bloc transplants are being introduced. The use of kidneys from elderly donors was thought to be an option with a sub-optimal outcome. Yet, the evidence suggests that kidneys from older donors, even those with a slightly reduced functional capacity, appear to do well in both older and younger patients.

Eurotransplant has responded to the continuing shortage of organ donors and the changing characteristics of donors, by adapting its kidney allocation algorithm to include donors aged 65 years or older in Eurotransplant Senior Program (ESP). Preliminary data from ESP in conjunction with data from other studies suggest that, provided transplant conditions are optimized and donor and recipient are carefully selected, there is a good chance of maximizing outcome as is illustrated in chapter 9 .

However, as the clinical needs of patients must be constantly weighed against the need to allocate organs in a just way, restrictions must be lifted with caution and only on the basis of sound scientific research. For example, the decision to use kidneys from donors aged 65 years or older may increase the pool of donors, but it may also increase risk for individual patients. Therefore, the allocation algorithms employed by organ exchange organizations must be updated regularly to take into account developments such as the use of suboptimal donor organs. If they are not adapted, organs will not be allocated in the fairest possible way. 

Samenvatting 


\section{Enkele ethische overwegingen betreffende orgaantransplantatie}

Doordat steeds meer organen getransplanteerd kunnen worden alsmede door de verbeterde transplantatieresultaten is er een groot tekort aan orgaandonoren ontstaan. Nieuwe ethische dilemma's die daar het gevolg van zijn, zoals de rechtvaardige toewijzing van organen en het aanwenden van alternatieve bronnen voor donororganen, zijn redenen voor zorg. Deze worden besproken in hoofdstuk 2. Het vaststellen van rechtvaardige prioriteiten bij de toewijzing van organen is een groot probleem in de orgaantransplantatie. Vanuit ethisch standpunt zou dit door de gehele samenleving bepaald moeten worden in plaats van alleen door de medische beroepsgroep. leder voorstel om het tekort aan orgaandonoren op te lossen, waaronder het gebruik van verwanten als donor, gedeeltelijke orgaantransplantatie, celtransplantatie waarbij gebruik wordt gemaakt van foetaal weefsel en het gebruik van dierlijke organen ("xenotransplantatie"), heeft zijn specifieke ethische beperkingen. Handel in organen moet gezien worden als een onethische activiteit in plaats van een ethisch dilemma, omdat donoren dan handelen uit geldmotieven en niet uit humane overwegingen. Deze dilemma's kunnen grotendeels vermeden worden door het grote tekort aan postmortale orgaandonaties effectief terug te dringen.

\section{Handel in organen}

De handel in organen voor transplantatie is bekend, maar niet duidelijk omschreven. Alhoewel het woord handel een overdracht van geld suggereert, gaat het in werkelijkheid vaak om transacties waarbij geen winst gemaakt wordt. Niettemin is er bij sommige transacties van menselijke organen sprake van geld en dus van winst. Het kopen en verkopen van organen voor transplantatiedoeleinden is nog steeds niet ongewoon in te veel landen. Wanneer men dit soort praktijken toestaat, zal het duidelijk zijn dat deze alleen ten goede komen aan diegenen die het zich kunnen veroorloven. Het leidt ongetwijfeld ook tot nog meer horrorverhalen in de media. Een aantal van die verhalen uit het verleden wordt in hoofdstuk 3 beschreven. Hoewel ze zelden gebaseerd zijn op harde bewijzen worden politici erdoor beïnvloed, hetgeen repercussies heeft op wetgeving en beschikbaarheid van transplantatieorganen. Hierdoor kan ook de bereidheid van het publiek verminderen om orgaandonor te worden, hetgeen bijdraagt tot een aanhoudend tekort aan orgaandonoren. Orgaanuitwisselingsorganisaties, zoals Eurotransplant, hebben veel moeite gedaan om onethische praktijken te voorkomen. Niettemin blijven er verhalen over zulke transacties circuleren en het is onwaarschijnlijk dat ze zullen verdwijnen zolang de vraag naar transplantatieorganen groot en het aanbod klein is. Een internationale commissie van toezicht -een uitwisselingscentrum voor informatie over kwade praktijken-zou een oplossing voor dit probleem kunnen zijn, omdat voorkomen wordt dat artsen meewerken aan onethische transplantatieprocedures.

\section{Veranderingen op het gebied van orgaandonaties}

Orgaantransplantatie is de beste behandelingsoptie voor patiënten die zich in het eindstadium van orgaanfunctiestoornissen bevinden. Het succes van 
transplantatie heeft in de afgelopen tien jaar geleid tot een progressieve toename van de wachtlijsten. Helaas is tussen 1990 en 1994 het aantal orgaandonoren constant gebleven terwijl het aantal getransplanteerde organen van die donoren slechts met $10 \%$ gestegen is. Deze ontwikkeling wordt beschreven in hoofdstuk 4. Als gevolg van de omvang van het huidige orgaantekort worden oudere mensen steeds vaker geaccepteerd als orgaandonor. Het overlevingspercentage van getransplanteerden met nieren van donoren ouder dan 55 jaar is echter na een jaar $5 \%$ lager dan bij nieren van jongere donoren en is drie jaar na de transplantatie zelfs $9 \%$ lager. Het overlevingspercentage van getransplanteerden is ook duidelijk lager bij organen van donoren die aan een beroerte (CVA) zijn overleden dan bij organen van donoren die zijn overleden aan een hersentrauma. Het aantal patiënten dat wacht op een donororgaan anders dan een nier is de afgelopen jaar eveneens snel toegenomen. Als gevolg hiervan wordt een steeds groter aantal donornieren nu verkregen door zogenaamde multi-orgaandonoren, d.w.z. donoren die behalve nieren ook andere organen afstaan. Het gunstige overlevingspercentage van getransplanteerden met nieren van een multi-orgaandonor, in vergelijking met patiënten die nieren kregen van een donor die slechts nieren doneert, bewijst dat die groep donoren zeer geschikt is voor niertransplantaties.

\section{Ontwikkelingen in orgaandonatie}

Transplantatiegegevens over de periode 1989-1996 in zeven geografische regio's in de wereld werden verzameld en worden in hoofdstuk 5 besproken. In West-Europa en Noord-Amerika is het aantal nierdonoren in deze periode gestegen met respectievelijk 926 en 2743 . Het totale aantal transplantaties is in beide gebieden gestegen met respectievelijk 3756 en 6936 . Ongeveer $60 \%$ van het totale aantal transplantaties betrof niertransplantaties. Terwijl het aantal niertransplantaties in West-Europa vrijwel onveranderd bleef, is het aantal in Noord-Amerika toegenomen met 3055. Buiten West-Europa en Noord-Amerika omvatte het aantal "niet-nier" transplantaties slechts 3-18\% van het totale aantal. Het aantal levende nierdonoren in Noord-Amerika is ieder jaar toegenomen en was aanzienlijk groter dan het aantal nieuw geworven donoren in West-Europa (3389 tegen 943 in 1996). Behalve in Oost-Europa, waar bijna geen niertransplantaties werden uitgevoerd met organen van levende donoren, is het aantal levende nierdonoren in de andere geografische regio's sterk gestegen. In Latijns-Amerika van 29\% in de jaren 1970-1988 tot $51 \%$ in 1995 . In Azië werd zelfs $90 \%$ van de nieren van levende donoren verkregen. Omdat de kwaliteit van donororganen uit overledenen vaak niet optimaal is, zal het gebruik van levende donoren in zowel West-Europa als Noord-Amerika waarschijnlijk verder toenemen, maar het is niet te verwachten dat dit de belangrijkste bron van organen in deze gebieden zal worden.

\section{Een Europese visie op donorwerving}

Het wereldwijde tekort aan donororganen heeft geleid tot nationale en internationale maatregelen om donoren te werven. Deze ontwikkeling wordt 
beschreven in hoofdstuk 6 . Genoemde maatregelen bevorderen niet alleen de donatie van organen, maar waarborgen eveneens een rechtvaardige toewijzing van beschikbare donororganen door een combinatie van wetgeving, orgaanuitwisselingsorganisaties (OEO's), transplantatie-coördinatoren, publiciteitscampagnes, donorprogramma's en opleidingen voor professionals. De ontwikkeling van nationale en internationale orgaan-uitwisselingsorganisaties is belangrijk in dit proces, omdat zij wachtlijsten bijhouden en het meest geschikt zijn om organen toe te wijzen. In de meeste landen zijn ook transplantatiecoördinatoren werkzaam wier taak het is een schakel te vormen tussen transplantatiecentra en intensive care-afdelingen, protocollen op te stellen voor orgaandonatie en het ziekenhuispersoneel te helpen omgaan met alle vertrouwelijke zaken rondom orgaandonatie. Een initiatief op het gebied van de professionele voorlichting, zoals het door Eurotransplant ontwikkelde European Donor Hospital Education Programme, wordt nu in 30 landen wereldwijd gebruikt. Het doel van het programma is om het begrip voor wettelijke en ethische zaken rondom donatie en transplantatie bij professionals te vergroten en om hen te helpen doeltreffender en op een empatische wijze te communiceren met de nabestaanden van potentiële donoren. Andere initiatieven omvatten programma's zoals het Donor Action Programme dat opgezet is door professionele organisaties in de VS en Europa. Dit programma wil ziekenhuizen helpen een donorwervingsprogramma op maat te maken, zodat alle potentiële donoren worden herkend en gemeld en de getroffen familie op een zorgzame en meelevende manier wordt opgevangen.

\section{EDHEP}

Bij de medische beroepsgroep bestaat een gebrek aan training en/of ervaring in de omgang met nabestaanden en het directe verzoek om orgaandonatie. EDHEP is ontwikkeld om dit probleem aan te pakken. Het programma is vooral bedoeld om een voor heel Europa geschikt educatief programma op te zetten, dat het medische personeel bijbrengt hoe zij op een verantwoorde wijze een diepbedroefd familielid om orgaandonatie kunnen vragen.

De opvallende internationale belangstelling voor EDHEP toont aan, dat er een grote bezorgdheid bestaat over het tekort aan donororganen en het gebrek aan communicatie-vaardigheidstrainingen binnen de medische en verpleegkundige opleidingen.

De workshop "vaardigheidsbewustwording" komt tegemoet aan de huidige behoefte van medewerkers op de kritieke zorgafdeling van ziekenhuizen. Op de lange termijn beoogt EDHEP dat zij zich positief opstellen tegenover orgaantransplantatie. Hierdoor kan het verdriet van de nabestaanden mogelijk verlicht worden, waardoor het aantal orgaandonaties zal kunnen toenemen.

\section{Donor Action}

Donor Action (DA) is een internationaal initiatief dat intensive care-afdelingen (IC's) in staat stelt donatie te bevorderen en wordt verder beschreven in 
hoofdstuk 8 . De beste procedures uit de hele wereld zijn samengevoegd in dit kwaliteitsplan. $\mathrm{Na}$ een zogenaamde Diagnostic Review van de ziekenhuisafdeling worden de zwakke plekken in de donatieprocedure opgespoord en passende veranderingen voorgesteld. Corrigerende maatregelen zijn ontwikkeld in de vorm van een programma dat bestaat uit vijf kernmodules, die corresponderen met de belangrijkste stappen in het donatieproces en die integraal- afhankelijk van de specifieke situatie- afzonderlijk toegepast kunnen worden. Medical Records Review (MRR) en Hospital Attitude Surveys (HAS) werden uitgevoerd in 11 IC-afdelingen in Spanje (2), Nederland (2), Groot-Brittannië (1) en Canada (6). Op afdelingen waar potentieel donaties kunnen voorkomen, werd een aantal basisgegevens verzameld over de houding van het personeel ten opzichte van donatie en een zelfrapportage over vaardig-heden/zelfvertrouwen bij het uitvoeren van een aantal taken in het donatieproces. De analyse van de gegevens werd gebruikt om het programma aan te passen aan de eisen van afzonderlijke IC-afdelingen. MRR-gegevens van 579 gevallen toonden aan dat $69 \%$ (398) van de overledenen potentieel geschikt was voor donatie; daarvan werd maar $31 \%$ (124) uitgevoerd. Het niet herkennen en uitvoeren $(166 ; 42 \%)$ alsmede weigering van donatie $(104 ; 26 \%)$ waren de belangrijkste redenen voor het verloren gaan van potentiële donoren. Uit de HAS die door het ziekenhuispersoneel werden teruggestuurd (2129), bleek steeds weer dat men van mening is dat orgaandonatie levens redt $(97 \%)$. Steun aan donatie $(94 \%)$ en de bereidheid om eigen organen te doneren (79\%) scoorden hoog in alle onderzochte landen. Percentages voor vaardigheden/zelfvertrouwen waren het hoogst waar het het opvangen van de familie betrof $(70 \%)$. Men voelde zich minder gemakkelijk als het erom ging de hersendood uit te leggen (44\%) of te beginnen over orgaandonatie $(38 \%)$ resp. de familie te vragen om voor donatie te kiezen $(31 \%)$. Na de introductie van de geschikte programmamodules werd een verhoogd donatiepercentage van 33\% geconstateerd. De Donor Action HAS en MRR blijken geschikte methoden om problemen in het donatieproces te achterhalen en resulteren in het doorvoeren van maatregelen en verbeteringen, waardoor het aantal orgaandonaties stijgt.

\section{Toekomstige ontwikkelingen bij de toewijzing van organen}

Het voortdurende tekort aan donororganen heeft ertoe geleid dat de beperkingen, die eerder golden voor potentiële donoren moeten worden herzien. Het is dan ook nodig om voortdurend na te gaan of deze beperkingen nog wel gegrond zijn. De mogelijkheid van alternatieve strategieën wordt nu onderzocht, zoals het gebruik van "non-heart beating" donoren, minder "goede" donoren, oudere donoren, enz. Daarnaast worden nieuwe chirurgische technieken zoals de split-liver techniek en en-bloc transplantaties geïntroduceerd.

Het gebruik van nieren van oudere donoren werd altijd gezien als een optie die minder goede resultaten gaf. $\mathrm{Er}$ is echter bewezen dat nieren van oudere donoren, zelfs bij een wat verminderde nierfunctie, goed blijken te functioneren bij zowel oudere als jonge patiënten. Eurotransplant heeft in reaktie op het 
voortdurende tekort aan orgaandonoren en de veranderde donorkenmerken besloten om zijn algoritme voor nierallocatie uit te breiden en donoren van 65 jaar of ouder op te nemen in het speciale Eurotransplant Senior Program (ESP). Voorlopige gegevens van het ESP en gegevens van andere studies wijzen er op dat de kans groot is dat de resultaten bijzonder goed zullen uitvallen, vooropgesteld dat de voorwaarden voor transplantatie geoptimaliseerd worden en de donor en de ontvanger zorgvuldig geselecteerd worden (zie hoofdstuk 9).

Het opheffen van beperkingen moet echter voorzichtig gebeuren en alleen op basis van zorgvuldig wetenschappelijk onderzoek. Bijvoorbeeld, het besluit om nieren te gebruiken van donoren van 65 jaar en ouder zal het aanbod van donoren weliswaar vergroten, maar kan ook een groter risico betekenen voor de individuele patiënten. De allocatie algoritmen die door de orgaanuitwisselingsorganisaties worden gebruikt, moeten daarom regelmatig bijgesteld worden om met nieuwe ontwikkelingen -zoals het gebruik van minder goede donororganen- rekening te houden. Als deze algoritmen niet aangepast worden, zullen organen niet op de meest rechtvaardige manier worden toegewezen. 
Acknowledgments 


\section{Acknowledgments}

Finally, I should like to thank the many people who have helped and inspired me. Before mentioning one or two by name, I would first like to offer my own tribute to the people whose willingness to donate organs has made a transplant possible for tens of thousands of patients. The Eurotransplant employees also deserve special commendation. Their motivation and hard work has resulted in tremendous achievements. I would also like to extend my gratitude to the many people who helped me while I was writing this thesis. I shall mention just a few: Joe D'Amaro, Jacqueline Smits, Sharon Dorrell, Johan De Meester and Yves Vanrenterghem.

I am also extremely grateful to my supervisor Gauke Kootstra for his expert advice. A very special word of thanks goes to my co-supervisor Guido Persijn. I have enjoyed an extraordinary working relationship with him for over the past 25 years, without which this thesis would have been impossible.

Celia Wight also deserves a particular mention as it is partly thanks to her unstinting efforts and unbridled wanderlust that the European Donor Hospital Education Programme and Donor Action Programme have now become internationally recognized successes in the field of donor recruitment.

I owe a special debt of gratitude to Maya de Beer for helping me write this thesis. Without her critical reading and high-tech word processing wizardry, it would not have been possible.

My final word of thanks is reserved for the people who matter most to me: Adri and Sharon. They were my greatest supporters throughout the period of writing this thesis. 
Curriculum vitae 


\section{Curriculum vitae}

Bernard Cohen was born on November 1, 1947 in Bloemendaal, the Netherlands, but grew up in the Hague, where he graduated from the Dalton Lyceum. Bernard read economics at the Free University of Amsterdam, during which time he also worked as a teacher and as an office manager for a computer company. He graduated in 1975 and became the Director of Eurotransplant International Foundation and the Dutch Transplant Foundation (formerly known as Eurotransplant Netherlands). In 1982, he also became the Economic Director of the Red Cross Bloodbank in Leiden, which later became the Bloodbank Leiden-Haaglanden after merging with the Bloodbank of the Hague. Bernard also founded Bio Implant Services (BIS Foundation) in 1987 and became its first director. In 1988, he became a guest professor at the Free University of Brussels, Belgium and, in 1994, founded the Donor Action Foundation. Bernard is married with one daughter. 



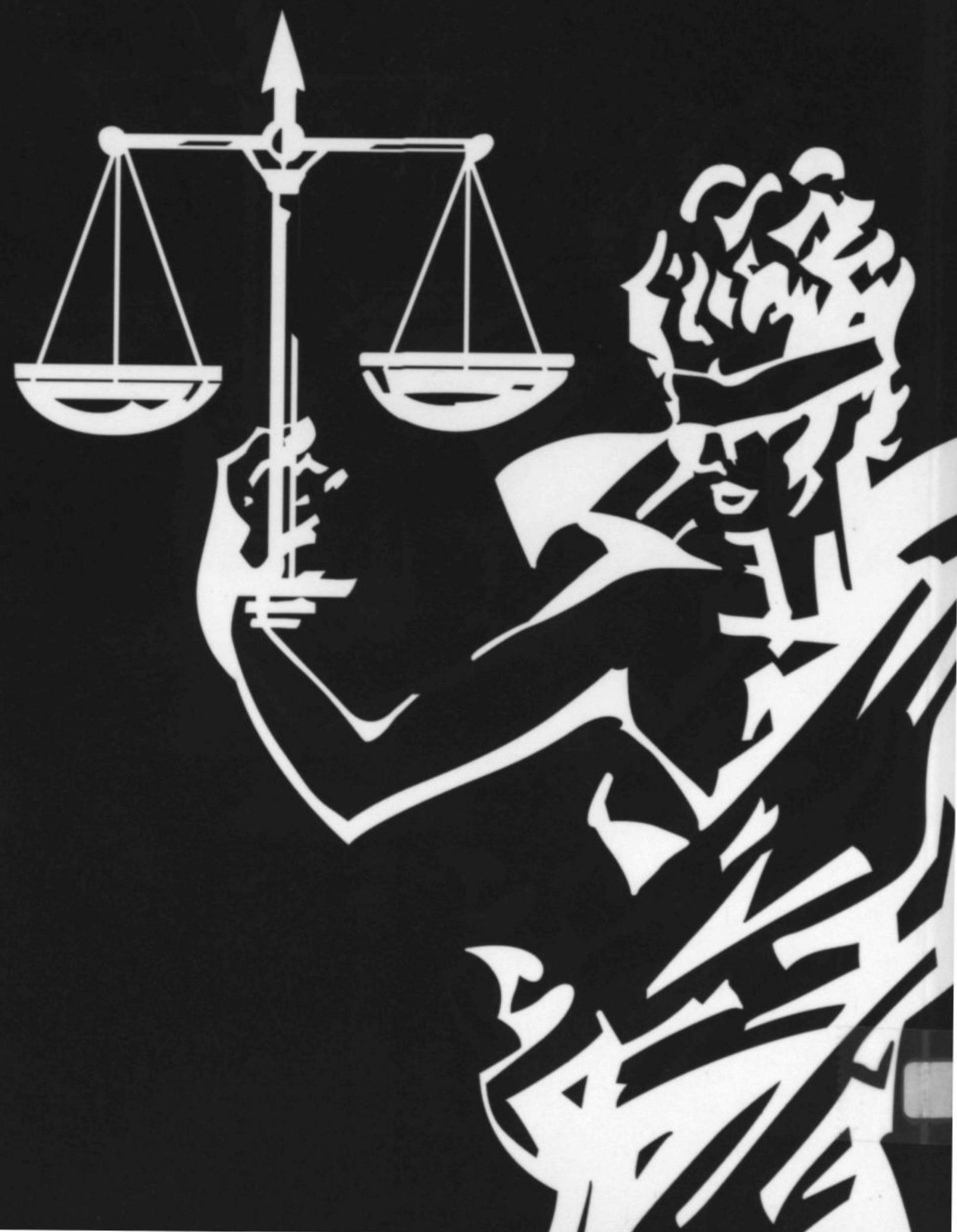

